Florida International University

FIU Digital Commons

4-17-2019

\title{
Developing a Meta-Population Framework for Caribbean Spiny Lobster (Panulirus argus) Stocks
}

Nan Yao

Florida International University, nyao001@fiu.edu

Follow this and additional works at: https://digitalcommons.fiu.edu/etd

Part of the Biology Commons

\section{Recommended Citation}

Yao, Nan, "Developing a Meta-Population Framework for Caribbean Spiny Lobster (Panulirus argus) Stocks" (2019). FIU Electronic Theses and Dissertations. 4279.

https://digitalcommons.fiu.edu/etd/4279

This work is brought to you for free and open access by the University Graduate School at FIU Digital Commons. It has been accepted for inclusion in FIU Electronic Theses and Dissertations by an authorized administrator of FIU Digital Commons. For more information, please contact dcc@fiu.edu. 


\section{FLORIDA INTERNATIONAL UNIVERSITY}

Miami, Florida

\section{DEVELOPING A META-POPULATION FRAMEWORK FOR CARIBBEAN SPINY LOBSTER (PANULIRUS ARGUS) STOCKS}

A dissertation submitted in partial fulfillment of the requirements for the degree of

DOCTOR OF PHILOSOPHY

in

\section{BIOLOGY}

by

Nan Yao

2019 
To: Dean Michael R. Heithaus

College of Arts, Sciences and Education

This dissertation, written by Nan Yao, and entitled Developing a Meta-population Framework for Caribbean Spiny Lobster (Panulirus argus) Stocks, having been approved in respect to style and intellectual content, is referred to you for judgment.

We have read this dissertation and recommend that it be approved.

William Anderson

Heather Bracken-Grissom

Shouraseni Sen Roy

Joel Trexler

Yuying Zhang, Major Professor

Date of Defense: April 18, 2019

The dissertation of Nan Yao is approved.

Dean Michael R. Heithaus

College of Arts, Sciences and Education

Andrés G. Gil

Vice President for Research and Economic Development and Dean of the University Graduate School

Florida International University, 2019 
(C) Copyright 2019 by Nan Yao

All rights reserved. 


\section{DEDICATION}

Thanks to my parents for having me. Thanks Brian Hunting for taking me and thanks to my cats for yelling at me everyday. 


\section{ACKNOWLEDGMENTS}

First of all, I must thank my major professor, Dr. Yuying Zhang, who has become a great friend and lifetime mentor. Her knowledge and life experience, including being International has always inspired me. Her "no time for nonsense" policy had made me who I am today. I owe my career and publications to her, or as she says, "You owe me two publications." I also need to thank all my committee members for all the help and encouragement they gave me over the years. Dr. Heather Bracken-Grissom, who generously allowed me to parasitize in her lab for a year, and lent me a couple of great minds to help me carry out my genetic chapter. Later on, she also taught me to be a better writer and presenter (I owe my best student presentation at ICWL to her), and became my spinning instructor. I also want to thank Dr. Joel Trexler, who always ends our conversation by saying “that's interesting, maybe you should find out more." He is also constantly challenging me to be good at both writing and talking science. I will proudly carry all of his criticism and encouragement for the rest of my life. I also want to thank

Dr. Sen Roy for being my outside committee member; she always encourages me to think outside the box. Her specialty concerning spatial statistics have led to an interesting project, and the skills I learned from her class will benefit me for the rest of my life. The wealth of knowledge of stable isotopes I would gain from even a quick meeting with Dr. William Anderson, and also thanks him for letting me explore the stable isotope method for my dissertation.

Without the help from the Florida Fish and Wildlife Conservation Commission (FLFWC) lobster team (Thomas Matthews, Gabby Renchen, Marie Cooksey, Carrie Butler and Emily Hutchinson), who provided all the samples for my project, my project 
will not be possible. A special thanks to Thomas Matthew for his knowledge regarding and financial support for my dissertation. I also want to thank him for always being supportive and willing to answer questions. I am also grateful that Gabby Renchen has been super flexible and helpful, and took me for a ride now and then.

Thanks to my undergraduate intern, Danielle Smart, who helped me dissect, bake and grind baby lobsters over the course of 3 months. I hope she still wants to be a biologist.

This dissertation would not have been possible without financial support from Sea Grant project (R/LR-B-69 and R/LR-B-74) in the form of a four-year research assistantship and Florida International University for a one-year teaching assistantship Additional financial support for fieldwork, travel and scholarships were provided by the Sea Grant scholar program, FWC fund, FIU Adolfo Henriques Scholarship 2016, 2017, UWS Scholarship 2015, 2018, SGA Graduate Scholarship, the Judith Evans Parker Travel Award Scholarship and Tinker Field Research Grants.

Lastly, I want to thank my family and friends for dealing with me, and always supporting me on my journey. My dad, Professor Yao, who always had a zoo in our backyard growing up; you are the reason I became a biologist. My mom, Professor Huang, who taught me how to be a great speaker. My partner, Brian Hunting, a man who resides in every "Acknowledgements" section of my publications. I am grateful to him for dealing with my constant yelling, complaining, and craziness (in addition to reading all of my writing). To my friends from graduate school including, but not limited to, Beth, Camila, Lisa, Sonja, Lori, Jimmy, Ivan, and Jonathan; thank you for all your 
support, and all the great times we had together. I will treasure these precious relationships for the rest of my life. 


\title{
ABSTRACT OF THE DISSERTATION \\ DEVELOPING A META-POPULATION FRAMEWORK FOR CARIBBEAN SPINY \\ LOBSTER (PANULIRUS ARGUS) STOCKS
}

\author{
by \\ Nan Yao \\ Florida International University, 2019 \\ Miami, Florida \\ Professor Yuying Zhang, Major Professor
}

The Caribbean spiny lobster (Panulirus argus) provides many ecological and economic benefits to the Southeast United States, as well as many South American and Caribbean countries. However, limited knowledge on the recruitment dynamics of this valuable species has long been an issue for the fishery management. Panulirus argus has a pelagic larval stage called the phyllosoma. During the larval stage, a phyllosoma can drift with currents from six to nine months. This long pelagic life stage leads to the hypothesis that $P$. argus stocks in the Caribbean are demographically open. Evidences from biophysical modeling and genetic analysis have supported this hypothesis. However, this new knowledge contradicts the assumption that each stock is isolated from others during the fishery assessment and management procedure. Previous studies have shown that misspecification of the spatial structure among stocks could lead to bias estimation on the stock status (e.g., spawning stock biomass) and reduce the effectiveness of the management. Therefore, understanding the spatial structure among stocks, as well as the impacts of spatial structure on stock assessment and management, are crucial to the 
development of a sustainable spiny lobster fishery in the Southeast US and Caribbean Region.

In the present dissertation, stable isotope analysis, genetic markers and biophysical modeling were applied to monthly recruit samples arriving at the Florida Keys from August 2014 to July 2016. The purpose of these analyses was to investigate the connectivity between the Florida stock and upstream stocks in the Caribbean. Then, a meta-population framework was developed on the basis of this connectivity. This framework was then used to evaluate the impact of spatial structure on stock assessment, as well as the effectiveness of fishery management scenarios.

The results of my studies have revealed, by applying stable isotope analysis, genetic markers and biophysical modeling, high levels of connectivity between the Florida stock and upstream Caribbean stocks. This therefore bolsters the hypothesis that the Florida stock is demographically open. Furthermore, my studies also detected significant bias in results from the stock assessment in which spatial structure was ignored. Finally, the results of management strategies evaluations have suggested that the Florida stock condition could be heavily influenced by the management of other stocks in the Caribbean, and an international cooperation of fisheries management could be highly beneficial for this species. 


\section{TABLE OF CONTENTS}

CHAPTER

PAGE

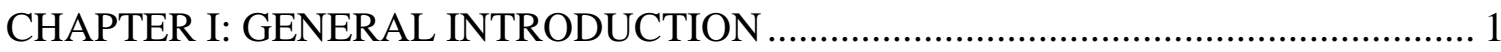

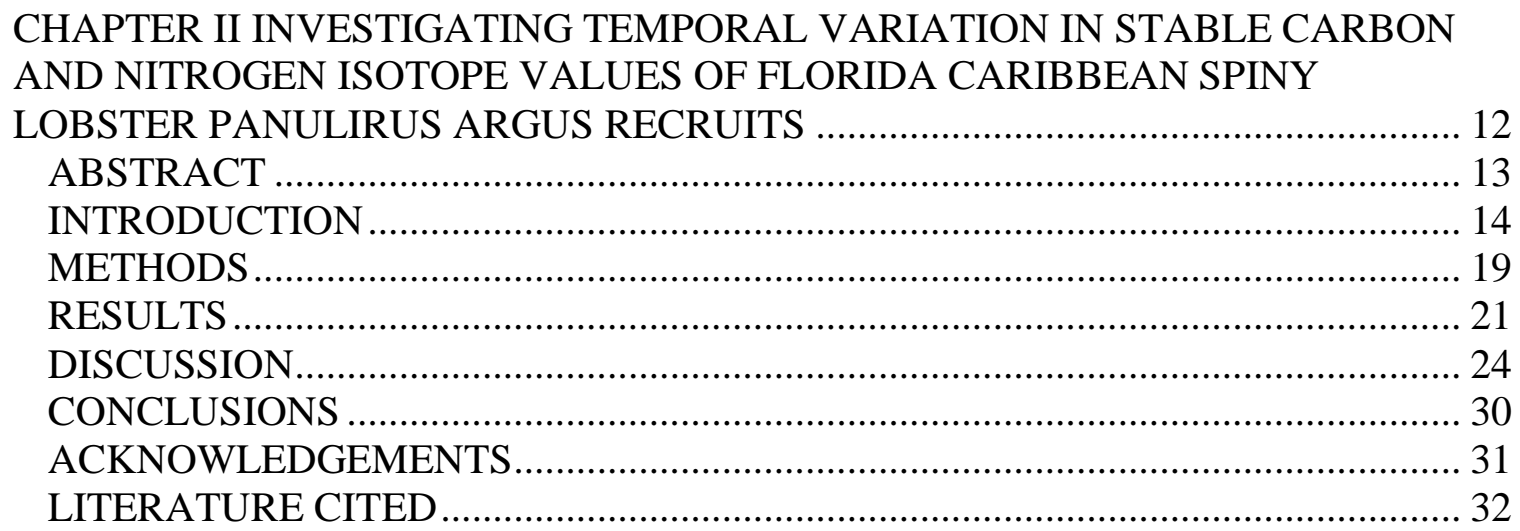

CHAPTER III RECRUITMENT DYNAMICS OF THE FLORIDA CARIBBEAN SPINY LOBSTER (PANULIRUS ARGUS) REVEALED BY MICROSATELLITES AND ITS IMPLICATION FOR FISHERY MANAGEMENT....................................... 54

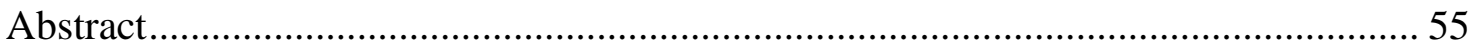

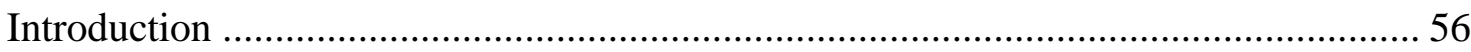

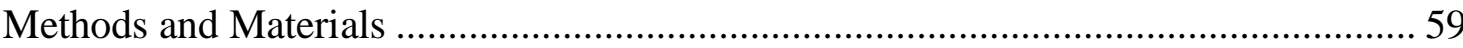

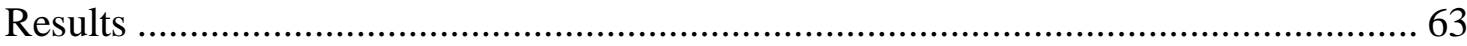

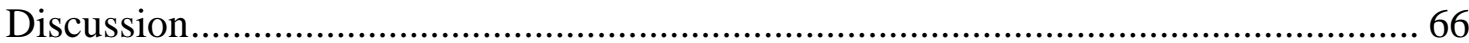

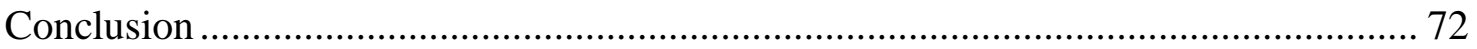

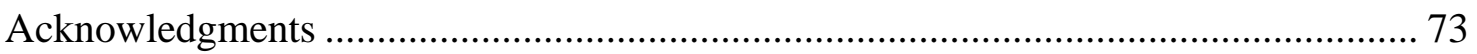

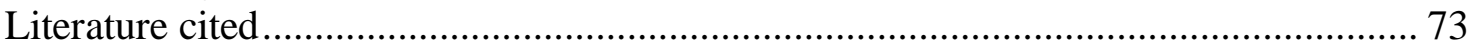

CHAPTER IV IMPACTS OF STOCK SPATIAL STRUCTURE AND

CONNECTIVITY ON THE STOCK ASSESSMENT AND MANAGEMENT OF

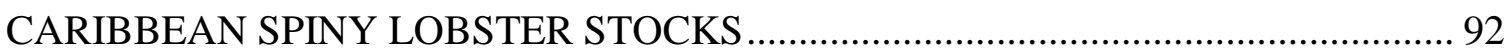

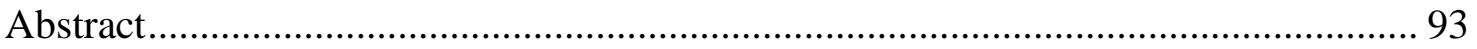

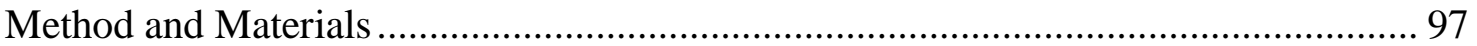

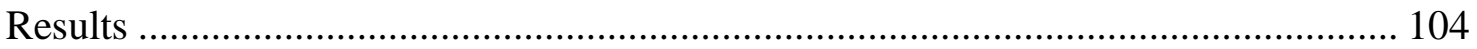

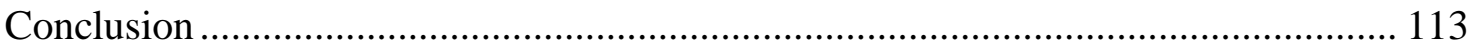

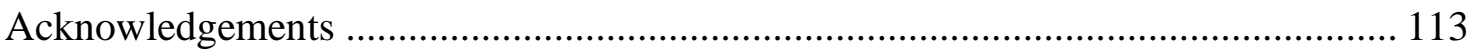

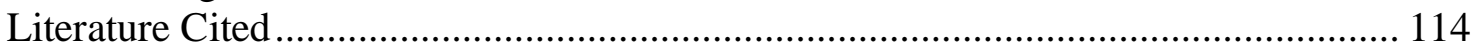

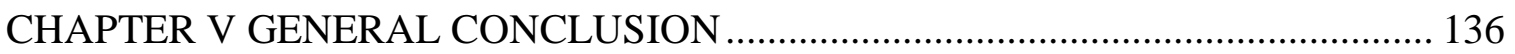

VITA ……… 


\section{LIST OF TABLES}

TABLE

PAGE

\section{CHAPTER II.}

Table S1. Pairwise comparisons of the monthly $\delta^{13} \mathrm{C}$ value of the samples excluding juveniles. $p$-values for each combination of months. Significant difference detected between two months, after Benjamini-Hochberg false discovery rate control (FDR) are shown in bold $(p<0.05)$.

Table S2. Pairwise comparisons of the monthly $\delta^{15} N$ value of the samples excluding juveniles. $p$-values for each combination of months. Significant difference detected between two months, after Benjamini-Hochberg false discovery rate control (FDR) are shown in bold $(p<0.05)$.

\section{CHAPTER III.}

Table 1. Results of the Analysis of Molecular Variance (AMOVA) on ten microsatellite loci among the monthly Caribbean spiny lobster recruits that were collected from two sites in the Keys. The inbreeding coefficients $\left(F_{\text {IS }}\right)$ and the fixation index $(F \mathrm{ST})$ are given in the table. Significant $\mathrm{P}$-values are indicated by asterisks.

\section{CHAPTER IV.}

Table 1. The input regulation of Caribbean spiny lobster fishery of stocks in the Caribbean 118

Table 2. Descriptions and levels of the management regulations used for the management strategies evaluation (MSE)

Table 3. The results of RA and ABA bias between the "true" parameters and parameters estimated from stock assessment without spatial structure scenario (i) and stock assessment with the "correct" spatial structure scenario (ii)

Table 4. The results of the optimal management scenarios selected based on the 6 performance measures 


\section{LIST OF FIGURE}

FIGURE

PAGE

\section{CHAPTER II}

Figure 1: Map of the two sampling sites: Long Key (LK) and Big Munson (BM) in the Keys, Florida, United States of America, from which samples were collected.

Figure 2: The monthly mean values of (A) $\delta^{13} \mathrm{C}$ values and (B) $\delta^{15} N$ of the samples that were collected from August 2014 to July 2016 excluding juveniles. The difference on the $\delta^{13} C$ value and the $\delta^{15} N$ values were significant among months based on the Fisher-Pitman permutation test $(p<0.05)$. Both Data are presented as mean \pm SEM (standard error of the mean).

Figure 3: The dual isotope plot $\left(\delta^{13} \mathrm{C}\right.$ vs. $\left.\delta^{15} N\right)$ for four clusters from our study and the POM from Lamb and Swart (2008). The results of the cluster analysis of $\delta^{13} \mathrm{C}$ values and $\delta^{15} N$ values of the samples that were collected from August 2014 to July 2016 excluding juveniles. The entire collection of postlarvae was clustered into four groups, determined by the elbow method based on both $\delta^{13} \mathrm{C}$ values and $\delta^{15} \mathrm{~N}$ values. Data are presented as mean \pm SEM (standard error of the mean).

Figure 4: The monthly proportion of clusters from the results of the cluster analysis based on the samples that were collected from August 2014 to July 2016, excluding juveniles. The entire collection of postlarvae was clustered into four groups, determined by the elbow method based on both $\delta^{13} \mathrm{C}$ values and $\delta^{15} \mathrm{~N}$ values.

Figure 5: The monthly proportion of the three postlarval sub-stages (clear, semipigmented, and pigmented) and the first juvenile stage from August 2014 to July 201637

Figure S1. Mean values of $\delta 13 C$ and $\delta^{15} N$ of the samples from two sample sites: Long Key (LK) and Big Munson (BM). (A). $\delta^{13} C$ value including juveniles. (B). $\delta^{15} N$ value including juveniles. (C). $\delta^{13} \mathrm{C}$ value excluding juveniles. (D). $\delta^{15} N$ value excluding juveniles. Data are presented as mean \pm SEM (standard error of the mean). Values annotated with the same letter are not significantly different $(p>0.05)$.

Figure S2. Mean values of (A) $\delta^{13} C$ and (B) $\delta^{15} N$ of the samples of three pueruli substages (clear, semi-pigmented, and pigmented), and the first juvenile stage. Data are presented as mean \pm SEM (standard error of the mean). Values annotated with the same letter are not significantly different $(p>0.05)$

Figure S3. The results of the autocorrelation analysis of (A) $\delta^{13} C$ and (B) $\delta^{15} N$ of the postlarvae that were collected from August 2014 to July 2016 excluding juveniles. 
Figure S4. The result of the elbow method for cluster analysis based on both $\delta^{13} \mathrm{C}$ and $\delta^{15} N$.

Figure S5. The results of the cluster analysis of $\delta^{13} \mathrm{C}$ and $\delta^{15} \mathrm{~N}$ of the samples that were collected from August 2014 to July 2016 excluding juveniles. The entire collection of postlarvae was clustered into four groups, determined by the elbow method based on both $\delta^{13} C$ and $\delta^{15} N$. (A. Cluster 1: white; B. Cluster 2: light grey; C. Cluster 3: dark grey; D. Cluster 4: black).

Figure S6. The pie chart of the proportion of each month's samples (August 2014 to July 2016) in each cluster (A. Cluster 1; B. Cluster 2; C. Cluster 3; D. Cluster 4). 46

\section{CHAPTER III.}

Figure 1. Map of the two sites: Long Key (LK) and Big Munson (BM) in the Keys, Florida, United States of America, from which samples were collected.

Figure 2. Results of the pairwise genetic differentiation ( $G$ "sт) analysis of the postlarvae collected at Florida Keys monthly from August 2014 to July 2016. (A) Heatmap of pairwise $G$ "st values of the monthly postlarvae. The levels of the genetic differentiation are color-coded (blue = low value, red $=$ high value). (B) Temporal autocorrelation function for $G$ "sт value of the postlarvae.

Figure 3. Proportions of observed full- and half-siblings of the postlarvae collected at Florida Keys monthly from August 2014 to July 2016 that are different from the proportions expected by chance. The expected proportions of kinship were calculated using 1000 pairs of randomized populations for each month. The significant differences between observed and expected percentages of the half- and full-siblings are indicated by asterisks.

Figure 4. Subdivision of clusters according to the results of DAPC analysis. The entire postlarvae samples are clustered into three groups based on genetic similarity. Unique genetic clusters are indicated with different colors (blue $=$ Cluster 1 , yellow $=$ Cluster 2 , and green $=$ Cluster 3 )

Figure 5. The composition of the three clusters (Blue=Cluster 1, yellow=Cluster 2, and green $=$ cluster 3 ) of the postlarvae that were collected from August 2014 to July 2016 based on the results of DAPC analysis. (A) Monthly composition of the three clusters. The entire collection of postlarvae is clustered into three groups, determined by Bayesian Information Criterion based on the genetic similarity. (B) Membership probabilities of individual Caribbean spiny lobster recruit belonging to genetically unique clusters. Each 
vertical bar represents an individual spiny lobster and is divided into color segments that are proportional to the probability of belonging to a genetically unique cluster. The month is displayed on top of the figure and the black vertical line separates each month.

Figure S1. Proportions of each of the three discrete genetic clusters on 10 locations thought out the greater Caribbean identified by the population genetics program STRUCTURE from Truelove et al. 2017.

\section{CHAPTER IV.}

Figure 1. Results of Florida recruitment composition of 2014 derived from the results of biophysical modeling. A. Dry Season. B. Wet Season.

Figure 2. The map of sub-stocks in the Caribbean that are included in the metapopulation framework.

Figure 3. The value of "true" parameters and results of parameters estimated from the stock assessment ignores the spatial structure (i) and the stock assessment model specifics the "correct" spatial structure (ii). (A. Fishing mortality. B. Spawning stock biomass)

Figure 4. The results of minimum spawning stock biomass (SSB) of the Florida stock (Min-SSB-FL) from management scenarios with different minimum-size limit (X-axis) and lengths of closedd season (Y-axis) under metapopulation framework under metapopulation framework. A. heatmap of the management scenarios with female conservation. B. heatmap of the management scenarios without female conservation. The result values are color-coded (blue $=$ low value, red $=$ high value).

Figure 5. The results of final year spawning stock biomass (SSB) of the Florida stock (Fin-SSB-FL) from management scenarios with different minimum-size limit (X-axis) and lengths of closed season (Y-axis) under metapopulation framework. A. heatmap of the management scenarios with conservation. B. heatmap of the management scenarios without conservation. The result values are color-coded (blue = low value, red $=$ high value).

Figure 6. The results of commercial landing of the Florida stock (L-FL) from management scenarios with different minimum-size limit (X-axis) and lengths of closed season (Y-axis) under metapopulation framework. A. heatmap of the management scenarios with conservation. B. heatmap of the management scenarios without conservation. The result values are color-coded (blue $=$ low value, red $=$ high value) 
Figure 7. The results of commercial landing variation of the Florida stock (LV-FL) from management scenarios with different minimum-size limit (X-axis) and lengths of closed season (Y-axis) under metapopulation framework. A. heatmap of the management scenarios with conservation. B. heatmap of the management scenarios without conservation. The result values are color-coded (blue $=$ low value, red $=$ high value)

Figure 8. The results of final year spawning stock biomass (SSB) of the metapopulation (Fin-SSB-Meta) from management scenarios with different minimum-size limit (X-axis) and lengths of closed season (Y-axis) under metapopulation framework. A. heatmap of the management scenarios with conservation. B. heatmap of the management scenarios without conservation. The result values are color-coded (blue $=$ low value, red $=$ high value)

Figure 9. The results of commercial landing of the metapopulation (L-Meta) from management scenarios with different minimum-size limit (X-axis) and lengths of closed season ( $\mathrm{Y}$-axis) under metapopulation framework. A. heatmap of the management scenarios with conservation. B. heatmap of the management scenarios without conservation. The result values are color-coded (blue $=$ low value, red $=$ high value).

Figure 10. The comparisons of the selected optimal management scenarios (minimumsize limit 76mm CL, 81mm CL, 82mm CL and 96mm CL) mean $\pm \mathrm{sd}$. A. Minimum spawning stock biomass (SSB) of the Florida stock (Min-SSB-FL). B. Final spawning stock biomass (SSB) of the Florida stock (Fin-SSB-FL). C. Total Florida commercial landing (L-FL). D. Landing variation of the Florida stock (LV-FL). E. Final year spawning stock biomass (SSB) of the metapopulation (Fin-SSB-Meta). F. Total commercial landing of the metapopulation (L-Meta).

Figure 11. The comparisons of the selected optimal management scenarios (minimumharvest size 76mm CL and 4.5 months closed fishing season, 82mm CL with 4 month closed fishing season and 96mm CL with 3.5 months closed fishing season) and the current management. The gradient is based on the minimum and the maximum values in each performance measures. 
CHAPTER I: GENERAL INTRODUCTION 
The Caribbean spiny lobster, Panulirus argus, is widely distributed throughout the Caribbean and the tropical and subtropical western Atlantic (Herrnkind and Butler 1986). It is also harvested by 30 countries and supports one of the most valuable fisheries in the region (Ehrhardt 2010). According to FAO (2018), the global production of this fishery has reached 39,244 metric tons in 2016 and created an average value of $\$ 1$ billion USD annually.

However, it suggested that the stocks of this valuable species are either in decline or fished at their full capacity. Because of its economic and ecological importance, building sustainable Caribbean spiny lobster fisheries has become a pressing issue. However, the limited knowledge on recruitment dynamics has hindered the success of the fishery management. Caribbean spiny lobster has a pelagic larvae stage known as the phyllosoma. After hatching, the phyllosoma larvae drift with the current for six to nine months (Lewis 1951; Yeung 1996; Matsuda et al. 2008) before metamorphosing into postlarvae. Then, the postlarvae drift from offshore to inshore, and eventually settle in shallow and vegetated habitats (Lipcius et al. 1994). This unique life stage has led to two contradictory hypotheses regarding the connectivity among the $P$. argus stocks in the Caribbean. One hypothesis suggests that the Caribbean spiny lobster stocks are demographically open (Kough et al. 2013; Truelove et al. 2017; Yao and Zhang 2018). The other hypothesis has insisted that most recruitment is a response to local spawning stock biomass, and has little contribution from other stocks (Ehrhardt and Fitchett 2010). Over the last decades, numerous studies have been applied to test these two hypotheses and investigate the connectivity among $P$. argus stocks. 
Understanding the recruitment dynamics of the Caribbean spiny lobster could be the missing piece to the development of effective fishery management. Therefore, the objectives of my dissertation are 1. to investigate the connectivity among Caribbean spiny lobster stocks using different approaches, then 2. to develop a meta-population framework for P. argus on the basis of connectivity to improve stock assessment and management.

Many approaches have been used to track animal movements. Generally, these methods could be separated into two categories: biophysical modeling and biological tagging. The biophysical modeling method integrates a hydrodynamic model with animal behavior to estimate long-distance dispersal (cite). The biophysical modeling is the most feasible method to estimate dispersal kernels for multiple species from a variety of potential sites (Cowen and Sponaugle 2009). The biophysical modeling method has also been widely used to estimate the connectivity of pelagic larvae species; these include reef fishes in the Caribbean (Pairs et al. 2004), as well as the lionfish in the Gulf of Mexico (Kitchens et al. 2017). The biophysical model has also been applied to the Caribbean spiny lobster. In previous research, it has been used to investigate the connectivity among Caribbean $P$. argus stocks (Butler et al. 2011; Kough et al. 2013). The results of these previous studies support the hypothesis that $P$. argus stocks in the Caribbean are demographically open.

The other common approach is biological tagging. It includes both internal and external tagging. The external tag is attached to an individual physically (e.g., electronic tag and acoustic tag). The external tagging could be used to obtain information on stock identity, movement, abundance, and growth. The external tagging has been used on a wide range of marine and freshwater species (Lucas and Baras 2001; Ehrenbery and Steig 2003). The body 
length of the phyllosoma instar ranges from 25.6-28.2 mm (Goldstein et al. 2008) and larvae molt frequently during their six- to nine-month drifting phase. Therefore, the external tagging method cannot be used for tracking phyllosoma larvae movement.

Contrarily, internal tagging, including genetic markers and stable isotope markers, could be ideal for tracking phyllosoma larvae dispersion. A genetic marker is a gene or DNA sequence with a known location on a chromosome that can be used to identify individuals or species. Internal tagging has been widely used to study the population structure of terrestrial as well as aquatic species (Hedgecock et al. 2007). For the past decade, scientists have applied multiple genetic markers to understand the connectivity among $P$. argus stocks in the Caribbean. The markers used include mitochondrial (Cytochrome Oxidase I and 16S ribosomal genes), nuclear (Adenine Nucleotide Transporter gene) sequences markers, and microsatellite markers. The results of the phylogenetic study (COI, 16S and nuclear gene) suggest the presence of two subspecies: Panulirus argus argus, representing populations from the Caribbean, and Panulirus argus westonii, representing populations from Brazil (Sarver et al. 2000; Diniz et al. 2005). Meanwhile, the results of population genetic analysis have revealed the presence of high-levels connectivity among marine protected areas (MPAs) in the Mesoamerican Barrier Reef System (MBRS) of Central America (Truelove et al. 2015), MPAs on the Caribbean coast of Mexico (Truelove et al. 2015), as well as nine locations throughout Bermuda and the greater Caribbean (Truelove et al. 2017). In my dissertation, microsatellite markers were selected to provide information on the population level. 
Another frequently used internal tagging method is the stable isotope marker. The natural abundance of isotope signatures can be used to investigate mechanisms at the singleorganism level, characterize trophic relationships, and follow whole ecosystem nutrient cycling in both terrestrial and marine systems (Rubenstein and Hobson 2004; Hobson 2008). In recent years, the stable isotope method has been widely applied to track animal movement, particularly those in aquatic systems, including marine mammals, insects, and birds (Munroe et al. 2015). For instance, stable isotope values of $\delta 13 C, \delta^{18} O$, and $\delta^{87} S r$ in the otoliths of marine and anadromous fish are commonly used to infer migration patterns (Campana 1999; Thorrold et al. 2006). However, the stable isotope method has never been used to investigate dispersal pattern of phyllosoma larvae of lobster species because of the molting process of crustaceans. For finfish, scales and otoliths are structures that permanently record stable isotope signatures from different locations. Conversely, phyllosoma larvae of $P$. argus molt frequently during their six- to nine-month drifting phase, renewing all hard structures and their isotope signatures repeatedly (Lewis 1951; Goldstein et al. 2008). The lack of permanent calcified structures makes traditional isotope analyses inappropriate in tracking crustaceans' migration. An alternative method is to investigate the $\delta^{13} \mathrm{C}$ and $\delta^{15} \mathrm{~N}$ values in muscle tissue. Recent studies using these values from muscle tissue taken from landlocked gobies were able to reveal their migration patterns (Maruyama et al. 2001). The stable isotopies technique was also successfully used to investigate the movements of tropical reef fish among the mangrove, seagrass, and reef habitats (de la Morinière et al. 2003). There is thus promise for the stable isotope approach to elucidate the variability in Florida $P$. argus recruitment. 
In my dissertation, three different approaches (genetic markers, stable isotope analysis and biophysical modeling) are used to understand the recruitment dynamics of the monthly recruits arriving at Florida from August 2014 to July 2016. Furthermore, the connectivity results of these three different methods over the matching two-year time frame is compared.

The second objective of my dissertation is to improve current management of Florida P. argus fishery by evaluating the impacts of spatial structure on the stock assessment, as well as the candidate management strategies. Stock assessment is a scientific application that investigates the population dynamics and provides high-quality information for fisheries management of stocks. Fisheries management aims at achieving optimal and sustainable utilization of the fishery resource while safeguarding the ecosystem. These two tools are used in conjunction to rebuild stock and promote sustainable fisheries. Traditional Caribbean spiny lobster stock assessment and fishery management both assume that individuals within one population form a discrete group; they share the same gene pool, are self-sustaining, and are isolated from other populations (Quinn and Deriso 1999; King 2007). Under the isolated population assumption, every individual in the population is expected to experience the same life history and fisheries processes, and no mixing is considered among the target stock and its neighbors (Cooper 2006; Botsford et al. 2009). The common management regulations of the Caribbean spiny lobster fishery include a closed fishing seasons, a minimum harvest size, and a prohibition for harvesting female lobsters with eggs. These management regulations were created following the assumption that the local recruitment receives contribution 
exclusively from the local spawning stock. However, on the basis of our understanding on life history, the isolated population assumption does not accurately reflect reality. Ignoring spatial structure could introduce bias to the stock assessment, and consequently reduce the effectiveness of the fishery management (Stephenson 1999; Holland 2003; Stelzenmüller et al. 2008). Therefore, a meta-population framework has been proposed to include the spatial structure into the stock assessment and management. Each sub-stock within the metapopulation framework is linked by immigration and emigration (Gotelli 2008). The metapopulation framework has been used by fishery scientists to produce more accurate stock assessment and provide more effective fisheries management strategies (Fromentin and Powers 2005; Goethel et al. 2014; Archambault et al. 2016).

Fishery management strategy evaluation (MSE) involves using simulations to compare the effectiveness among different management scenarios in terms of achieving management objectives (Punt et al. 2016). Among a set of candidate strategies, simulation could identify the management strategies that are robust to the uncertain and capable of balancing multiple objectives (Holland 2010). Over the last two decades, the MSE method has been increasingly used by fisheries scientists to evaluate the impact of ignoring spatial structure in stock assessment as well as fisheries management (Plaganyi et al. 2013; Dichmont et al. 2013).

The objective of my dissertation is to further our understanding of recruitment ecology, as well as improve the stock assessment and management of the Florida Caribbean spiny lobster. To increase our knowledge of recruitment dynamics of the Florida $P$. argus stock, three methods (genetic markers, stable isotope and biological modeling) have been 
applied from August 2014 to July 2016. Subsequently, MSE has been used to evaluate influences of the spatial structure on stock assessment and management of the P. argus Florida stock.

\section{LITERATURE CITED}

Archambault, B., Le Pape, O., Baulier, L., Vermard, Y., Véron, M., \& Rivot, E. (2016). Adult-mediated connectivity affects inferences on population dynamics and stock assessment of nursery-dependent fish populations. Fisheries research, 181:198-213.

Botsford, L.W., Brumbaugh, D.R., Grimes, C., Kellner, J.B., Largier, J., O’Farrell, M.R., Ralston, S., Soulanille, E., \& Wespestad, V. (2009). Connectivity, sustainability, and yield: bridging the gap between conventional fisheries management and marine protected areas. Reviews in Fish Biology and Fisheries, 19(1):69-95.

Campana, S.E. (1999). Chemistry and composition of fish otoliths: pathways, mechanisms and applications. Marine Ecology Progress Series, 188:263-297.

Clegg, S. M., Kelly, J. F., Kimura, M., \& Smith, T. B. (2003). Combining genetic markers and stable isotopes to reveal population connectivity and migration patterns in a Neotropical migrant, Wilson's Warbler (Wilsonia pusilla). Molecular Ecology, 12(4): 819-830.

Cook, B. D., Bunn, S. E., \& Hughes, J. M. (2007). Molecular genetic and stable isotope signatures reveal complementary patterns of population connectivity in the regionally vulnerable southern pygmy perch (Nannoperca australis). Biological Conservation, 138(1):60-72.

Cooper, A. B. A guide to fisheries stock assessment: from data to recommendations. University of New Hampshire, Sea Grant College Program, 2006.

Cowen, R. K., \& Sponaugle, S. (2009). Larval dispersal and marine population connectivity. Annual review of marine science, 1: 443-466.

de la Morinière E. C., Pollux B. J., Nagelkerken, I, Hemminga, M. A., Huiskes A. H., \& Van der Velde, G. (2003). Ontogenetic dietary changes of coral reef fishes in the mangrove-seagrass-reef continuum: stable isotopes and gut-content analysis. Marine Ecology Progress Series, 246:279-289. 
Dichmont, C. M., Ellis, N., Bustamante, R. H., Deng, R., Tickell, S., Pascual, R., Lozano-Montes, H., \& Griffiths, S. (2013). Evaluating marine spatial closures with conflicting fisheries and conservation objectives. Journal of Applied Ecology, 50(4): 1060-1070.

Diniz, F. M., Maclean, N., Ogawa, M., Cintra, I. H., \& Bentzen, P. (2005). The hypervariable domain of the mitochondrial control region in Atlantic spiny lobsters and its potential as a marker for investigating phylogeographic structuring. Marine Biotechnology, 7(5): 462-473.

Ehrhardt, N. M., \& Fitchett M. (2010). Dependence of recruitment on parent stock of the spiny lobster, Panulirus argus, in Florida. Fisheries Oceanography. 19:6.434-447.

Fromentin, J. M., \& Powers, J. E. (2005). Atlantic bluefin tuna: population dynamics, ecology, fisheries and management. Fish and Fisheries, 6: 281-298.

Goethel, D. R., Legault, C. M., \& Cadrin, S. X. (2014). Testing the performance of a spatially explicit tag-integrated stock assessment model of yellowtail flounder (Limanda ferruginea) through simulation analysis. Canadian Journal of Fisheries and Aquatic Sciences, 72(4): 582-601.

Goldstein, J. S., Matsuda, H., Takenouchi, T., \& Butler, M. J. (2008). The complete development of larval Caribbean spiny lobster Panulirus argus (Latreille, 1804) in culture. Journal of Crustacean Biology, 28(2):306-327.

Hedgecock, D., Barber, P., \& Edmands, S. (2007). Genetic approaches to measuring connectivity. Oceanography, 20:70-79.

Herrnkind, W. F., Butler, I. V., \& Mark, J. (1986). Factors regulating settlement and microhabitat use by spiny lobsters Panulirus argus. Marine Ecology Progress Series, 34.

Hobson, K. A. (2008). Isotopic tracking of migrant wildlife. In: Michener R, Lajtha K, editors. Stable isotopes in ecology and environmental science. 2nd ed. Hoboken: John Wiley \& Sons. p. 155-170.

Holland, D. S. (2003). Integrating spatial management measures into traditional fishery management systems: The case of the Georges Bank multispecies groundfish fishery. ICES Journal of Marine Science, 60: 915-929.

King, M. 2007. Fisheries Management, in Fisheries Biology, Assessment and Management, Second Edition, Blackwell Publishing Ltd., Oxford, UK. 
Kitchens, L. L., Paris, C. B., Vaz, A. C., Ditty, J. G., Cornic, M., Cowan, J. H., \& Rooker, J. R. (2017). Occurrence of invasive lionfish (Pterois volitans) larvae in the northern Gulf of Mexico: characterization of dispersal pathways and spawning areas. Biological Invasions, 19(7): 1971-1979.

Kough, A. S., Paris, C. B., \& Butler, M. J. (2013). Larval Connectivity and the International Management of Fisheries. PloS one, 8, e64970.

Lewis, J. B. (1951). The phyllosoma larvae of the spiny lobster, Panulirus argus. Bulletin of Marine Science, 1: 89-103.

Lipcius, N. R. (1985). Size-dependent reproduction and molting in spiny lobsters and other long-lived decapods. Crustacean, 3:129-148.

Maruyama, A., Yamada, Y., Rusuwa, B., \& Yuma, M. (2001). Change in stable nitrogen isotope ratio in the muscle tissue of a migratory goby, Rhinogobius sp., in a natural setting. Canadian Journal of Fisheries and Aquatic Sciences, 58(11): 2125-2128.

Matsuda, H., Goldstein, J.S., Takenouchi, T. \& Butler, M.J. IV (2008) A description of the complete development of larval Caribbean spiny lobster Panulirus argus (Laterille, 1804) in culture. Journal of Crustacean Biology, 28:306-327.

Munroe, S. E., Heupel, M. R., Fisk, A. T., Logan, M., \& Simpfendorfer, C. A. (2015). Regional movement patterns of a small-bodied shark revealed by stable-isotope analysis. Journal of fish biology, 86(5):1567-1586.

Paris, C. B., \& Cowen, R. K. (2004). Direct evidence of a biophysical retention mechanism for coral reef fish larvae. Limnology and Oceanography, 49(6): 1964-1979.

Plagányi, É. E., Skewes, T. D., Dowling, N. A., \& Haddon, M. (2013). Risk management tools for sustainable fisheries management under changing climate: a sea cucumber example. Climatic Change, 119(1): 181-197.

Punt, A. E., Butterworth, D. S., de Moor, C. L., De Oliveira, J. A., \& Haddon, M. (2016). Management strategy evaluation: best practices. Fish and Fisheries, 17(2): 303-334.

Quinn, T. J., \& Deriso, R. B. (1999). Quantitative fish dynamics. Oxford University Press.

Rubenstein, D. R., \& Hobson, K. A. (2004). From birds to butterflies: animal movement patterns and stable isotopes. Trends in ecology \& evolution, 19(5): 256-263.

Sarver, S. K., Freshwater, D. W., \& Walsh, P. J. (2000). The occurrence of the provisional Brazilian subspecies of spiny lobster (Panulirus argus westonii) in Florida waters. Fishery Bulletin-National Oceanic and Atmospheric Administration, 98(4): 870-873. 
Steig, T. W., Skalski, J. R., \& Ransom, B. H. (2005). Comparison of acoustic and PIT tagged juvenile Chinook, steelhead and sockeye salmon (Oncorhynchus, spp.) passing dams on the Columbia River, USA. In Proceedings of the Fifth Conference on Fish Telemetry: 9-13 June 2003; Ustica, Italy (pp. 275-286). FAO.

Stelzenmüller, V., Rogers, S. I., \& Mills, C. M. (2008). Spatio-temporal patterns of fishing pressure on UK marine landscapes, and their implications for spatial planning and management. ICES Journal of Marine Science, 65(6): 1081-1091.

Stephenson, R. L. (1999). Stock complexity in fisheries management: a perspective of emerging issues related to population sub-units. Fisheries Research, 43: 247-249.

Thorrold, S. R., Jones, G. P., Planes, S., \& Hare, J. A. (2006). Transgenerational marking of embryonic otoliths in marine fishes using barium stable isotopes. Canadian Journal of Fisheries and Aquatic Sciences, 63(6): 1193-1197.

Truelove, N. K., Kough, A. S., Behringer, D. C., Paris, C. B., Box, S. J., Preziosi, R. F., \& Butler, M. J. (2017). Biophysical connectivity explains population genetic structure in a highly dispersive marine species. Coral Reefs, 36(1): 233-244.

Truelove, N. K., Ley-Cooper, K., Segura-García, I., Briones-Fourzán, P., Lozano-Álvarez, E., Phillips, B. F., ... \& Preziosi, R. F. (2015). Genetic analysis reveals temporal population structure in Caribbean spiny lobster (Panulirus argus) within marine protected areas in Mexico. Fisheries research, 172: 44-49.

Truelove, N. K., Griffiths, S., Ley-Cooper, K., Azueta, J., Majil, I., Box, S. J., ... \& Preziosi, R. F. (2015). Genetic evidence from the spiny lobster fishery supports international cooperation among Central American marine protected areas. Conservation genetics, 16(2): 347-358.

Yao, N., \& Zhang, Y. (2018). Investigating Temporal Variation in Stable Carbon and Nitrogen Isotope Values of Florida Caribbean Spiny Lobster Panulirus argus Recruits. Bulletin of Marine Science, 94(3): 847-861.

Yeung, C. (1996). Transport and Retention of Lobster Phyllosoma Larvae in the Florida Keys. PhD dissertation, Coral Gables, FL, USA: University of Miami, pp. 217. 
CHAPTER II INVESTIGATING TEMPORAL VARIATION IN STABLE CARBON AND NITROGEN ISOTOPE VALUES OF FLORIDA CARIBBEAN SPINY LOBSTER

PANULIRUS ARGUS RECRUITS 


\section{ABSTRACT}

The limited information available on the recruitment dynamics of the Caribbean spiny lobster Panulirus argus (Latreille, 1804) has long been an issue for biologists. The long pelagic larval stage and the surface circulation in the Caribbean Sea have led many researchers to hypothesize that Caribbean lobster stocks are demographically open, implying connectivity among stocks in this region. Multiple approaches have been applied to investigate potential stock connectivity in this species, including bio-physical modeling and genetic markers. Stable isotope analysis has proven to be a useful tool to study animal movement, and has been widely applied in studies of both terrestrial and aquatic species. However, this method has never been applied to Caribbean spiny lobster recruits. In this study, we performed carbon and nitrogen stable isotope analyses on three sub-stages of the non-feeding pueruli (clear, semi-pigmented, and pigmented) as well as on the feeding, first juvenile stage, that settled in the Florida Keys from August 2014 to July 2016. Results indicated that the stable isotope values differed between the feeding and non-feeding stages. The $\delta^{13} \mathrm{C}$ and $\delta^{15} \mathrm{~N}$ values of the lunar monthly samples displayed notable temporal variation and oscillated during the two-year sampling period. Cluster analyses of the stable isotope values suggested that four clusters could have contributed to the observed Florida recruits. The results of our study reveal the possibility that the Florida spiny lobster stock receives recruits from multiple source populations outside Florida, in addition to self-recruitment. 


\section{INTRODUCTION}

The Caribbean spiny lobster, Panulirus argus (Latreille 1804), is widely distributed in coastal tropical and subtropical waters of the western Atlantic Ocean (Herrnkind and Butler 1986). It is one of the most economically and ecologically important species in the Caribbean Sea (Chávez 2008; Ehrhardt and Fitchett 2010). According to the Food and Agriculture Organization of the United Nations, the global production of Caribbean spiny lobster was 37,428 metric tons in 2015 . Efforts have been made to better assess the stock conditions and improve fishery management. However, information on the relationship between the species' spawning stock biomass and recruitment (i.e., larvae and settlers) is limited. Such limited knowledge is mainly due to the long pelagic larval stage of $P$. argus. After hatching, the phyllosoma larvae of $P$. argus drift as plankton for six to nine months (Lewis 1951; Goldstein et al. 2008). During the drift, the pelagic phyllosoma larvae feed from the surrounding environment (Jeffs 2007). They then metamorphose into non-feeding transparent pueruli (i.e., the clear pueruli) and move inshore to shallow, vegetated habitats actively by locomotion and passively by wind-driven currents (Yeung and McGowan 1991; Lipcius and Cobb 1994; Butler and Herrnkind 2000). Once settled in the inshore habitat, they quickly become pigmented (i.e., they develop through the clear pueruli, semi-pigmented pueruli and pigmented pueruli), and eventually molt into the juvenile stage. It takes a $P$. argus approximately one week to complete the metamorphosis from a puerulus to a juvenile (Goldstein et al. 2008). One of the most important characteristics in distinguishing among the collected samples is the ability to ingest food. The clear pueruli, semi-pigmented pueruli, and pigmented pueruli are non- 
feeding (Wolfe and Felgenhauer 1991; Phillips et al. 2005; Phillips et al. 2006), while in the first juvenile stage of the P. argus, starts to feed on organic material from the surrounding environment (Herrnkind and Butler 1986; Butler and Herrnkind 1991).

In Florida, as elsewhere in the Caribbean, there is uncertainty regarding stock dynamics of $P$. argus that limits the study and management of fisheries. There are two contradicting hypotheses involving the recruitment dynamics of spiny lobster to the Southeast US stock. One hypothesis suggests that the Florida $P$. argus stock is demographically open, while the other suggests that the Southeast US stock is sustained by self-recruitment. Over the last few decades, researchers have used different approaches to understand recruitment and connectivity of the Florida Caribbean spiny lobster stock. The most common methods applied were bio-physical modeling, genetic methods, and empirical observations on the recruitment. The results of bio-physical modeling (Kough et al. 2013) and analyses of genetic markers (Sarver et al. 1998; Hunt et al. 2009) support the hypothesis that Florida receives recruits from other locations. Conversely, analyses of fishery landings and recruitment indices suggest that the stocks are mainly self-recruiting (Ehrhardt and Fitchett 2010). At present, there is no clear conclusion on the recruitment dynamics of the Southeast spiny lobster stock. Importantly, there is previously established reasoning that lead one to expect different methods' estimates of recruitment dynamics to disagree. For example, genetic results are usually generated from one-time sampling events that may not capture the temporal dynamics of recruitment processes (e.g., variability of connectivity across years). Further, genetic connectivity 
measurements and those derived from direct observations of movement (e.g., tagging, and dispersal modeling) are likely not comparable due to differences in time scale (e.g., genetic structure of a population develops over much longer than a single generation; Lowe and Allendorf 2010). Connectivity results from independent biomarkers are needed to validate results from modeling (and genetic) methods. Stable isotope analysis may provide such a tool that can be used to reveal the recruitment dynamics of the Southeast spiny lobster stock.

Stable isotope analysis has been shown to be a useful tool for answering ecological questions. The natural abundance of isotope signatures can be used to investigate spatial movement and characterize trophic relationships in both terrestrial and marine systems (Rubenstein and Hobson 2004; Hobson 2008). In the past decades, ecologists have used this technique extensively to track animal movement, particularly of those in aquatic systems, including marine mammals, insects, and birds (Rubenstein and Hobson 2004; Munroe et al 2015). For instance, stable isotope values of $\delta^{13} \mathrm{C}, \delta^{18} \mathrm{O}$, and $\delta^{87} \mathrm{Sr}$ in the otoliths of marine and anadromous fish are commonly used to infer migration patterns (Campana 1999; Thorrold et al. 2006). However, it has never been used to investigate dispersal pattern of phyllosoma larvae of lobster species due to the molting process of crustaceans. For finfish, scales and otoliths are structures that permanently record stable isotope signatures from different locations. Conversely, phyllosoma larvae of $P$. argus molt frequently during their six- to nine-month drifting phase, renewing all hard structures and their isotope signatures repeatedly (Lewis 1951; Goldstein et al. 2008). 
Lacking of permanent calcified structures makes traditional isotope analyses inappropriate in tracking crustaceans' migration. An alternative method is to investigate the $\delta^{13} C$ and $\delta^{15} N$ values in the muscle tissue. Studies using these values from muscle tissue of landlocked gobies were able to reveal their migration patterns (Maruyama et al. 2001). This technique was also successfully used to investigate the movements of tropical reef fish among the mangrove, seagrass, and reef habitats (de la Morinière et al. 2003). There is thus promise for this approach to elucidate the variability in spiny lobster recruitment.

Understanding the feeding ecology during the different life stages of spiny lobster is crucial in discerning its movement patterns through stable isotope analysis. So far, knowledge concerning the diet of phyllosoma larvae is limited. This is mainly due to the complex life histories of the phyllosoma larvae, which makes the application of traditional stomach content analysis or field observation impractical. Scientists have indirect and direct evidence of phyllosoma diet from laboratory culture (Kittaka 1997; Jeffs and Hooker 2000), and inferences were made based on the anatomy of the digestive system (Cox and Johnston 2004; Jeffs 2007), enzyme profiles (Booth and Phillips 1994; Johnston et al. 2004), and DNA-based diet research (O'Rorke et al. 2012). Results of various approaches all suggested that gelatinous zooplankton, especially Siphonophora and Ctenophora, were the main food source for phyllosoma larvae (Jeffs 2007). Results from DNA-based diet research also suggested that the phyllosomas might scavenge on detritus (O’Rorke et al. 2012). The prey sources of $P$. argus in the juvenile stage have 
been well-studied via morphological and behavioral observations. The results concluded that small crustaceans, worms, molluscs and echinoderms are the main food sources of the early-juvenile P. argus (Marx and Herrnkind 1985; Cox et al. 2008). Meanwhile, with the development of the digestive system in the late juvenile stage, the diets of spiny lobster switch to gastropods, bivalves, chitons and other crustaceans (Herrnkind et al. 1988; Cox et al. 1997; Nizinski 2007).

In this study, we conducted the first stable isotope analyses on the recruits of the Palinuridae family. We examined $\delta 13 C$ and $\delta^{15} N$ values in the muscle tissues of the lunar-month recruitment pulses that arrived in Florida from August 2014 to July 2016. We estimated the stable isotopic fraction differences between the feeding and non-feeding stages based on their feeding ecology. The three postlarval sub-stages are non-feeding. Hence, the spiny lobster larvae could possess stable isotope signatures from their source population locations (Phillips et al. 2006). In contrast, the feeding first juvenile stage would be expected to carry a signature similar to what is measured from the settlement environment (Butler and Herrnkind 1991; Hobson 1999). The temporal variation of recruits' $\delta^{13} C$ and $\delta^{15} N$ values within and among months was estimated. The potential number of different source populations and their proportions for each lunar cycle are also presented in this study. 


\section{METHODS}

\section{SAMPLE COLLECTION}

All $P$. argus individuals used in the stable isotope analysis were collected from two sites:

Long Key (LK) and Big Munson (BM), which are located in the Florida Keys (Fig. 1). These two sites have also been used in a long-term recruitment monitoring program, started in 1987 (Acosta et al. 1997). From August 2014 to July 2016 (including the 2014-2015 and 20152016 fishing years), postlarvae from three sub-stages (clear, semi-pigmented, and pigmented), as well as first-stage juveniles, were collected seven days after the new moon phase by using the Witham Collectors and Blue Collectors (Witham et al. 1964; Phillips and Booth 1994). Live individuals were preserved using $2 \mathrm{ml}$ tubes and frozen immediately after collection to avoid enzymatic reactions. A total of 50 individuals per month ( 25 from each sampling site) were transported to Florida International University (FIU) using dry ice ($20^{\circ} \mathrm{C}$ ) for stable isotope analysis.

\section{STABLE ISOTOPE ANALYSIS}

All samples were kept frozen until the sample preparation. First, in each sample, the puerulus sub-stages were identified based on the amount of pigment present in the individual (Wolfe and Felgenhauer 1991; Goldstein et al. 2008). Then, 10 samples were selected from the entire collection per site per month in an attempt to balance the sample size for each stage. For each selected sample, the tail muscle was removed from the exoskeleton and dried in the oven at $65^{\circ} \mathrm{C}$ for 48 hours. Dried samples were then homogenized by hand using a mortar and pestle. About 0.4-0.7 g of each homogenized 
tissue sample was weighed into a tin capsule. Carbon and nitrogen isotope composition was measured on a ThermoFinnigan Delta $\mathrm{V}$ isotope ratio mass spectrometer (IRMS) coupled with a NA 1500 NE elemental analyzer at the Florida International University Stable Isotope Laboratory. The ${ }^{13} \mathrm{C} /{ }^{12} \mathrm{C}$ and ${ }^{15} \mathrm{~N} /{ }^{14} \mathrm{~N}$ isotopic ratios were standardized and expressed in per mil (\%) using delta notation based on the following (McKinney et al. 1950):

$\delta X=\left[\left(\frac{R_{\text {sample }}}{R_{\text {standard }}}\right)-1\right] \times 1000$

where $X$ is $\delta^{13} C$ or $\delta^{15} N, R_{\text {sample }}$ is the corresponding ratio of $13 \mathrm{C} / 12 \mathrm{C}$ or $15 \mathrm{~N} / 14 \mathrm{~N}$, $R_{\text {standard }}$ represented the International Atomic Energy Agency (IAEA) standard for $\delta^{13} C$ or $\delta^{15} N$ (ANU Sucrose for $\delta^{13} C$ and atmospheric $N_{2}$ for $\delta^{15} N$ ).

$\delta^{13} C$ and $\delta^{15} N$ values of the particulate organic matter (POM) used in our study were derived from Lamb and Swart (2008). In their study, the carbon and nitrogen isotope composition of the POM were measured from surface water samples collected from 35 sites positioned from nearshore to offshore in the Florida Keys (including BM and LK) from June 2000 to August 2002.

STATISTICAL ANALYSES

The spatial differences of stable isotope values between the two sample sites were tested 
using the Hotelling's t-test, a commonly-used multivariate hypothesis test to detect the statistical differences for both $\delta^{13} C$ and $\delta^{15} N$ values (Hotelling 1951). A Student's t-test was used to test for differences in the $\delta^{13} \mathrm{C}$ and $\delta 15 \mathrm{~N}$ values between the non-feeding stage (clear pueruli, semi-pigmented pueruli and pigmented pueruli) and the feeding stage (juvenile). A Fisher-Pitman permutation test based on 9999 Monte-Carlo resampling iterations (Berry et al. 2002) was used to test for stable isotopic differences in monthly $\delta^{13} \mathrm{C}$ and $\delta^{15} N$ values. Subsequently, pairwise permutation tests with the Benjamini-Hochberg false discovery rate (FDR) control were used as post-hoc tests for the monthly $\delta^{13} \mathrm{C}$ and $\delta^{15} N$ values (Benjamini and Hochberg 1995). To investigate the temporal pattern of the stable isotope values, an autocorrelation analysis was applied to the lunar-monthly $\delta^{13} \mathrm{C}$ and $\delta^{15} N$ time series. In order to detect the variability of the $\delta^{13} C$ and $\delta^{15} N$ values among the lunar monthly samples, a K-means cluster analysis was also applied. Analysis of variance (ANOVA) was employed to test the difference among the clusters and the POM.

\section{RESULTS}

We found that $\delta^{13} \mathrm{C}$ and $\delta^{15} \mathrm{~N}$ values did not significantly differ between our two sampling sites, neither for samples including juveniles (Hotelling's t-test: $t=0.73 ; p=0.48$;

Supplementary Material, Fig. S1A, B) nor for samples excluding juveniles (Hotelling's t-test: $t=1.63 ; p=0.20 ;$ Supplementary Material, Fig. S1C, D). This indicated that samples from both sites could be treated equally. Therefore, the samples of each month from both sites were pooled together as replicates for the further analyses. 
We found significant differences in the $\delta^{13} \mathrm{C}$ values between three puerulus sub-stages and juvenile stage (permutation test: $X^{2}=42.91 ; p<0.05$; Supplementary Material, Fig. S2A), but $\delta^{15} N$ did not differ between stages (permutation test: $X^{2}=4.14 ; p<0.05$;

Supplementary Material, Fig. S2B). With the purpose of eliminating the impacts from the feeding stages on stable isotope values of recruits, we excluded the juvenile samples from further time series and cluster analyses.

Both $\delta^{13} \mathrm{C}$ and $\delta^{15} \mathrm{~N}$ values for the aggregated non-feeding stage displayed variations among months (Fig. 2). During the sampling period, the $\delta^{13} \mathrm{C}$ value ranged from $-21.34 \%$ to $-13.36 \%$, and the $\delta^{15} N$ value ranged from $5.04 \%$ to $9.89 \%$. The results of the permutation test suggested that the difference on the $\delta^{13} \mathrm{C}$ value and the $\delta^{15} \mathrm{~N}$ values were significant $\left(\delta^{13} C: X^{2}=138.78 ; p<0.05 ; \delta^{15} N: X^{2}=68.39 ; p<0.05\right)$. The $\delta^{13} C$ value reached its highest value in August, dropped sharply afterward, and maintained a relatively lower value until the end of the dry season (March or April) in both years (Fig. 2A). The $\delta^{15} N$ value displayed a similar pattern, with a peak occurring in the late wet season, a reduced value in the dry season, and then an increased value again at the end of dry season (Fig. 2B). However, over time, the $\delta^{15} \mathrm{~N}$ value did not vary as much as the $\delta^{13} \mathrm{C}$ value did.

The results of autocorrelation analysis did not detect any significant temporal self-repeat patterns in either $\delta^{13} \mathrm{C}$ or $\delta^{15} \mathrm{~N}$ values for the entire time series (Supplementary Material, Fig. S3). However, for each lunar cycle, the $\delta^{13} C$ values exhibited seasonal patterns with a negative correlation occurring at a time lag of four months. This negative correlation reached 
a minimum at a time lag of six to seven months, and then switched to positive correlation at a time lag of 11 months. A similar pattern was observed from $\delta^{15} N$ values, but was much weaker.

When the stable isotope values time series were analyzed using the K-means cluster analysis, the elbow method was used to determine the optimal number of clusters. We found that four was the appropriate number of clusters to apply, and $73 \%$ of the total variance in the data can be explained. The mean $\delta^{13} C$ and $\delta^{15} N$ values $( \pm \mathrm{SD})$ of the four clusters from our study and the POM from Lamb and Swart (2008) were shown in Fig. 3. A distinct gradient in both $\delta^{13} \mathrm{C}$ and $\delta^{15} \mathrm{~N}$ values of the four clusters were observed. Cluster One has the highest $\delta^{13} \mathrm{C}$ value, $-15.9 \%$ ( $( \pm 0.63 \%)$, and its $\delta^{15} N$ value is $6.7 \%$ ( $( \pm 0.46 \%)$. The $\delta^{13} C$ value of the Cluster Two is $-17.5 \% 0\left( \pm 0.37 \%\right.$ ) and it displayed a similar $\delta^{15} N$ value $(6.7 \pm 0.34 \%$ ) to Cluster One. Cluster Three and Four exhibited a similar range of $\delta^{13} C$ values (Cluster Three: $-18.3 \pm 0.46 \%$; Cluster Four: $-18.4 \pm 0.45 \%$ ), but differed in the $\delta^{15} N$ value (Cluster Three: $6.2 \pm 0.44 \%$; Cluster Four: $7.7 \pm 0.66 \%$ ). The only overlap of the $\delta^{13} C$ value between the POM and four clusters occurred between inshore sites and Clusters Three and Four. The rest of the $\delta^{13} \mathrm{C}$ values of POM sites and clusters differ significantly from each other $\left(F_{6,363}=310.4 ; p<0.05\right)$. The $\delta^{15} N$ values of the four clusters were significantly higher than the results from the $\operatorname{POM}\left(F_{6,363}=151.5 ; p<0.05\right)$.

Furthermore, results indicated that the proportion of the four clusters oscillated during the two-year sampling period (Fig. 4). Specifically, Cluster Two (light grey in Fig. 4) and Cluster 
Four (black in Fig. 4) were more prevalent than other clusters, with Cluster Four observed in 20 months and Cluster Two only absent from two months during the 24-month sampling period. The proportion of Cluster Four also increased dramatically in the second year. The proportion of Cluster Two, however, was relatively stable with a slight decrease in wet season (April to September). Cluster Three (dark grey in Fig. 4) occupied most of the months from the middle of dry season and the beginning of wet season (December to June), then reduced or disappeared in the next dry season (Fig. 4). Conversely, Cluster One (white in Fig. 4) was rarely observed in the dry season (November to March) but occurred in most of the months of the wet season (from April to October).

\section{DISCUSSION}

VARIATION OF STABLE ISOTOPE VALUES AMONG PUERULUS SUB-STAGES AND

\section{FIRST JUVENILE STAGE}

The differences observed between the three puerulus sub-stages and the first juvenile stage are expected as they transition from planktonic to benthic habitat. This distinctive life history trait is reflected in the stable isotope values we examined. The $\delta^{13} \mathrm{C}$ value of the feeding stage was significantly higher than the value of the three non-feeding sub-stages. This is mainly due to the feeding ecology of the different life stages and the transition of prey environment (Hobson 1999). Previous research has suggested that there is a remarkable difference between the $\delta^{13} \mathrm{C}$ values of coastal and oceanic habitats (Evans et al. 2006; Lamb and Swart 2008). The phyllsoma larvae feed on the oceanic environment. Once settled, juveniles start to feed on the shallow, vegetated coastal habitats. This result confirmed that 
the $\delta^{13} \mathrm{C}$ value would change once a settling lobster switched its feeding habitat. It also confirmed that the non-feeding pueruli originated from phyllosoma larvae that feed somewhere else before moving inshore. Therefore, we excluded the juvenile stage from analyses related to estimating stock connectivity (i.e., via dispersal of phyllosomas). Our study also provided insights for the turnover rate of $P$. argus from different life stages. Isotopic turnover rate was first quantified by Fry and Arnold (1982), and is defined as the time it takes for a given consumer tissue to reflect the isotopic composition of food resources. This study illustrates that the turnover rate is a result of isotopic dilution due to growth and catabolic replacement. Even for the malacostraca, the turnover rate ranges from 8 to 23 days (e.g., the brown shrimp postlarvae Penaeus aztecus; Fry and Arnold 1982) to 10 weeks (e.g., the larval krill Euphausia superba; Frazer et al. 1997). Unfortunately, there is no information regarding the postlarvae turnover rate for any lobster species. Only one previous study indicated that the $\delta^{13} \mathrm{C}$ turnover rate for adult rock lobsters (Jasus edwardsii) was 116.8 days for hemolymph, compared with 147.0 days for the muscle (Suring and Wing, 2009). In our study, significant fluctuations of the $\delta^{13} \mathrm{C}$ value during the short transition period between the non-feeding postlarval sub-stages and the feeding juvenile stage could imply that the postlarvae of $P$. argus has a relatively rapid turnover rate. The significant difference between the turnover rate of the postlarvae samples from our study and the adult samples from Suring and Wing (2009) confirms that feeding ecology and life history could strongly influence turnover rate. Therefore, understanding of the turnover rate of stable isotope signals among different life stages is imperative, and future studies 
should be designed with caution. Otherwise, the derived migrations and trophic interactions results could be biased.

Compared to the $\delta^{13} \mathrm{C}$ values, the $\delta^{15} N$ values in this study did not differ between three puerulus sub-stages and juvenile stage. Due to the highly diverse prey sources, juveniles should feed at a different trophic level than phyllosoma larvae. However, our results did not reflect this shift, perhaps because the juvenile samples were collected close to the transitional period between the phyllosoma larvae stage and the juvenile stage. According to Cox et al. (2008), early stage juveniles did not possess full functionality. Therefore, they may still prey at a similar trophic level as phyllosomas.

The lunar monthly proportions of individuals in different stages arriving at our sampling sites varied, but they are consistent in terms of the inter-annual changes typically observed in South Florida's tropical climate. Specifically, in this region, there is one wet season from May to October, and one dry season from November to April. A larger proportion of the juvenile stage was observed during the wet season (Fig. 5). This is chiefly because the intermolt periods are the shortest during the wet season months when the temperature is higher (Lipcius and Herrnkind 1982). Excluding juveniles may result in uneven and small sample sizes for some months. These caveats should be considered in the experimental design of future postlarvae stable isotope studies. 


\section{MONTHLY VARIATION IN $\delta^{13} C$ and $\delta^{15} N$ VALUES}

Our results showed that there was great variation of stable isotope values among the two-year lunar-monthly samples. In general, patterns in both the mean and deviation from the mean of stable isotope values displayed seasonality. We found that samples taken during the wet season had much higher $\delta^{13} \mathrm{C}$ and $\delta^{15} \mathrm{~N}$ values than those from the dry season. In general, phyllosoma larvae feed from the base of the food web (Jeffs 2007; Kittaka 1997; O'Rorke et al. 2012) and should possess a similar $\delta^{13} C$ value as their prey (Hobson 1999). If the recruitment of the Florida stock is assumed to be solely the result of self-recruitment, the variation of stable isotope values from the samples should match those from the base of the food web in Florida waters. The results of Lamb and Swart (2008) indicated the annual mean of $\delta^{13} C$ and $\delta^{15} N$ values from the base of the food web in the region was $-19.9 \%( \pm 0.60 \%$ o $)$ and 3.6\%o $\left( \pm 3.20 \%\right.$ ), respectively. Specifically, for the offshore, the annual mean of $\delta^{13} C$ and $\delta^{15} N$ values from the base of the food web was $-21.2 \%$ o $( \pm 0.74 \%$ o $)$ and $3.9 \%$ o $( \pm 2.40 \%$. The monthly mean $\delta^{13} \mathrm{C}$ and $\delta^{15} N$ values from our study were significantly different from Lamb and Swart (2008) $\left(t_{1,38}=-8.557 ; p<0.05\right)$. Also, our monthly deviations were much higher $\left(\delta^{13} C:-17.60 \pm 1.06 \% ; \delta^{15} N: 6.73 \pm 0.69 \%\right.$ ), and they were statistically greater over the two-year study period (Fig. 3). Even if the consumer-diet $\delta^{13} C$ discrimination for phyllosoma larvae was considered in interpreting the $\delta^{13} \mathrm{Cresults}$, there might still be a marked difference in the $\delta^{13} \mathrm{C}$ values between the postlarvae and the POM. Although it hasn't been recorded for crustacean phyllosomas, one study conducted on the adult rock lobster (Panulirus cygnus) indicated the $\delta^{13} \mathrm{C}$ discrimination between muscle tissues and diet was $1.13 \%$ (Waddington and MacArthur 2008). Hence, the mismatch of the stable isotope 
values among months observed in our study could provide evidence that the Florida stock is not sustained entirely by self-recruitment alone. A more accurate explanation could be that the recruitment originated from different source populations during different periods, which might still include contribution from self-recruitment.

The other notable pattern we observed was the seasonal pattern in values of $\delta^{13} \mathrm{C}$. For both sampling years, the $\delta^{13} \mathrm{C}$ values were lower in the dry seasons and higher in the wet seasons, with sharp drops in September. This pattern was also confirmed by the results of autocorrelation analysis. Since phyllosoma larvae assimilate their $\delta^{13} \mathrm{C}$ value from their prey, this value could represent the variance of the numerous environments at which they feed. This could indicate a migration pattern. The main factor impacting the migration of phyllosomas is the current (Kough et al. 2013). Hence, it would be useful if one could identify the timing of current variations related to spawning peaks in the Caribbean region, as it would make possible the inference of the locations of Florida recruits' spawning grounds. Recent studies have characterized the seasonal cycle of the Florida and Yucatan passages (Meinen et al. 2010; Rousset and Beal 2011) and the Loop Current (Alvera-Azcárate et al. 2009; Hall and Leben 2016). However, oceanographic circulation in the Caribbean varies over space and time, and the bottom topography, winds, and current physical conditions (e.g., temperature, and $\mathrm{pH}$ ) are all related to and impact the currents (Lindo-Atichati et al. 2013). Thus, it is inappropriate to conclude that the recruitment migration pattern is solely based on the oceanographic system. In addition, the seasonality of the $\delta^{13} \mathrm{C}$ value observed in recruits could result from massive spiny lobster spawning events in the Caribbean. In general, spiny 
lobsters spawn year-round, but populations located in the northern Caribbean display a main spawning peak from March to June (Chubb 2000; Briones-FourzÁn et al. 2008). The varying time length of the spawning season and the time lag of the larvae drift period could also affect the seasonality of the $\delta^{13} C$ value. Therefore, an alternate direction for future research could be to use the stable isotope results to validate hydrodynamic or bio-physical model outcomes and to identify the potential spawning grounds for Florida recruits.

\section{CLUSTERING OF $\delta^{13} \mathrm{C}$ and $\delta^{15} N$ VALUES}

The entire collection of samples could be separated into four clusters based on $\delta^{13} C$ and $\delta^{15} N$ values. Each cluster would be defined as a group of individual postlarvae carrying similar $\delta^{13} C$ and $\delta^{15} N$ values. One cluster could contain individuals from one stock or multiple stocks that traveled to Florida along similar routes. The results of cluster analysis suggest at least four potential source populations have contributed to the spiny lobster recruitment in Florida.

It is impractical to assign each recruitment cluster to its source population without stable isotope information from all potential source population areas in the Caribbean and intervening oceanic areas. However, our study provides evidence that stable isotope signals can be used in the study of $P$. argus (or its prey) to gain insight into connectivity among its stocks. The number of the clusters of the population estimated from our study agrees with the results of Cochrane and Chakalall (2001), who also concluded that the spiny lobsters residing in the Caribbean could be divided into four hypothetical stocks, based on the nature of the 
coastal shelf and the prevailing currents in the region. Even though we did not attain evidence to suggest that the four clusters in our study coincide with the four hypothetical stocks from their study, our study set a standard for future connectivity studies. Behringer and Bulter (2006) investigated the stable isotope values of marine organisms in a tropical marine hard-bottom community, including juvenile spiny lobster from the Florida Keys, but found different isotope values. The $\delta^{13} \mathrm{C}$ value of juvenile spiny lobsters in their study ranged from -11.1 to $-13.2 \%$, much higher than the $\delta^{13} \mathrm{C}$ value of our clusters (range from $13.6 \%$ to $-21.3 \%$ ). Since we only use postlarvae, one possible explanation would be that $\delta^{13} \mathrm{C}$ differed due to the different diet of $P$. argus phyllosomas and juveniles. Furthermore, the inshore POM of Lamb and Swart (2008) overlapped with the $\delta^{13} C$ value of Clusters Three and Four from our study (Fig. 3). Based on this, we speculate that recruits in Cluster Three and/or Four may represent self-recruitment by the Florida lobster stock. Cluster Three was the most prevalent across the sample period in our study. Cluster Four was mostly absent in the wet season and reappeared in the dry season. Neither of the clusters were observed to be the most numerically important contributor to recruitment. This finding coincides with the conclusion of Kough et al. (2013) that the Florida stock receives more recruitment from external source populations than it does from self-recruitment.

\section{CONCLUSIONS}

This is the first study that applied stable isotope analyses to $P$. argus recruits in Florida. It confirms that the shift of diet from phyllosomas to juveniles has an immediate impact on the $\delta^{13} \mathrm{C}$ value. This information could improve the experimental design of future stable isotope 
studies of organisms including both feeding and non-feeding life history stages. The monthly fluctuation of $\delta^{13} \mathrm{C}$ and $\delta^{15} \mathrm{~N}$ values and the variability of cluster composition indicate that the migration of recruits to or near Florida is a dynamic process, with various contributions from different source populations to recruitment through time. The results of this study support the hypothesis that the Florida stock of the $P$. argus are demographically connected to other Caribbean spiny lobster stocks, although we also discovered evidence of partial selfrecruitment. It demonstrates that spatial connectivity among $P$. argus stocks in the Caribbean stocks does exist, and its impact on lobster recruitment should not be ignored.

\section{ACKNOWLEDGEMENTS}

We acknowledge the help of the Florida Fish and Wildlife Conservation Commission (FLFWC) lobster team (T Matthews, G Renchen, M Cooksey, C B Butler and E Hutchinson) for collecting samples from each lunar cycle for the experiment. We are also grateful to D Smart for assistance with the laboratory work for stable isotope analyses. We want to thank the FIU stable isotope laboratory for assistance with the experiment. We would also like to thank the Associate Editor, the two anonymous reviewers, J Trexler and B Hunting for their helpful, detailed, and constructive comments, which greatly improved the manuscript. Funding for this study was provided by FIU, FLFWC, Florida Sea Grant Collage Program (R/LR-B-69 and R/LR-B-74) and the Sea Grant Scholar Award. All of the experiments performed during this study were in compliance with the laws of the United States of America. 


\section{LITERATURE CITED}

Acosta CA, Matthews MJ, Butler MJ. 1997. Temporal patterns and transport processes in recruitment of spiny lobster (Panulirus argus) postlarvae to south Florida. Mar Biol. 129:79-86.

Alvera-Azcárate A, Barth A, Weisberg RH. 2009 The surface circulation of the Caribbean Sea and the Gulf of Mexico as inferred from satellite altimetry. J Phys Oceanogr. Mar. 39(3):640-57.

Behringer DC, Butler MJ. 2006. Stable isotope analysis of production and trophic relationships in a tropical marine hard-bottom community. Oecologia.148(2):334341.

Benjamini Y, Hochberg Y. 1995. Controlling the false discovery rate: a practical and powerful approach to multiple testing. J R Stat Soc Series B Stat Methodol. 289-300.

Berry KJ, Mielke Jr PW, Mielke HW. 2002. The Fisher-Pitman permutation test: an attractive alternative to the F test. Psychol Rep. 90(2):495-502.

Booth J, Phillips BF. 1994. Early life history of spiny lobster. Crustaceana. 66:271-294.

Briones-FourzÁn P, Candela J, Lozano-Álvarez E. 2008. Postlarval settlement of the spiny lobster Panulirus argus along the Caribbean coast of Mexico: patterns, influence of physical factors, and possible sources of origin. Limnol Oceanogr. 53(3):970-985.

Butler MJ, Herrnkind WF. 1991. Effect of benthic microhabitat cues on the metamorphosis of pucruli of the spiny lobster Panulirus argus. J Crust Biol. 11:23-28.

Butler MJ, Herrnkind WF. 2000. Puerulus and juvenile ecology. In: Phillips BF, Kittaka J, editors. Spiny Lobsters: Fisheries and Culture. 2nd ed. Oxford: Blackwell Science Ltd. p. 276-301.

Campana SE. 1999. Chemistry and composition of fish otoliths: pathways, mechanisms and applications. Mar Ecol Prog Ser. 188:263-297.

Chávez EA. 2008. Socio-economic assessment for the management of the Caribbean spiny lobster. Proc Gulf Caribb Fish Inst. 60:193-196.

Chubb CF. 2000. Reproductive biology: issues for management. In: Phillips BF, Kittaka J, editors. Spiny Lobsters: Fisheries and Culture. 2nd ed. Oxford: Blackwell Science Ltd. p. 245-276.

Cochrane KL, Chakalall B. 2001. The spiny lobster fishery in the WECAFC region-An approach to responsible fisheries management. Mar Freshw Res. 52(8):1623-1631.

Cox SL, Johnston DJ. 2004. Developmental changes in foregut functioning of packhorse lobster, Jasus (Sagmariasus) verreauxi (Decapoda: Palinuridae), phyllosoma larvae. Mar Freshw Res. 55:145-153. 
Cox SL, Jeffs AG, Davis M. 2008. Developmental changes in the mouthparts of juvenile Caribbean spiny lobster, Panulirus argus: Implications for aquaculture. Aquaculture. 283(1):168-174.

Cox C, Hunt JH, Lyons WG, Davis GE. 1997. Nocturnal foraging of the Caribbean spiny lobster (Panulirus argus) on offshore reefs of Florida, USA. Mar Freshw Res. 48:671-679.

de la Morinière EC, Pollux BJ, Nagelkerken I, Hemminga MA, Huiskes AH, Van der Velde G. 2003. Ontogenetic dietary changes of coral reef fishes in the mangrove-seagrassreef continuum: stable isotopes and gut-content analysis. Mar Ecol Prog Ser. 246:279-289.

Ehrhardt NM, Fitchett M. 2010. Dependence of recruitment on parent stock of the spiny lobster, Panulirus argus, in Florida. Fish Ocean. 19:434-447.

Evans SL, Anderson WT, Jochem FJ. 2006. Spatial variability in Florida Bay particulate organic matter composition: combining flow cytometry with stable isotope analyses. Hydrobiologia. 569(1):151-165.

Frazer T, Ross R, Quetin L, Montoya J. 1997. Turnover of carbon and nitrogen during growth of larval krill, Euphausia superba Dana: a stable isotope approach. J Exp Mar Biol Ecol. 212:259-275.

Fry B, Arnold C. 1982. Rapid 13C/12C turnover during growth of brown shrimp (Penaeus aztecus). Oecologia. 54:200-204.

Goldstein JS, Matsuda H, Takenouchi T, Butler IV MJ. 2008. The complete development of larval Caribbean spiny lobster Panulirus argus (Latreille, 1804) in culture. J Crust Biol.28(2):306-327.

Hall CA, Leben RR. 2016. Observational evidence of seasonality in the timing of loop current eddy separation. Dynam Atmos Ocean. (76):240-267.

Herrnkind WF, and Butler MJ. 1986. Factors regulating postlarval settlement and juvenile microhabitat use by spiny lobster Panulirus argus. Mar Ecol Prog Ser. 34:23-30.

Herrnkind WF, Butler IV MJ, Tankersley RA. 1988. The effects of siltation on recruitment of spiny lobsters, Panulirus argus. Fish Bull. 86:331-338.

Hobson KA. 1999. Tracing origins and migrations of wildlife using stable isotopes: a review. Oecologia. 120:314-326.

Hobson KA. 2008. Isotopic tracking of migrant wildlife. In: Michener R, Lajtha K, editors. Stable isotopes in ecology and environmental science. 2nd ed. Hoboken: John Wiley \& Sons. p. 155-170.

Hotelling H. 1951. A generalized T test and measure of multivariate dispersion. Proc Second Berkeley Symp. p. 23-42. 
Hunt JH, Sharp W, Tringali MD, Bertelsen RD, Schmitt S. 2009. Using microsatellite DNA analysis to identify sources of recruitment for Florida's spiny lobster (Panulirus argus) stock. Final Report to the NOAA Fisheries Service Marine Fisheries Initiative (MARFIN) Program, Fish \& Wildlife Research Inst., FWC/FWRI File Code: F253905-08-F.

Jeffs AG (2007) Revealing the natural diet of the phyllosoma larvae of spiny lobster. Bull Fish Res. 20:9-13.

Jeffs AG, Hooker S. 2000. Economic feasibility of aquaculture of spiny lobsters Jasus edwardsii in temperate waters. J World Aquac Soc. 31:30-41.

Johnston D, Ritar AJ, Thomas C. 2004. Digestive enzyme profiles reveal digestive capacity and potential energy sources in fed and starved spiny lobster (Jasus edwardsii) phyllosoma larvae. Comp Biochem Phys. 132B:137-144.

Kittaka J. 1997. Application of ecosystem culture method for complete development of phyllosomas of spiny lobster. Aquaculture. 155:319-331.

Kough AS, Paris CB, Butler MJ. 2013. Larval Connectivity and the International Management of Fisheries. PloS ONE 8: e64970.

Lamb K, Swart PK. 2008. The carbon and nitrogen isotopic values of particulate organic material from the Florida Keys: a temporal and spatial study. Coral Reefs. 27(2):35162.

Lewis JB. 1951. The phyllosoma larvae of the spiny lobster, Panulirus argus. Bull Mar Sci. $1: 89-103$.

Lindo-Atichati D, Bringas F, Goni G. 2013. Loop Current excursions and ring detachments during 1993-2009. Int J Remote Sens. 34(14):5042-5053.

Lipcius RN and Herrnkind WF. 1982. Molt cycle alterations in behavior, feeding and diel rhythms of a decapod crustacean, the spiny lobster Panulirus argus. Mar Biol. 68(3):241-252.

Lipcius RN, Cobb JS. 1994. In: Phillips BF, Cobb JS, Kittaka JK, editors. Spiny lobster management. Oxford: Fishing news books. p. 1-30.

Lowe WH, Allendorf FW. 2010. What can genetics tell us about population connectivity? Mol Ecol. 19: 3038-3051.

Maruyama A, Yamada Y, Rusuwa B, Yuma M. 2001. Change in stable nitrogen isotope ratio in the muscle tissue of a migratory goby, Rhinogobius sp., in a natural setting. Can J Fish Aquat Sci. 58(11):2125-2128.

Marx JM, Herrnkind WF. 1985. Macroalgae (Rhodophyta: Laurencia spp.) as habitat for young juvenile spiny lobsters, Panulirus argus. Bull Mar Sci. 36:423-431. 
McKinney CR, McCrea JM, Epstein S, Allen HA, Urey HC.1950. Improvements in mass spectrometers for the measurement of small differences in isotope abundance ratios. Rev Sci Instrum. 21(8):724-730.

Meinen CS, Baringer MO, Garcia RF. 2010. Florida Current transport variability: An analysis of annual and longer-period signals. Deep Sea Res Part 1 Oceanogr Res Pap. 57(7):835-846.

Munroe SEM, Heupel MR, Fisk AT, Logan M, Simpfendorfer CA. 2015. Regional movement patterns of a small-bodied shark revealed by stable-isotope analysis. J Fish Biol. 86(5):1567-1586.

Nizinski MS. 2007. Predation in subtropical soft-bottom systems: spiny lobster and molluscs in Florida Bay. Mar Ecol Prog Ser. 345:185-197.

O'Rorke R, Lavery S, Chow S, Takeyama H, Tsai P, Beckley LE, Thompson PA, Waite AM, Jeffs AG. 2012. Determining the diet of larvae of western rock lobster (Panulirus cygnus) using high-throughput DNA sequencing techniques. PLoS One.7(8):e42757.

Phillips BF, Booth JD. 1994. Design, use, and effectiveness of collectors for catching the puerulus stage of spiny lobsters. Rev Fish Sci. 2(3):255-289.

Phillips BF, Cheng YW, Cox C, Hunt J, Jue NK, Melville-Smith R. 2005. Comparison of catches on two types of collector of recently settled stages of the spiny lobster (Panulirus argus), Florida, United States. New Zeal J Mar Fresh. 39(3):715-722.

Phillips BF, Booth JD, Cobb SJ, Jeffs AG, Mc William P. 2006. Larval and postlarval ecology. In: Phillips BF, editor. Lobsters: Biology, Management, Aquaculture and Fisheries. Oxford: Blackwell Publishing Ltd. p.231-262.

Rousset C, Beal LM. 2011. On the seasonal variability of the currents in the Straits of Florida and Yucatan Channel. J Geophys Res: Oceans. 116:C08004.

Rubenstein DR, Hobson KA. 2004. From birds to butterflies: animal movement patterns and stable isotopes. Trends Ecol Evolut. 19(5):256-263.

Sarver SK, Silberman JD, Walsh PJ. 1998. Mitochondrial DNA sequence evidence supporting the recognition of two subspecies or species of the Florida spiny lobster Panulirus argus. J Crust Biol. 18(1):177-186.

Suring E, Wing SR. 2009. Isotopic turnover rate and fractionation in multiple tissues of red rock lobster (Jasus edwardsii) and blue cod (Parapercis colias): Consequences for ecological studies. J Exp Mar Bio Ecol. 370(1):56-63.

Thorrold SR, Jones GP, Planes S. Hare JA. 2006. Transgenerational marking of embryonic otoliths in marine fishes using barium stable isotopes. Can J Fish Aquat Sci.

63(6):1193-1197. 
Waddington K, MacArthur L. 2008. Diet quality and muscle tissue location influence consumer-diet discrimination in captive-reared rock lobsters (Panulirus cygnus) Mar Biol. 154: 569.

Witham R, Ingle RM, Sims Jr. HW. 1964. Notes on postlarvae of Panulirus argus. Quart Journ Florida Acad Sci. 27:289-297.

Wolfe SW, Felgenhauer BE. 1991. Mouthpart and foregut ontogeny in larval, postlarval, and juvenile spiny lobster, Panulirus argus Latreille (Decapoda, Palinuridae). Zool Scri. 20(1):57-75.

Yeung C, McGowan MF. 1991. Differences in inshore-offshore and vertical distribution of Phyllosoma larvae of Panulirus, Scyllarus and Scyllarides in the Florida Keys in May-June, 1989. Bull Mar Sci. 49(3):699-714. 


\section{Figure Captions}

Figure 1. Map of the two sampling sites: Long Key (LK) and Big Munson (BM) in the Keys, Florida, United States of America, from which samples were collected.

Figure 2. The monthly mean values of (A) $\delta^{13} \mathrm{C}$ values and (B) $\delta^{15} N$ of the samples that were collected from August 2014 to July 2016 excluding juveniles. The difference on the $\delta^{13} \mathrm{C}$ value and the $\delta^{15} \mathrm{~N}$ values were significant among months based on the Fisher-Pitman permutation test $(p<0.05$ ). Both Data are presented as mean \pm SEM (standard error of the mean).

Figure 3. The dual isotope plot $\left(\delta^{13} \mathrm{C}\right.$ vs. $\left.\delta^{15} N\right)$ for four clusters from our study and the POM from Lamb and Swart (2008). The results of the cluster analysis of $\delta^{13} C$ values and $\delta^{15} N$ values of the samples that were collected from August 2014 to July 2016 excluding juveniles. The entire collection of postlarvae was clustered into four groups, determined by the elbow method based on both $\delta^{13} C$ values and $\delta^{15} N$ values. Data are presented as mean \pm SEM (standard error of the mean).

Figure 4. The monthly proportion of clusters from the results of the cluster analysis based on the samples that were collected from August 2014 to July 2016, excluding juveniles. The entire collection of postlarvae was clustered into four groups, determined by the elbow method based on both $\delta^{13} \mathrm{C}$ values and $\delta^{15} N$ values.

Figure 5. The monthly proportion of the three postlarval sub-stages (clear, semi-pigmented, and pigmented) and the first juvenile stage from August 2014 to July 2016. 
Figure 1.
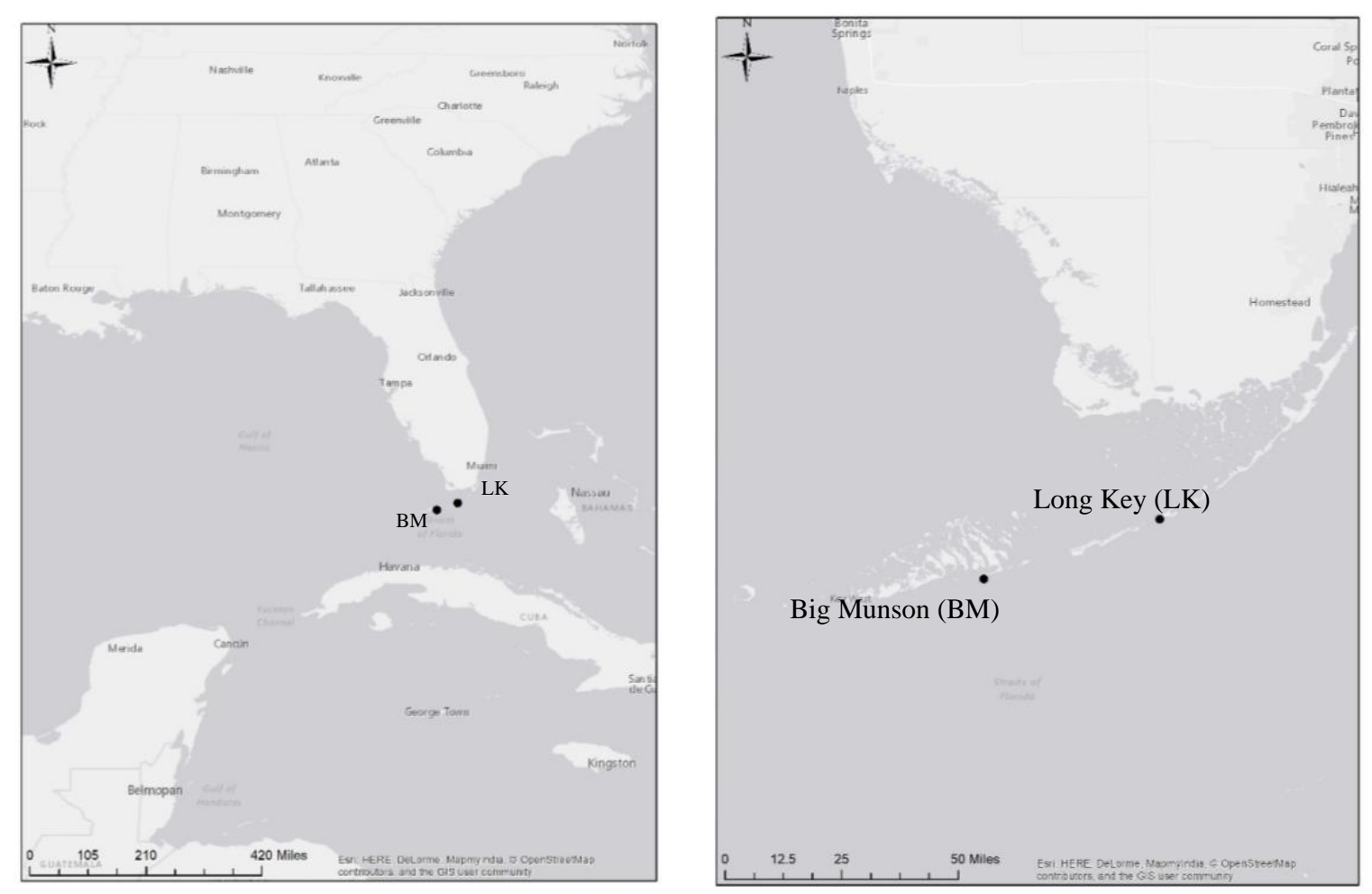
Figure 2.
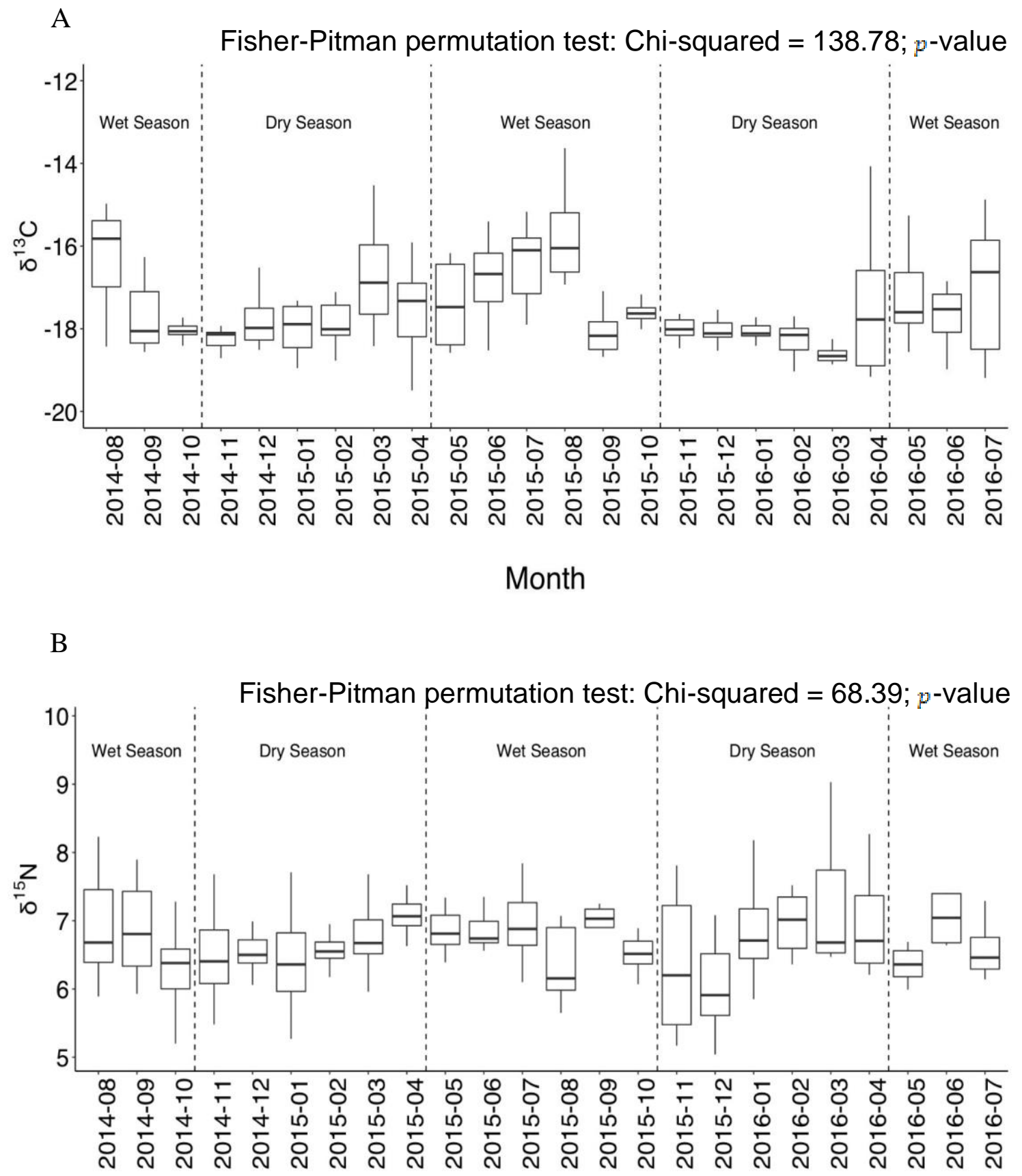

Month 
Figure 3.

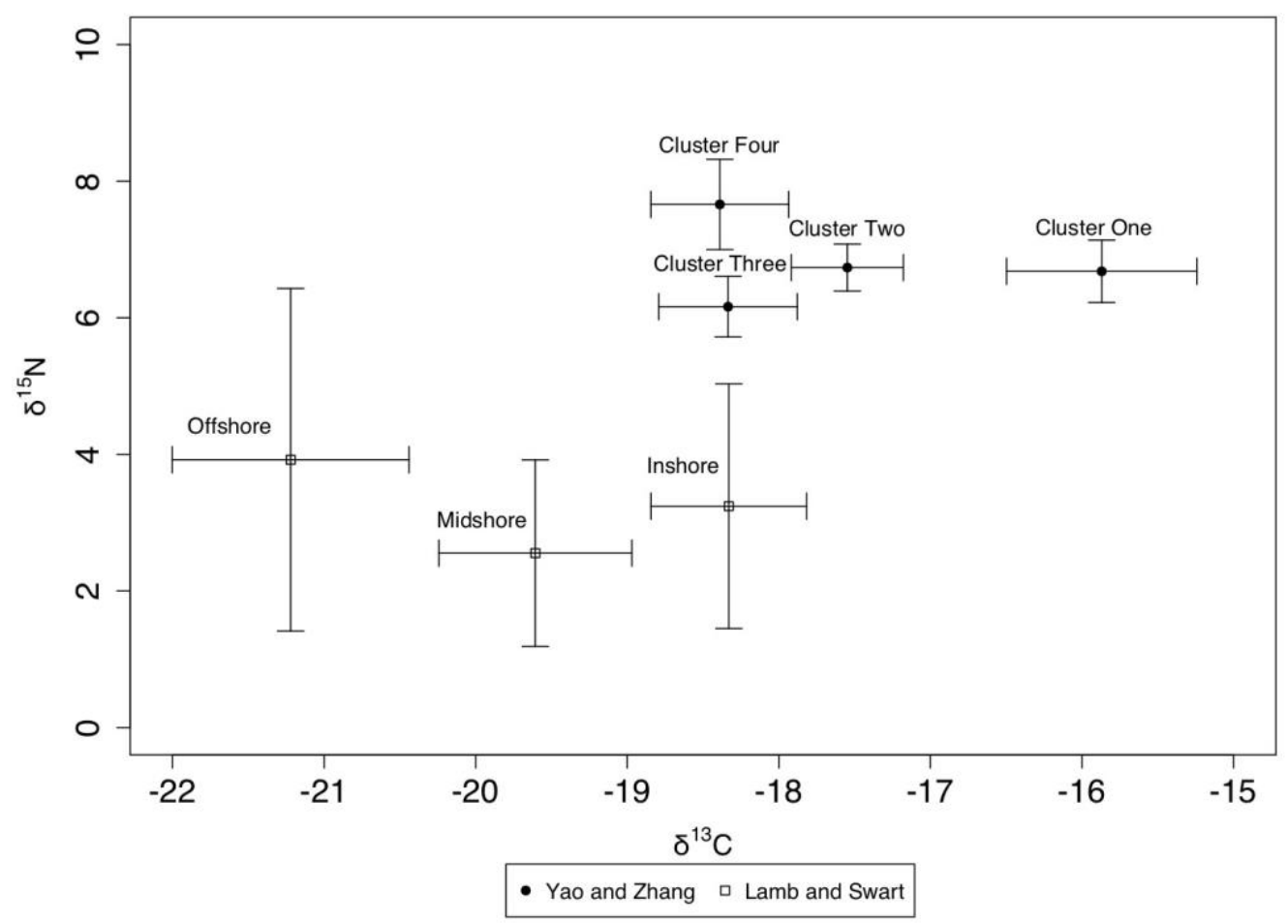


Figure 4.

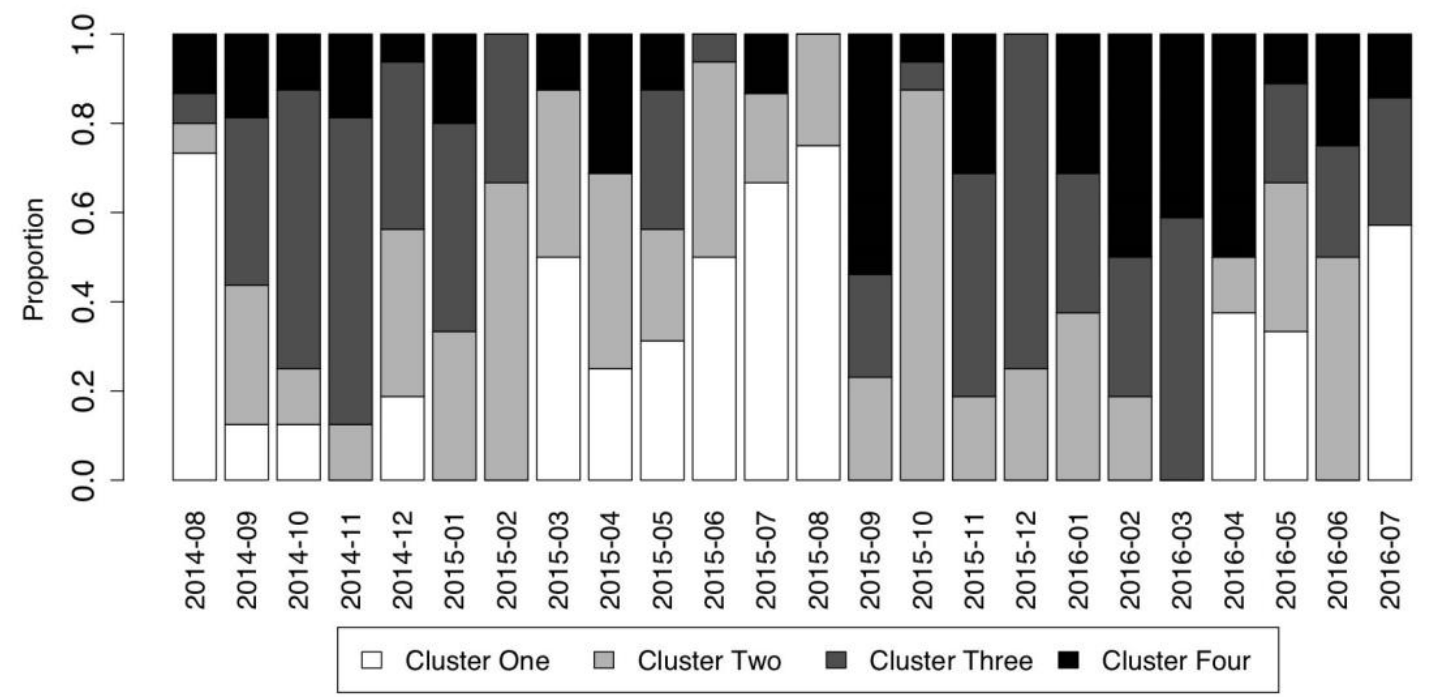


Figure 5.

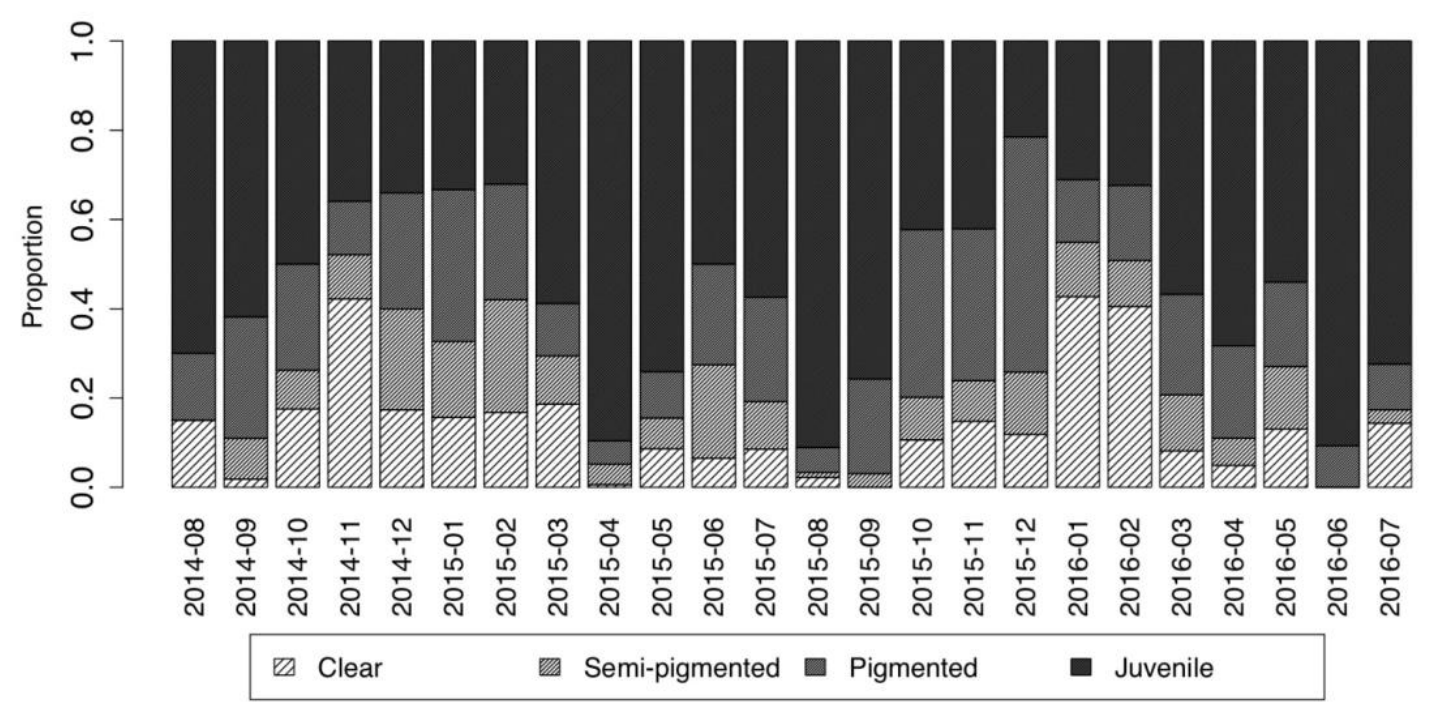




\section{SUPPLEMENT MATERIALS}

\section{Table Caption.}

Table S1. Pairwise comparisons of the monthly $\delta^{13} \mathrm{C}$ value of the samples excluding juveniles. $p$-values for each combination of month. Significant difference detected between two months, after Benjamini-Hochberg false discovery rate control (FDR) are shown in bold $(p<0.05)$.

Table S2. Pairwise comparisons of the monthly $\delta^{15} N$ value of the samples excluding juveniles. $p$-values for each combination of month. Significant difference detected between two months, after Benjamini-Hochberg false discovery rate control (FDR) are shown in bold $(p<0.05)$. 
Table S1.

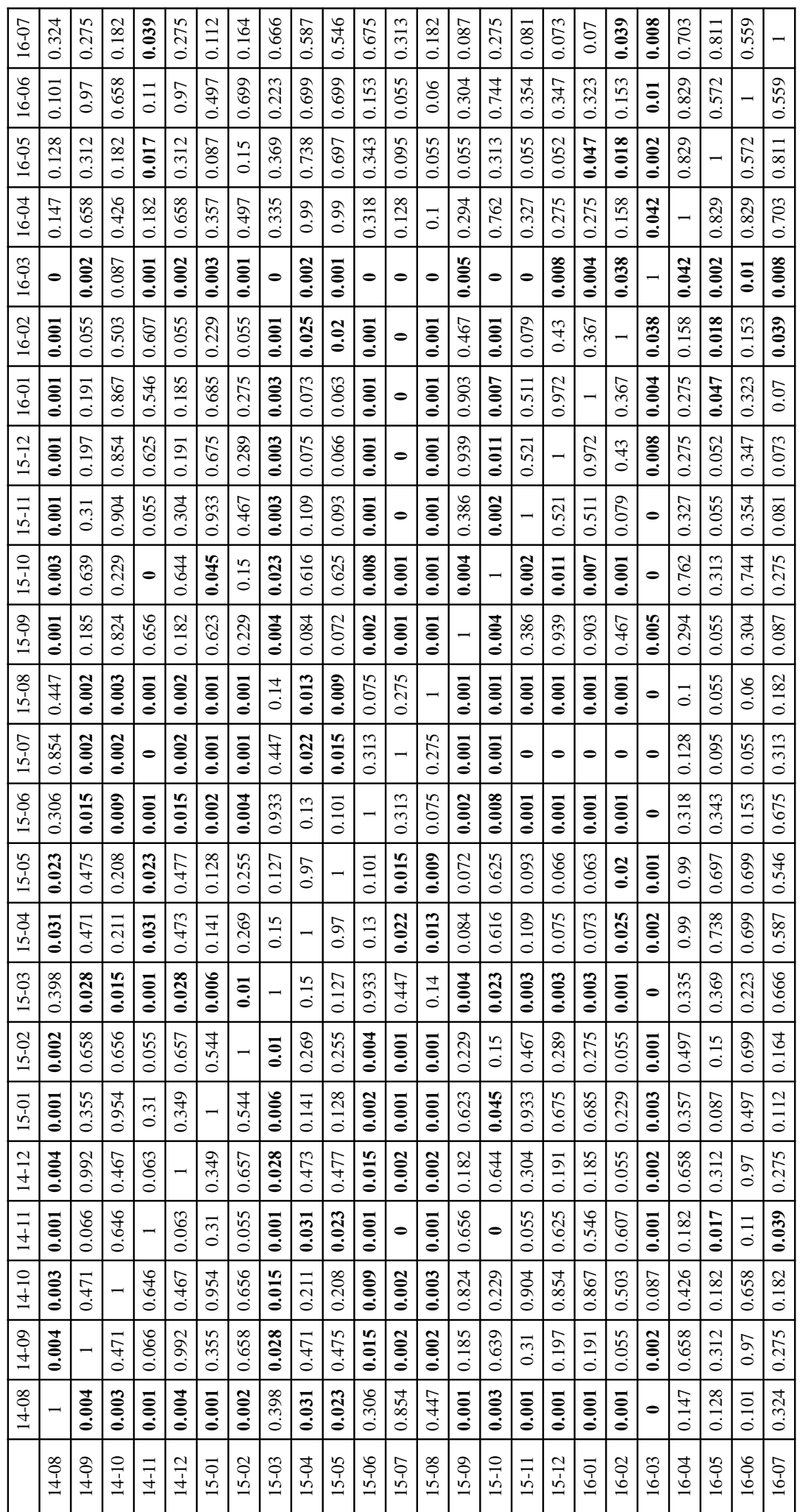


Table S2.

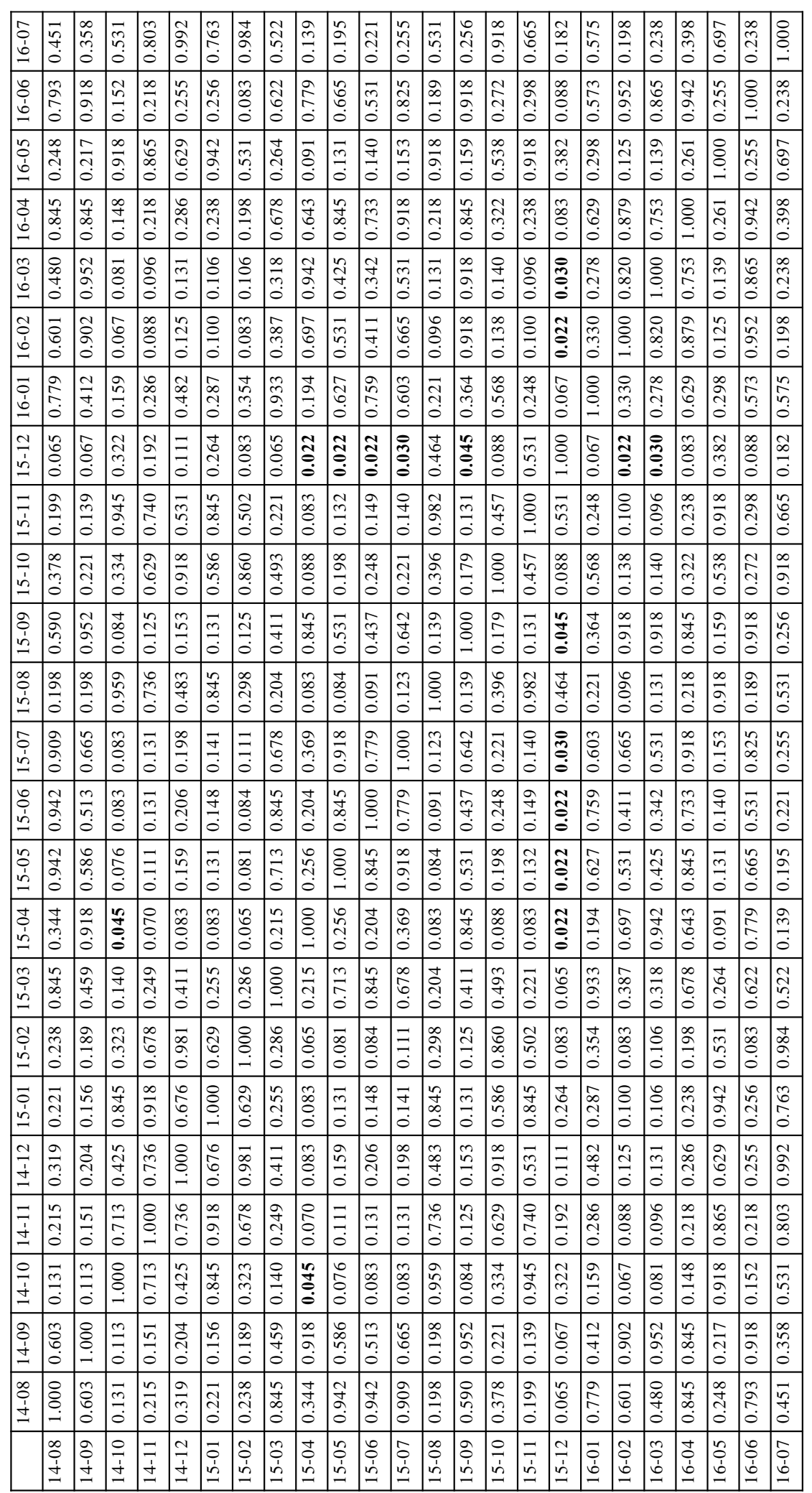




\section{Figure Caption.}

Figure $\mathrm{S} 1$. Mean values of $\delta 13 C$ and $\delta^{15} N$ of the samples from two sample sites: Long Key (LK) and Big Munson (BM). (A). $\delta^{13} C$ value including juveniles. (B). $\delta^{15} N$ value including juveniles. (C). $\delta^{13} \mathrm{C}$ value excluding juveniles. (D). $\delta^{15} \mathrm{~N}$ value excluding juveniles. Data are presented as mean \pm SEM (standard error of the mean). Values annotated with the same letter are not significantly different $(p>0.05)$.

Figure S2. Mean values of (A) $\delta^{13} C$ and (B) $\delta^{15} N$ of the samples of three pueruli substages (clear, semi-pigmented, and pigmented), and the first juvenile stage. Data are presented as mean \pm SEM (standard error of the mean). Values annotated with the same letter are not significantly different $(p>0.05)$.

Figure S3. The results of the autocorrelation analysis of (A) $\delta^{13} C$ and (B) $\delta^{15} N$ of the postlarvae that were collected from August 2014 to July 2016 excluding juveniles. Figure S4. The result of the elbow method for cluster analysis based on both $\delta^{13} \mathrm{C}$ and $\delta^{15} N$.

Figure S5. The results of the cluster analysis of $\delta^{13} \mathrm{C}$ and $\delta^{15} \mathrm{~N}$ of the samples that were collected from August 2014 to July 2016 excluding juveniles. The entire collection of postlarvae was clustered into four groups, determined by the elbow method based on both $\delta^{13} C$ and $\delta^{15} N$. (A. Cluster 1: white; B. Cluster 2: light grey; C. Cluster 3: dark grey; D. Cluster 4: black).

Figure S6. The pie chart of the proportion of each month's samples (August 2014 to July 2016) in each cluster (A. Cluster 1; B. Cluster 2; C. Cluster 3; D. Cluster 4). 
Figure S1.

A

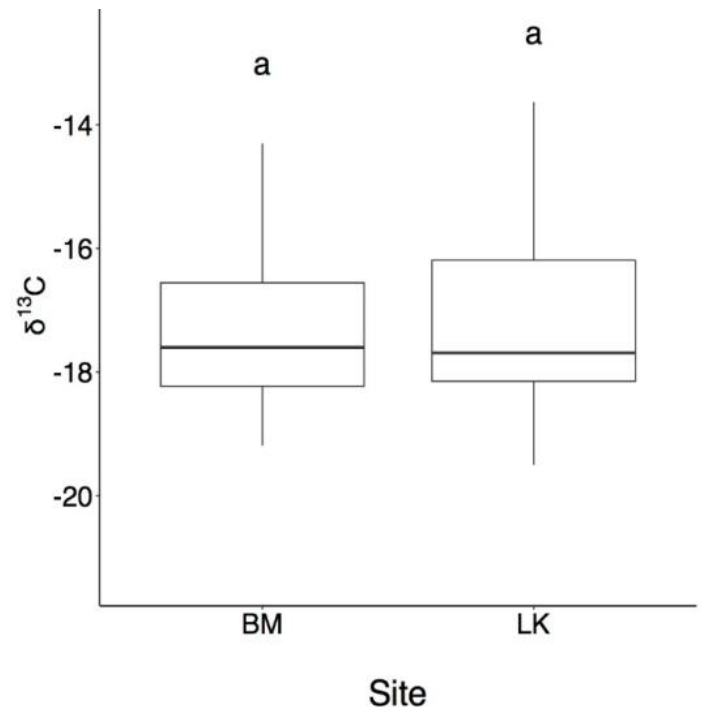

C

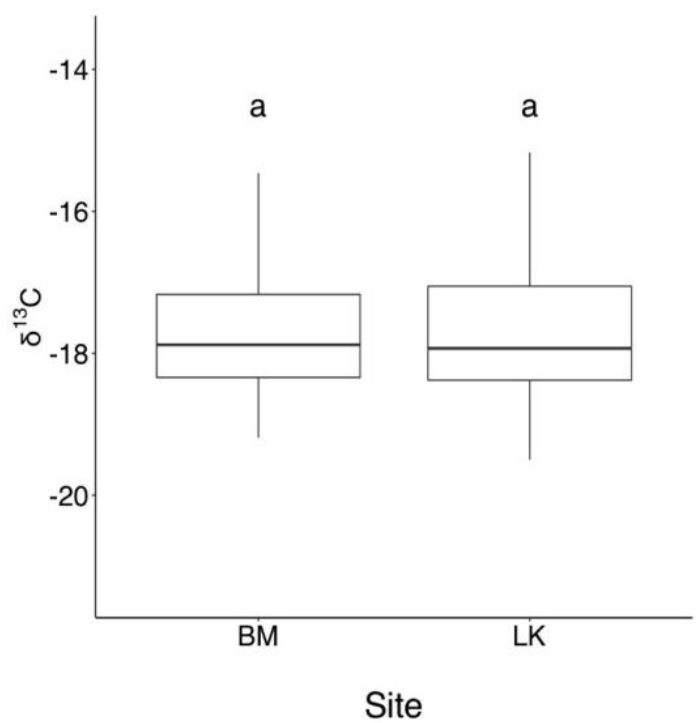

B

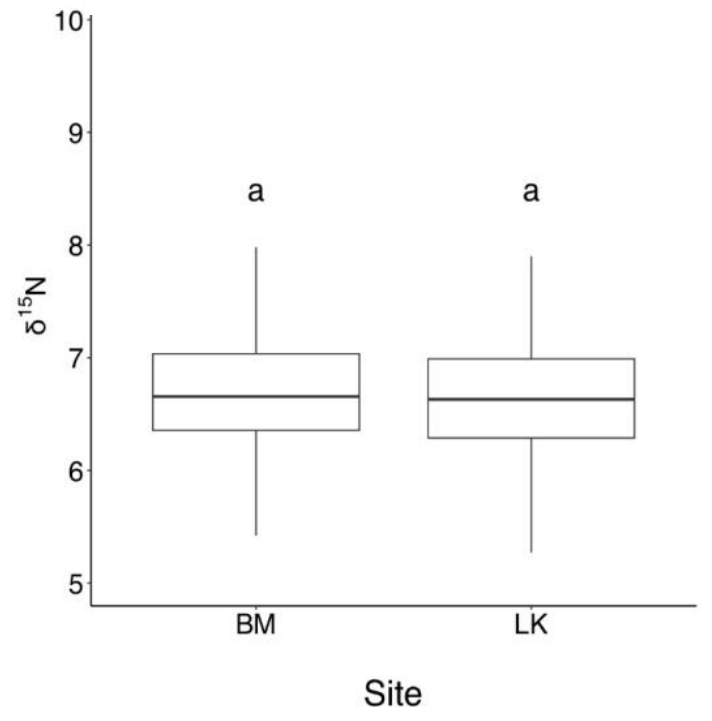

D

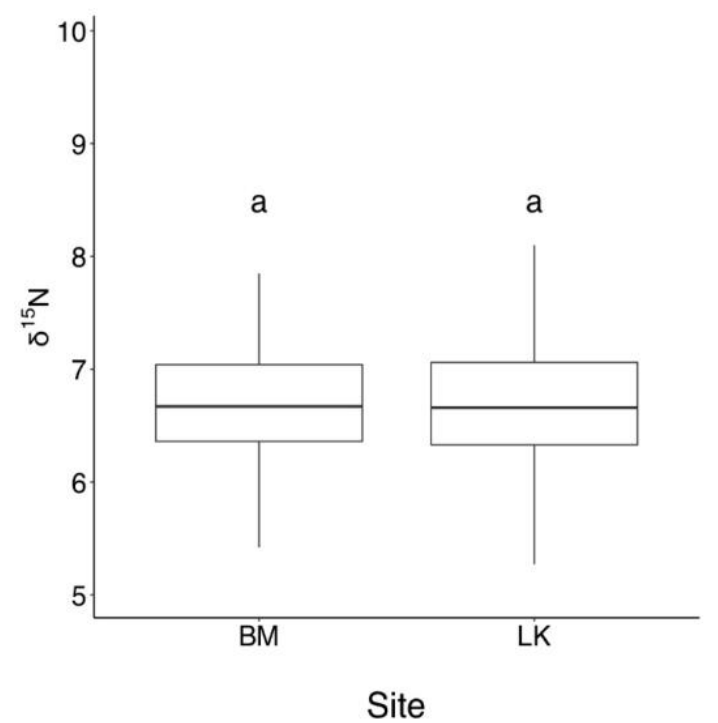


Figure S2.

A

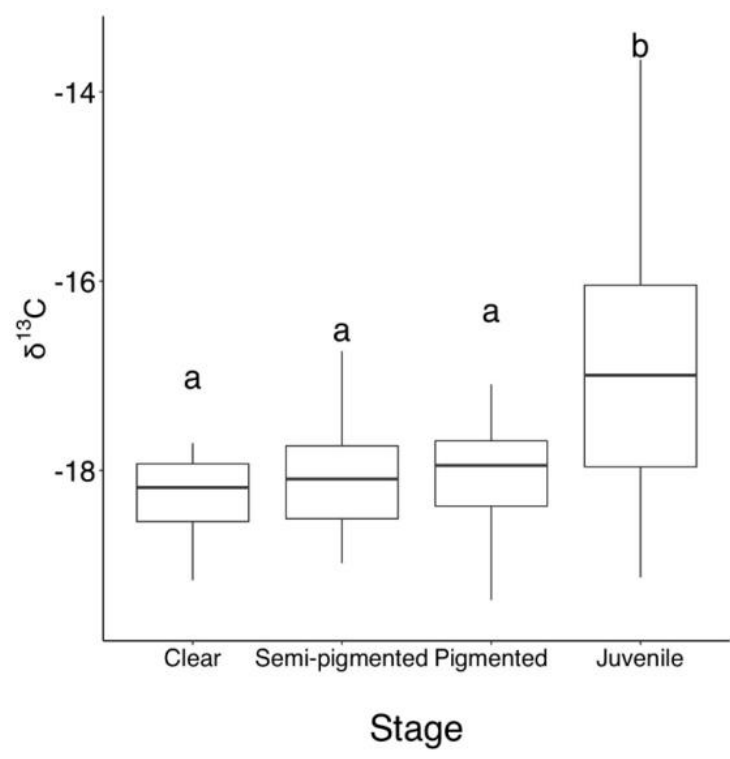

B

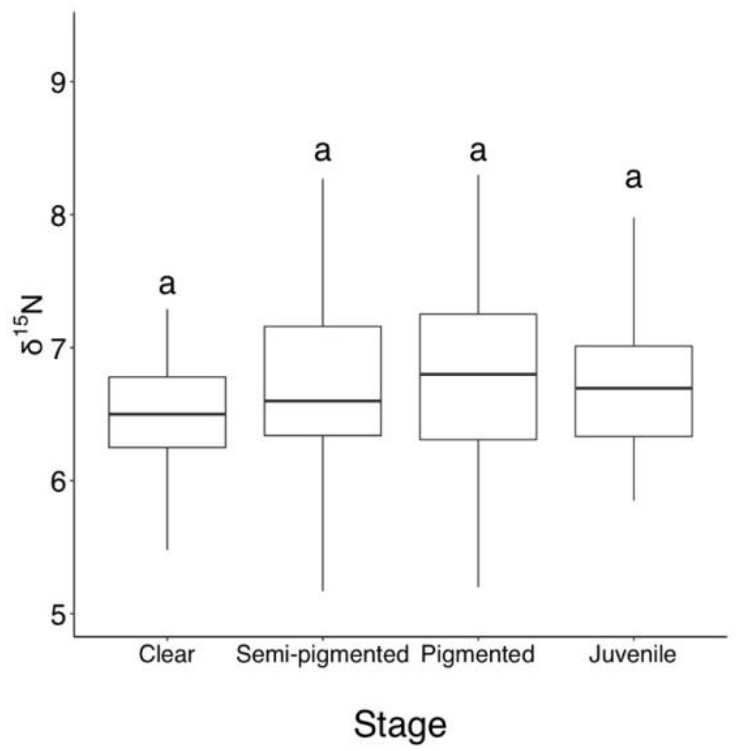


Figure S3.

A

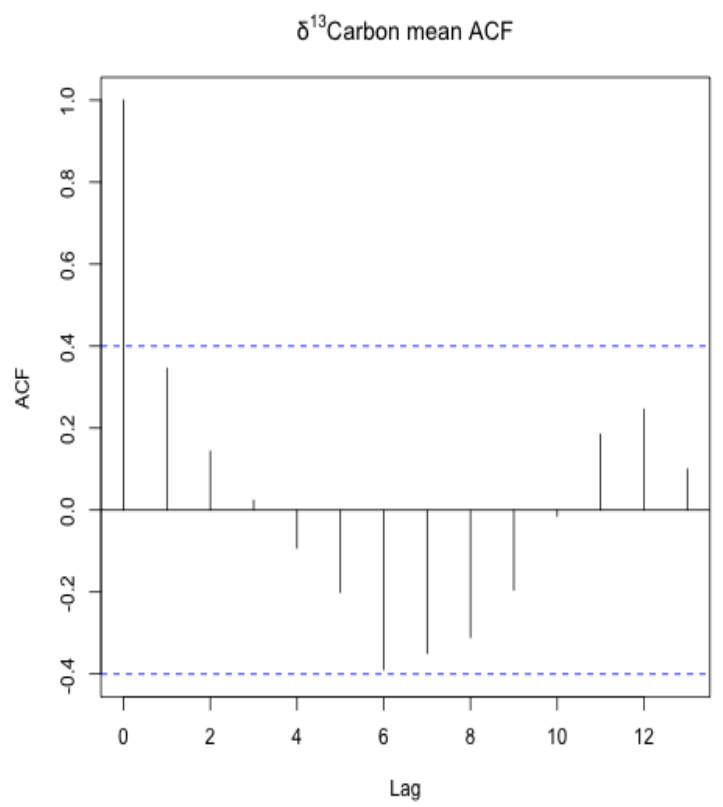

B

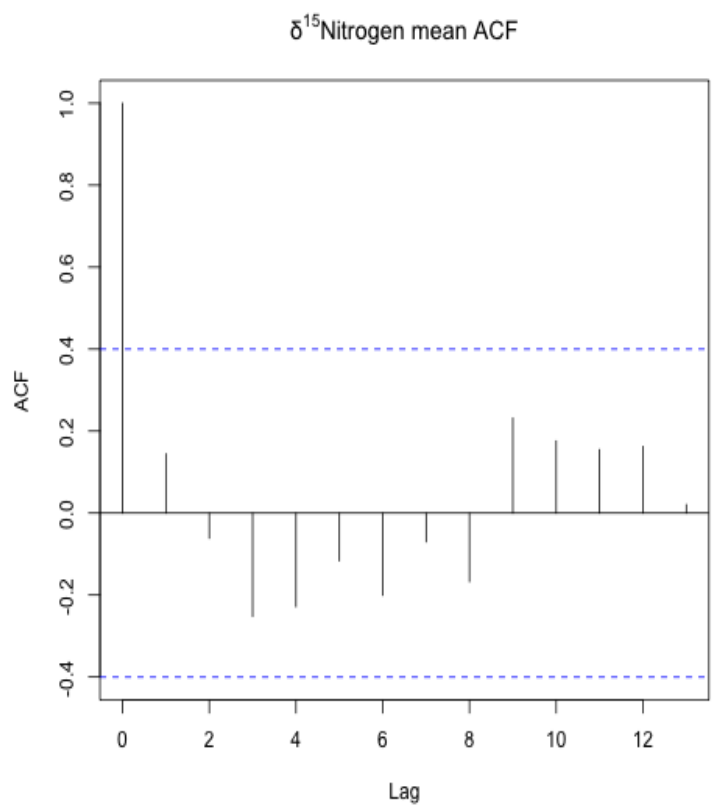


Figure S4.

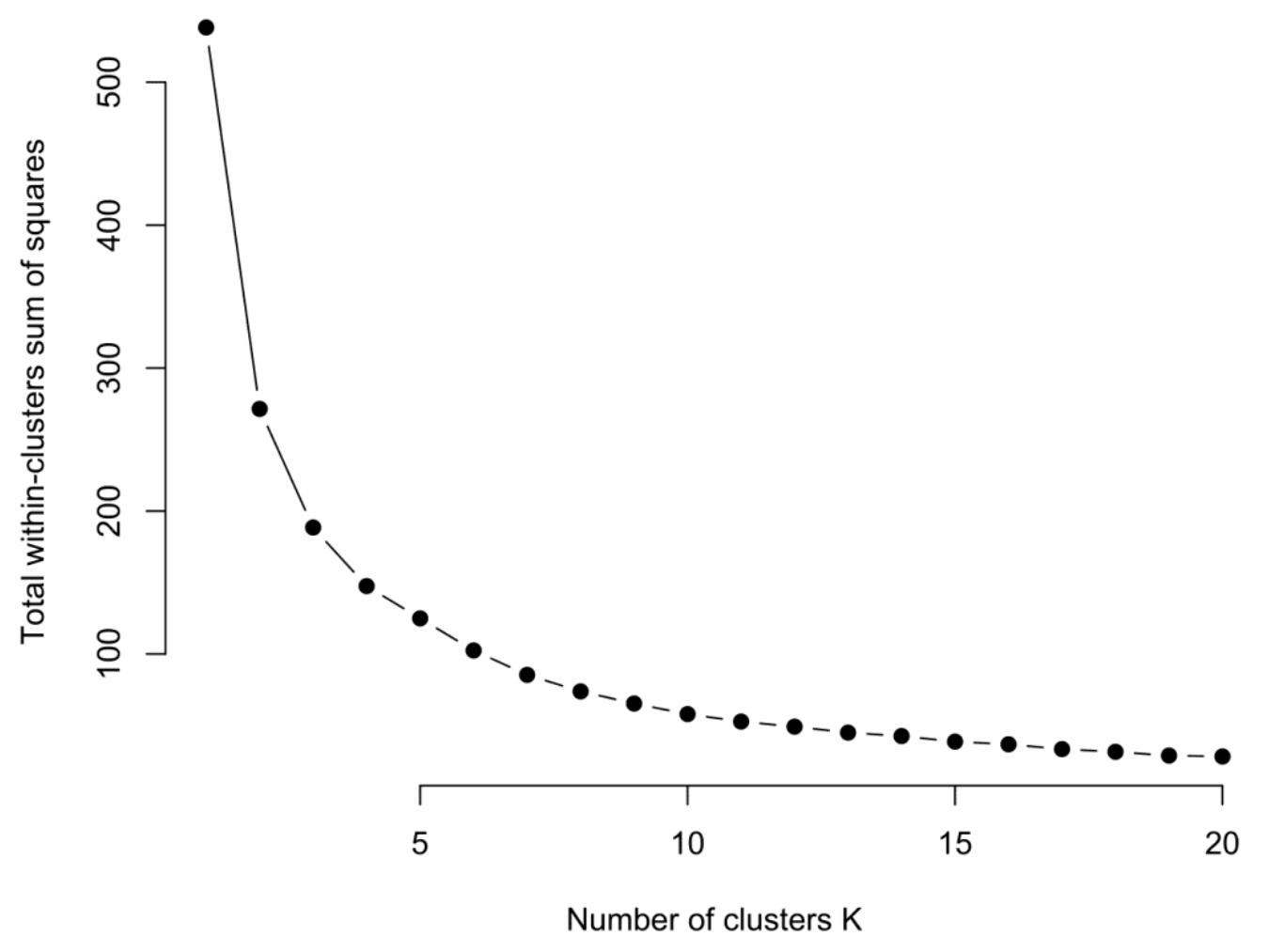


Figure S5.

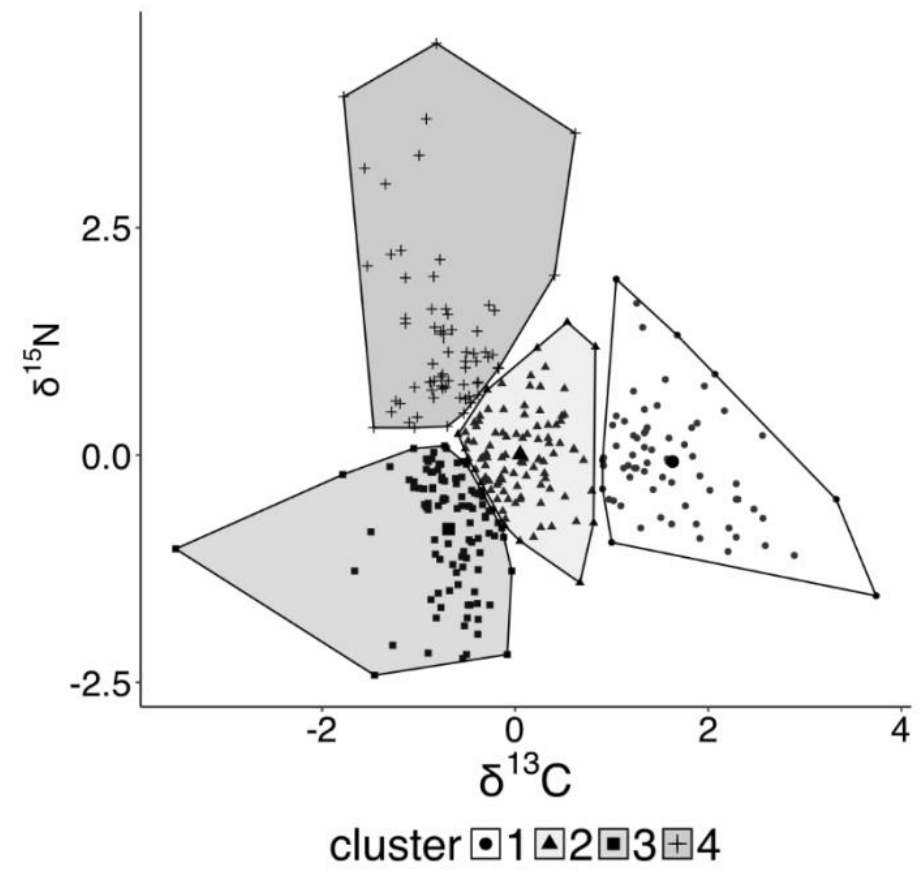


Figure S6.

A

Pie chart of cluster 1

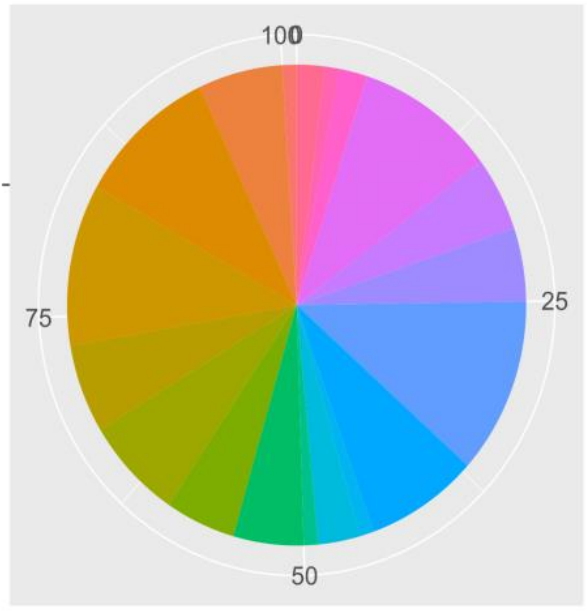

C

Pie chart of cluster 3

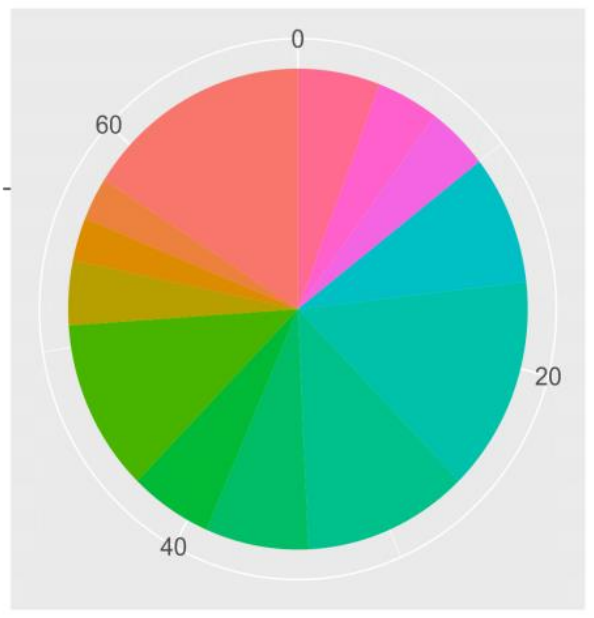

B

Pie chart of cluster 2

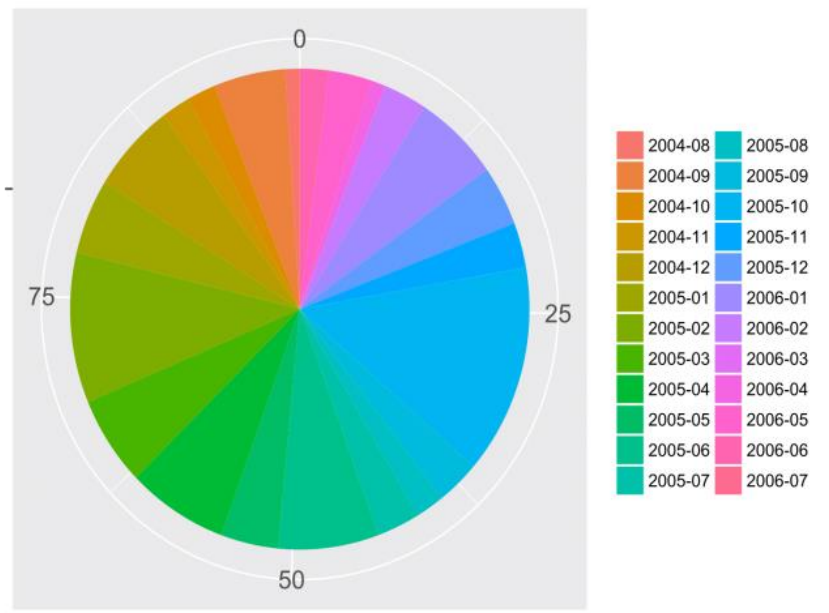

D

Pie chart of cluster 4

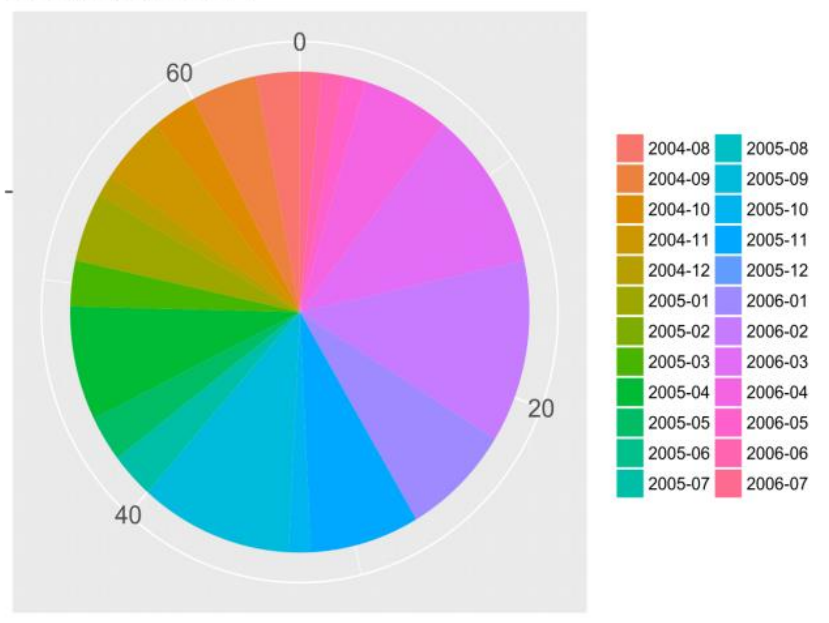


Chapter II (in modified form) was published in Bulletin of Marine Science. This chapter is printed (with permission) by to the Rosenstiel School of Marine \& Atmospheric Science, University of Miami.

Reference:

Yao N, Zhang Y. (2018). Investigating temporal variation in stable carbon and nitrogen isotope values of Florida Caribbean spiny lobster Panulirus argus (Latreille, 1804) recruits. Bulletin of Marine Science. 94(3):847-861. 
CHAPTER III RECRUITMENT DYNAMICS OF THE FLORIDA CARIBBEAN SPINY LOBSTER (PANULIRUS ARGUS) REVEALED BY MICROSATELLITES AND ITS IMPLICATION FOR FISHERY MANAGEMENT 


\begin{abstract}
The Caribbean spiny lobster (Panulirus argus) provides many ecological and economic benefits to the Southeast United States, as well as many South American and Caribbean countries. However, the limited knowledge on the recruitment dynamics of this valuable species has long been an issue for fishery management. The long pelagic larval stage has led many researchers to hypothesize that Caribbean lobster stocks are demographically open. Over the past two decades, microsatellites have proven to be a useful tool to investigate the connectivity among the populations, with a recent study revealing genetic structures among the stocks in the Caribbean. However, most of the previous research has focused on the spatial rather than the temporal scale. I applied 12 microsatellites on the postlarvae arriving in the Florida Keys monthly from August 2014 to July 2016, to explore the recruitment dynamics of the Florida recruits. The connectivity derived from our microsatellite analysis is compared with those derived from previous stable isotope analysis and biophysical modeling. The results of our study provide evidence of temporal genetic differentiation among the monthly recruits, revealing the possibility that the Florida spiny lobster stock receives recruits from multiple source populations depending on the time of year.
\end{abstract}




\section{Introduction}

The Caribbean spiny lobster (Panulirus argus) is an economically important species, that has been harvested by 30 countries throughout the world, and supports one of the most valuable fisheries in the region. The global production of this valuable species has reached 39,244 metric tons in 2016 (FAO, 2018) and yields nearly \$1 billion USD profit annually (Ehrhardt et al., 2010). Unfortunately, most $P$. argus stocks are considered to be either in decline or fully exploited (Chavez, 2009). In terms of the Southeast US stock specifically, the production of the Caribbean spiny lobster peaked in the early 1990s and has declined significantly in the last two decades (Sharp et al., 2005). Therefore, developing effective management strategies for the $P$. argus fisheries has become a pressing issue.

The knowledge of the recruitment dynamics is fundamental for the success of fisheries management (King et al., 2015). Currently, P. argus stocks in the Caribbean are managed independently by their countries. The common management regulations include closed fishing seasons, minimum-size limits, and protection of egg-bearing female lobsters. These management regulations are created on the based of the sole assumption that the local recruitment receives contribution exclusively from the local spawning stock. However, the isolated population assumption most likely does not accurately reflect the reality because of the life history of the species in question. The Caribbean spiny lobster has a uniquely long pelagic larvae stage called the phyllosoma. After hatching, the phyllosoma larvae can drift with currents from six to nine months and travel an average of 3,000 kilometers (Goldstein et al., 2008; Kough et al., 2013). The highly 
mobile larvae stage has led to a more reasonable hypothesis that $P$. argus stocks in the Caribbean are demographically open. The hypothesis has been supported by previous results of biophysical modeling (Butler et al., 2011; Kough et al., 2013), as well as stable isotope analysis (Yao and Zhang, 2018). Therefore, understanding the recruitment dynamics of the Caribbean spiny lobster could advance our knowledge in recruitment ecology, as well as aid the development of effective fisheries management strategies for stocks in the Caribbean.

Microsatellites are tandem repeats of two to ten base pair nucleotide motifs that are highly variable among individuals (Hellberg et al., 2002). They have proven to be useful tools identifying connectivity of marine populations, especially for the life stages or species where physical tagging is not applicable, for example, phyllosoma larvae (Hedgecock, 1994; Hedgecock et al., 2007; Abdul-Muneer, 2014). In the last two decades, microsatellites have also been applied to the $P$. argus to explore the connectivity among stocks in the Caribbean. These studies have detected the presence of high-level connectivity among marine protected areas (MPAs) in the Mesoamerican Barrier Reef System (MBRS) of Central America (Truelove, Griffiths et al., 2015), MPAs in the Caribbean coast of Mexico (Truelove, Ley-Cooper et al., 2015), as well as nine locations throughout the greater Caribbean and Bermuda (Truelove et al., 2017). Most previous research focuses on recruitment dynamics across a spatial scale with conclusions derived from on the assumption that the observed genetic structure among populations is, from a practical standpoint, stable over time (Tessier and Bernatchez, 1999). However, recent studies have revealed that the assumption that the observed genetic structure stable over 
time could be tenuous (Charbonnel et al., 2002; McElroy et al., 2011). The genetic structure may become temporally unstable, or equilibrium may not be attained; this unstable status may be caused by the environmental fluctuation (e.g., shifts of currents). Investigating the temporal change in population genetic structure is needed alongside spatial studies to further our knowledge in recruitment dynamics (Manel et al., 2003).

The main objective of our study was to assess population genetic structure and genetic diversity in Caribbean spiny lobster recruits using microsatellite markers. Before our hypothesis testing, we first validated the assumption that all recruits used in our study were of the same species. Then, we hypothesized that there were multiple source populations contributing to Southeast US recruits as a result of the long pelagic larvae stage. The hypothesis was tested by examining the levels of genetic differentiation among months as well as individuals during the sampling period. Our second hypothesis was that the recruits arriving during the same month originated from the same source populations because of oceanic surface currents and animal behavior. Our second hypothesis was tested by a kinship analysis of all individuals arriving at Florida within the same month. Furthermore, we examined the genetic diversity of the monthly recruits by clustering the entire collection of samples into different groups on the basis of genetic similarity. In addition to the main objective, we also explored the temporal pattern of the monthly genetic diversity for the sampling period to understand recruitment dynamics. 


\section{Methods and Materials}

\section{Taxon Sampling and Sampling Locations}

The Caribbean spiny lobster postlarvae samples used in our study were collected from two sites (Long Key and Big Munson) located in the Florida Keys, United States of America (Fig. 1). From August 2014 to July 2016, 50 postlarvae samples were collected monthly using Witham Collectors and Blue Collectors (Witham et al., 1964; Phillips and Booth, 1994). Live P. argus postlarvae were preserved in $85 \%$ ethanol immediately after collection and then transferred to Florida International University (FIU). All the samples were kept at $-20^{\circ} \mathrm{C}$ until the genetic analysis was performed.

\section{DNA Barcoding and Population Genetic Analysis}

Ten samples were selected haphazardly from each site each month over 24 months $(\mathrm{N}=480)$. The total genomic DNA of each individual was extracted from the tail muscle tissue using Qiagen DNeasy Blood and Tissue kit (Qiagen, Germantown, USA).

As a result of the difficulty in using morphology to identify Panulirus argus postlarvae, we used DNA barcoding methods to ensure accurate identification. Results from previous phylogenetic analysis indicate that only one species ( $P$. argus) was present in the Florida stock (Sarver et al., 1998). To confirm the assumption that only one species was present in the Florida stock within our study, we subsampled $20 \%$ of the total postlarvae samples for DNA barcoding. For each month over the two-year sampling period, 4 samples from the 20 DNA extractions were haphazardly selected. Therefore, a total number of $\sim 96$ subsamples were selected for the sequencing. Two primers (16SAR- 


\section{L: 5'-CGCCTGTTTATCAAAAACAT-3' and 16SBR-H: 5'-}

CCGGTCTGAACTCAGATCACGT-3') that are commonly used in decapod DNA barcoding studies were used to amplify portions of the $16 \mathrm{~S}$ rRNA gene fragment (Palumbi et al., 1991). The PCR for the mitochondrial regions were performed as follow: $94^{\circ} \mathrm{C}$ for $3 \mathrm{~min}, 35$ cycles of $94^{\circ} \mathrm{C}$ for $30 \mathrm{~s}, 51^{\circ} \mathrm{C}$ for $30 \mathrm{~s}, 72^{\circ} \mathrm{C}$ for $1 \mathrm{~min}$, followed by $72^{\circ} \mathrm{C}$ for $7 \mathrm{~min}$. The PCR products were sent to Genewiz (Genewiz, Inc.3, South Plainfield, NJ) for Sanger sequencing. First, a BLAST search was performed on the obtained DNA sequences to confirm identification. Then, these sequences were edited and aligned with Geneious vers. 8.1.9 (Kearse et al., 2012). The genetic distance between all pairs of sequences were also estimated using Tamura-Nei model (Tamura and Nei, 1993). Sequences with $=<2.9 \%$ genetic divergence values were inferred to belong to the same species, as this is the genetic distance used to delimitate other species of Panulirus spp. in the previous study (Silberman et al., 1994).

Twelve microsatellite loci that were previously characterized for the Caribbean spiny lobster (Tringali et al., 2008; Truelove et al., 2017) were applied to each individual via two sextuple reactions with the fluorescent labelled primers 6-FAM, VIC, PET and NED (Schuelke, 2000) using QIAGEN Multiplex PCR Kit (Qiagen, Germantown, USA). The total volume of each PCR reaction was scaled down to $10 \mu l$ while keeping the concentrations of all PCR reagents the same. The PCR for the microsatellites were performed as follows: $95^{\circ} \mathrm{C}$ for $5 \mathrm{~min}, 26$ cycles of $95^{\circ} \mathrm{C}$ for $30 \mathrm{~s}, 57^{\circ} \mathrm{C}$ for $120 \mathrm{~s}, 72^{\circ} \mathrm{C}$ for $30 \mathrm{~s}$, followed by $60^{\circ} \mathrm{C}$ for $30 \mathrm{~min}$. Negative controls were used in all PCR reactions. The amplified alleles were checked by visualizing them with gel electrophoresis. The 
PCR products were sent to Massachusetts General Hospital Center for Computational and Integrative Biology, where the microsatellite genotyping was performed using an ABI 3730xl Genetic Analyzer (Applied Biosystems, Foster City, California) with GeneScan 500 LIZ size standard. The results of the microsatellite fragments were scored manually using GeneMapper software vers. 3.7 (Thermo Fisher Scientific, Waltham, MA).

\section{Statistical Analysis}

General summary statistics including the number of alleles per locus (Num), effective number of alleles (Effective Num), allelic richness (AR), observed heterozygosity (Ho), expected heterozygosity $\left(\mathrm{H}_{\mathrm{T}}\right)$ and inbreeding coefficient $\left(\mathrm{G}_{\mathrm{is}}\right)$ were tested for each population using GENODIVE vers. 2.0 (Meirmans and van Tienderen, 2004).

Afterwards, the results of each microsatellite locus were checked using MICROCHECKER vers. 2.2.3 (van Oosterhout et al., 2004) to detect the null alleles as well as the presence of scoring errors caused by the allelic dropout. GENEPOP vers. 4.5.1 (Rousset, 2008) was used to test the linkage disequilibrium (LD) of all combinations of loci. Deviations from Hardy-Weinberg Equilibrium (HWE) among all loci and populations were also tested with the population genetics software package GENODIVE vers. 2.0 (Meirmans and van Tienderen, 2004). The sequential goodness-of-fit correction for multiple tests (Castro-Conde et al., 2017) was applied to correct the $P$-values for HWE and LD.

Genetic differentiation was determined by analysis of molecular variance (AMOVA) in GENODIVE ver. 2.0 (Meirmans and van Tienderen, 2004). The corresponding to Weir 
and Cockerham's (1984) were calculated using an infinite allele model to measure the difference between the mean heterozygosity among populations $\left(F_{\mathrm{ST}}\right)$, and the proportion of the variance in the subpopulation contained in an individual $\left(F_{\text {IS }}\right)$ (Hartl and Clark, 1997). We first checked if there was any genetic differentiation between two sampling sites. Then, we estimated the genetic differentiation among monthly recruits as well as among all individuals. In order to interpret differentiation among the monthly recruits, pairwise comparisons of each month's genetic differentiation were calculated using both Hedrick's $G$ ”st and Jost'D with 500,000 permutations. These two indices were commonly used on high heterozygosity markers including microsatellites. Autocorrelation analysis was also applied to pairwise comparisons of genetic differentiation to detect the presence of any self-repeating pattern.

We used a kinship analysis to further understand the inter-individual relationship within each month's recruits. In the kinship analysis, the observed frequency of full- and half-siblings of our data is compared to the expected frequency of full- and half-siblings in a randomly generated population of non-related individuals using $\chi^{2}$ test. The observed frequency of full- and half-siblings were calculated using the genotype sharing method (Mxy) developed by Blouin et al. (1996) using R-package DEMERELATE (Kraemer and Gerlach., 2013).

Genetic diversity and population structures were examined by the discriminant analysis of principal components (DAPC). In the method, a K-means clustering of principal components was first applied to the microsatellites data to identify groups of 
individuals using genetic similarity. The K-means clustering method calculated the likelihood of the number of clusters under different numbers of clusters. Then, the Bayesian Information Criterion (BIC) was used to identify the best number of clusters. After the number of clusters was determined, we also calculated the pairwise genetic differentiation between clusters using $G$ "sт and the heterozygosity within each cluster using $\mathrm{H}_{\mathrm{s}}$ in GENODIVE ver. 2.0 (Meirmans and van Tienderen, 2004). The possible temporal pattern (i.e., alternating dry and wet seasonal pattern or annual pattern) of the monthly compositions of each cluster and the membership probabilities of each individual were also explored for DAPC to further our understanding on the recruitment dynamics.

\section{Results}

\section{DNA Barcoding}

The results of BLAST indicated that our samples matched those of $P$. argus (average of 99.5\% identity). The pairwise genetic divergence values of sequences from our study's subsamples ranged from $0 \%$ to $1.8 \%$. All the pairwise values were less than the $2.9 \%$ threshold. This result further supports the hypothesis that all the postlarvae samples collected in our study belonged to the same species.

\section{Population Genetics}

The number of alleles per locus ranged from 5 to 38. The rarefied levels of the AR ranged from 2.5 to 19.63 . The value of Ho scoped from 0.426 to 0.820 , and was slightly lower than $\mathrm{HT}$, which ranged from 0.463 to 0.940 over the whole population and loci (Suppl. 
Table 1). This result suggested the potential presence of null alleles. There was no evidence of linkage disequilibrium and scoring errors caused by stutter or the drop out of large alleles. Furthermore, we detected the deviations from HWE continually presented at locus Par7 and FWC08. The analysis with MICRO-CHECKER vers. 2.2.3 (van Oosterhout et al., 2004) suggested that the null allele was present at these two loci. The result of the present of null allele was consistent with previous research (Truelove, Griffiths et al., 2015). These two loci were removed from further analysis.

No genetic difference was detected between the samples collected from the two sampling sites $(F \mathrm{ST}=0.00 ; P=0.42)$. Therefore, the postlarvae samples from the two sampling sites of the same month were pooled together for further analysis. The AMOVA analysis (Table 1) on the pooled data detected significant population differentiation among the monthly recruits $\left(F_{\mathrm{ST}}=0.035 ; P<0.0001\right)$ as well as the whole individual recruits $\left(F_{\mathrm{ST}}=0.136 ; P<0.0001\right)$. The results of pairwise comparisons of genetic differentiation using $G$ ”'sT ranged from 0.01 to 0.348 (Fig. 2A). Significant levels of genetic differentiation were detected in the majority of the monthly recruits (Fig. 2A). The results of the genetic differentiation using Jost'D suggested an identical result. In addition, no clear alternating seasonal pattern was detected during the sampling period. Meanwhile, the results of autocorrelation revealed notable temporal patterns. It began with a significant positive self-repeating signal at a time lag of one month. Then, the positive autocorrelation switched to a negative autocorrelation at a time lag of four months, which lasted for eight months. Afterwards, the pattern switched back to positive self-repeating at a time lag of 12 months (Fig. 2B). 
The results of the kinship analysis found significantly more full-siblings observed than excepted in 6 out of 24 months. Meanwhile, more half siblings observed than expected were detected in 18 out of 24 months (Fig. 3). In addition, the percentages of difference between observed and expected number of full- and half-siblings were highly varied among the monthly recruits. It ranged from 50\% (e.g., in November 2015) to less than $1 \%$ (e.g., in August 2014). The percentages of full- and half-siblings reached its peak during the dry season of the second year. However, no apparent seasonal pattern was observed from the results of the kinship analysis.

The results of the DAPC analysis suggested the entire population could be clustered into three clusters without overlapping each other (Fig. 4). Each cluster was defined as a group of individuals that is genetically similar. Results of pairwise genetic differentiation detected significant genetic divergence between three clusters (Suppl. Table 2). We also found that the level of genetic diversity within each cluster was similar (Suppl. Table 2). The results of the monthly cluster composition indicated that three clusters were present in all months and the ratio of each cluster varied during the entire sampling period (Fig. 5A). No apparent seasonal pattern was observed. The results of the membership assignment also display a well-mixed pattern (Fig. 5B). The three clusters were present in all individuals. It suggested that $17.6 \%$ of individuals could not be assigned to a single cluster (the proportion of the main cluster $>=75 \%$ ). The ratio of the population assigned to each cluster was $1.7: 1.5: 1$. 


\section{Discussion}

In the present study, our objective was to understand the larval recruitment dynamics of Panulirus argus in Florida across a 2-year time period. To carry out this objective, we assessed the population genetic structures, investigated the inter-individual relationships, as well as observed the possible temporal patterns that were present in the monthly recruits.

\section{Species Identification}

One of the assumptions of population genetic analysis is that all individuals that were examined in the analysis belong to the same species. As a consequence of the taxonomic uncertainty at the larval stage, we used DNA barcoding to identify the P. argus postlarvae. The BLAST results and the genetic divergence values both suggested that the monthly recruits that arrived at Florida from August 2014 to July 2016 were the same species (Panulirus argus), which agrees with previous research (Sarver et al., 1998).

\section{Genetic Differentiation}

Significant genetic differentiation was observed among monthly recruits during the twoyear sampling period (Table 1). The significant genetic differentiation suggested that the recruits that arrived at Florida monthly are not from a single source population (e.g., selfrecruitment). It is consistent with the conclusion derived from biophysical modeling (Kough et al., 2013), as well as stable isotope analysis (Yao and Zhang, 2018). Moreover, the genetic differentiation among the monthly recruits $\left(F_{\mathrm{ST}}=0.035\right)$ in our study was higher than that among MPAs in the Caribbean coast of Mexico $(F \mathrm{ST}=0.00013$; Truelove, 
Griffiths et al., 2015), as well as in the MBRS ( $F \mathrm{ST}=0.0054$; Truelove, Ley-Cooper et al., 2015). We could not compare the $F_{\text {ST }}$ values directly, but the level of difference between the genetic differentiation value of our study and the values of previous studies was significant. The difference on $F$ ST values could imply that the monthly recruits arriving at Florida were contributed by source populations in a wider geographical range than those of the locations in the previous two studies.

No apparent seasonal (dry/wet) pattern was detected from the genetic differentiation $(G \mathrm{ST})$ of the monthly recruits as shown in the heatmap (Fig. 2A) using microsatellite marker analysis. In Yao and Zhang (2018), however, a significant seasonal (dry/wet) pattern was revealed from both carbon and nitrogen stable isotope signals. These signals were derived from the monthly recruits that were collected from the same locations during the same time period as in the present study. Stable isotope analyzes kinetic and biochemical reactions, while microsatellite marker analysis measures on genetic similarity. The seasonal shift observed in the stable isotope signals could represent the shift on the bottom of the food web, which would not impact the results of microsatellite markers. The difference could explain the discrepancy in the results between these two studies.

Both the stable isotope analysis from Yao and Zhang (2018) and the genetic analysis in the current study revealed a similar pattern from the autocorrelation analysis (Fig. 2B). The autocorrelation analysis was used to measure the internal correlation within the time period (Venables and Ripley, 2002). Since swimming ability is not fully developed in the 
phyllosoma larvae stage, the oceanic surface current circulations, including the Caribbean, Yucatan, Loop and Florida Currents in the Caribbean Sea should be the main driver for the larvae distribution pattern (Kough et al., 2013). Therefore, we could speculate that recognizing the correlation between Caribbean current variations and the postlarvae drifting duration could be the key to identify the possible locations of the source populations. However, the oceanographic circulation in the Caribbean Sea varies over space and time (Lindo-Atichati et al., 2013) and there was no stable temporal pattern had been observed. Furthermore, no significant seasonally or annually repeating temporal pattern was detected from the genetic differentiation (Fig. 2A) during the 24-month sampling period. It suggested that the genetic structure of the Florida stock is dynamic. What must be understood is that there is a fluctuation of the connectivity among the $P$. argus stocks in the Caribbean observed during the pelagic larvae stage. Therefore, a longterm monitoring program would potentially be suitable for understanding the connectivity among $P$. argus stocks in the Caribbean region. In addition, we should not assume a constant monthly recruitment due to its dynamic nature. The variations in monthly recruitment should be estimated and considered to avoid bias.

\section{Kinship Analysis}

The results of previous research have revealed that the percentages of full- and halfsiblings were all less than $15 \%$ across the 9 locations throughout the greater Caribbean and Bermuda (Truelove et al., 2017), and ranged from 5\% to 30\% among the MPAs in the MBRS (Truelove, Griffiths et al., 2015). Our kinship analysis results displayed a much broader range (from $0.1 \%$ to $56 \%$ ) compared to the results of previous studies (Fig. 
3). The magnitude of kinship variation provides evidence to support the hypothesis that the source population of monthly recruits varies from month to month. Unfortunately, we were not able to assign each individual recruit to its source as a result of limited information. One future research direction could be matching larvae with spawning adults in the Caribbean stocks using parentage analysis.

Furthermore, it has been accepted that groups of animals tend to navigate more effectively than isolated individuals (Couzin et al., 2005; Simons, 2005). Irisson et al. (2015) tested this hypothesis using the black-axil chromis (Chromis atripectoralis) at the stage of settlement, when navigation is required to find a habitat. Their results suggest that marine pelagic larvae could also navigate consistently and swim faster in groups than individual. The percentages of full- or half-siblings ( $>=30 \%)$ of the monthly recruits from our study was higher than that of previous studies (Truelove, Griffiths et al., 2015; Truelove et al., 2017). The result could indicate that pelagic phyllosoma larvae could benefit from travelling in groups. It is necessary to point out that the hypothesis of animals could benefit from travelling in groups is mostly supported by empirical evidence on avian species (e.g., pigeons) (Benvenuti and Baldaccini, 1985; Nagy et al., 2010). In addition, it has only been applied to species with a short-term pelagic phase (e.g., a few weeks) and not those with extended larval phases (as those in P. argus that last 6 to 9 months). As the progress in understanding the larval dispersal has put the assumption of the passive nature of larval dispersal in question, scientists began to investigate the potential importance of larval behavior in determining dispersal (Young and Chia, 1987; Krug and Zimmer, 2004). On the basis of the new knowledge, we could 
speculate that long-term dispersal larvae (e.g., phyllosoma larvae) could benefit more from traveling in groups in terms of when and where to settle.

\section{Genetic Diversity}

Cluster analysis was used to investigate the genetic diversity among the individuals. The cluster analysis has identified three non-overlapping clusters for the entire recruitment samples over two sampling years (Fig. 4). The number of clusters (three) was consistent with that detected from the nine Caribbean and Bermuda stocks, observed by Truelove et al. (2017; [Suppl. Fig. 1]). Moreover, Yao and Zhang (2018) detected 4 distinguished clusters from the entire recruitments via stable isotope analysis on the recruits that were collected from the same locations during the same time period. The consistent presence of multiple clusters from different methods further supports the hypothesis that multiple source populations contribute to the Florida stock.

We tried to link the Florida spiny recruits from our study to the upstream Caribbean adults qualitatively from Truelove et al. (2017). Seven out of 10 stocks that were sampled in their study only possessed 2 clusters, and 1 cluster would occupy the majority of the stock. Meanwhile, in our study, the proportion of the 3 clusters was relatively even; each cluster occupied between $28 \%$ to $47 \%$ of the total population. On the basis of the difference between the results of two studies, we could contemplate that Florida stock receives recruits outside these 10 stocks. 


\section{Temporal Genetic Diversity}

The monthly composition of clusters from the DAPC analysis suggested that three clusters presented in every single month during the sample period (Fig. 5A). However, we could not match the monthly cluster compositions with those from Truelove et al. (2017) on the temporal scale, either. As a consequence, it is also impossible to simply conclude that each cluster observed in our study is only sourced from any single stock. It is more likely that the monthly recruit is a combination of multiple inputs from the source populations. Nine out of 10 locations were sampled between September 2010 and October 2011 in Truelove et al. (2017), and each location was only sampled for a short period of time. In my study, postlarvae samples were collected from only one stock, but the sampling period lasted for two years. A possible reason that our study revealed more genetic diversity than Truelove et al. (2017) could be a result the different lengths of the sampling period. Furthermore, it is possible that the monthly recruits arriving at Florida came from stocks that were not covered by Truelove et al. (2017). In addition, the pairwise genetic differentiations among the three clusters were bigger than those among the monthly recruits (Suppl. Table 2). It further supports the hypothesis that the monthly recruits were contributed by multiple source populations. The results of the membership assignment display a remarkably similar well-mixed pattern. The well-mixed pattern suggested the presence of high connectivity among $P$. argus stocks in the Caribbean. To add, the results of our research indicated that the temporal factor could also impact the dynamics of genetic diversity. 


\section{Implication for Fishery Management}

Our results support the hypotheses that the Florida stock is not isolated and the extended length of the pelagic larvae stage of Panulirus argus could lead to increased connectivity across the distributional range. A demographically open stock, as our data suggests, provides important implications for the valuable spiny lobster fishery. First, life history and larval behavior could impact the recruitment process significantly. Inappropriate assumptions about the life history or behavior could lead to bias in understanding recruitment ecology as well as fisheries biology. Previous simulation research has illustrated that misidentifying the spatial structure among stocks would lead to bias and errors in stock assessment, and consequently reduce the efficacy of fishery management strategies (Stephenson, 1999; Stelzenmüller et al., 2008). Therefore, ignoring the connectivity among the Caribbean spiny lobster stocks could hinder the effectiveness of the fisheries managements. Additionally, the results of our research emphasize the importance of international collaborations in the Caribbean spiny lobster fishery managements. Currently, Caribbean countries manage their stocks independently, although in recent years, efforts have been put into developing an international cooperation among Caribbean spiny lobster fisheries. Developing Pan-Caribbean management could increase the effectiveness of spiny lobster fisheries, thus optimizing benefits for each country's fisheries.

\section{Conclusion}

Our study explored the genetic structures and temporal pattern of the spiny lobster recruits arriving at Florida monthly. Our results indicate that there are potentially 
multiple source populations contributing to the Florida stock. It has also been suggested that the currents and the drift time could impact the temporal pattern of the genetic differentiation. Because Florida spiny lobster recruitment is a dynamic process, only taking one snapshot is insufficient to fully understand the dynamics of this process, and could lead bias in fishery management. The high percentage of kinship that occurred in certain months during the two-year sampling period provides potential evidences for the hypothesis that pelagic marine larvae benefit from traveling in groups. The monthly clusters display a well-mixed pattern, indicating that the source population may change from month to month. The results of our study also suggest that an international cooperation of fisheries management could be highly beneficial for this species.

\section{Acknowledgments}

We acknowledge the help of the Florida Fish and Wildlife Conservation Commission (FLFWC) lobster team led by T Mathews for sample collections. We also want to acknowledge $\mathrm{N}$ Truelove for the suggestions on the method development, and B Hunting for the proofreading. This study was mainly funded by FIU, while part of the student support came from Florida Sea Grant College Program (R/LR-B-69 and R/LR-B-74). This is contribution \#X of the Marine Education and Research Center of the Institute for Water and the Environment at FIU.

Literature cited

Abdul-Muneer, P. M.

2014. Application of microsatellite markers in conservation genetics and fisheries management: recent advances in population structure analysis and conservation strategies. Genet. Res. Int. 2014:691759. 
Benvenuti, S., and N. E. Baldaccini.

1985. Pigeon orientation: a comparison between single birds and small flocks. Ornis Scand. 16:45-48.

Blouin, M. S., M. Parsons, V. Lacaille, and S. Lotz.

1996. Use of microsatellite loci to classify individuals by relatedness. Mol. Ecol. 5(3): 393-401.

Butler, M. J. IV, C. B. Paris, J. S. Goldstein, H. Matsuda, and R. K Cowen.

2011. Behavior constrains the dispersal of long-lived spiny lobster larvae. Mar. Ecol. Prog. Ser. 422:223-237.

Castro-Conde, I., S. Döhler, and J. de Uña-Álvarez.

2017. An extended sequential goodness-of-fit multiple testing method for discrete data. Stat. Methods. Med. Res. 26(5):2356-2375.

Charbonnel, N., M. Quesnoit, R. Razatavonjizay, P. Bremond, and P. Jarne.

2002. A spatial and temporal approach to microevolutionary forces affecting population biology in the freshwater snail Biomphalaria pfeifferi. Am. Nat. 160:741-755.

Chavez, E. A.

2009. Socio-economic assessment for the management of the Caribbean spiny lobster. Proc Gulf Carib Fish Inst 60:193-196.

Couzin, I. D., J. Krause, N. R. Franks, and S. A. Levin.

2005. Effective leadership and decision-making in animal groups on the move. Nature. 433(7025):513-516.

Ehrhardt, N. M., R. Puga, and M. J. Butler IV

2010. The Caribbean spiny lobster, Panulirus argus, fisheries. In: Towards Marine Ecosystem-Based Management in the Wider Caribbean. (L. Fanning, R. Mahon, and P. McConney, eds.), p. 157-175. Amsterdam Univ. Press, Amsterdam.

Goldstein, J. S., H. Matsuda, T. Takenouchi, and M. J. Butler IV.

2008. The complete development of larval Caribbean spiny lobster Panulirus argus (Latreille, 1804) in culture. J. Crustac. Biol. 28(2):306-327.

Hartl, D. L., and A. G. Clark.

1997. Principles of Population Genetics, 3rd ed. Sinauer Associates Inc., Sunderland, MA.

Hedgecock, D.

1994. Population genetics of marine organisms. US. Globec. News. 6:1-16. 
Hedgecock, D., P. Barber, and S. Edmands.

2007. Genetic approaches to measuring connectivity. Oceanography. 20:70-79.

Hellberg, M. E., Burton, R.S., Neigel, J.E. and Palumbi, S.R.,

2002. Genetic assessment of connectivity among marine populations. Bull. Mar. Sci. 70(1):273-290.

Irisson, J. O., C. B. Paris, J. M. Leis, and M. N. Yerman.

2015. With a little help from my friends: Group orientation by larvae of a coral reef fish. PloS one. 10(12): p.e0144060.

Kearse, M., R. Moir, A. Wilson, S. Stones-Havas, M. Cheung, S. Sturrock, S. Buxton, A. Cooper, S. Markowitz, C. Duran, and T. Thierer.

2012. Geneious Basic: an integrated and extendable desktop software platform for the organization and analysis of sequence data. Bioinformatics. 28(12):1647-1649.

King, J. R., G. A. McFarlane, and A. E. Punt.

2015. Shifts in fisheries management: adapting to regime shifts. Philos. Trans. R. Soc. Lond., B. 370 (1659): 20130277.

Kough, A. S., C. B. Paris, and M. J. Butler IV.

2013. Larval Connectivity and the International Management of Fisheries. PloS ONE. 8: e64970.

Kraemer, P., and G. Gerlach.

2013. R Package "Demerelate.”. cran.r-project.org. pp1-33.

Krug, P. J., and R. K. Zimmer.

2004. Developmental dimorphism: consequences for larval behavior and dispersal potential in a marine gastropod. Biol. Bull. 207:233-46.

Lindo-Atichati, D., F. Bringas, and G. Goni.

2013. Loop Current excursions and ring detachments during 1993-2009. Int. J. Remote Sens. 34(14):5042-5053.

Manel S, Schwartz MK, Luikart G, Taberlet P. 2003. Landscape genetics: combining landscape ecology and population genetics.

Trends Ecol. Evol. 18:189-197.

McElroy, T. C., K. L. Kandl, and J. C. Trexler.

2011. Temporal population genetic structure of eastern Mosquitofish in a dynamic aquatic landscape. J. Hered. 102:678-687. 
Meirmans, P. G., and P. H. Van Tienderen.

2004. GENOTYPE and GENODIVE: two programs for the analysis of genetic diversity of asexual organisms. Mol. Ecol. Resour. 4(4):792-794.

Nagy, M., Z. Akos, D. Biro, and T. Vicsek.

2010. Hierarchical group dynamics in pigeon flocks. Nature. 464 (7290):890-893.

Palumbi, S., A. Martin, S. Romano, W.O. McMillan, L. Stice, and G. Grabowski. 1991. The Simple Fool's Guide to PCR. Honolulu: Department of Zoology.

Phillips, B. F., and J. D. Booth.

1994. Design, use, and effectiveness of collectors for catching the puerulus stage of spiny lobsters. Rev. Fish. Sci. 2(3):255-289.

Rousset, F.

2008. genepop'007: a complete re-implementation of the genepop software for Windows and Linux. Mol. Ecol. Resour. 8(1):103-106.

Sarver, S. K., J. D. Silberman, and P. J. Walsh.

1998. Mitochondrial DNA sequence evidence supporting the recognition of two subspecies or species of the Florida spiny lobster Panulirus argus. J. Crustac. Biol. 18(1):177-186.

Schuelke, $\mathrm{M}$.

2000. An economic method for the fluorescent labeling of PCR fragments. Nature. Biotechnol. 18(2):233.

Sharp, W.C., R. D. Bertelsen, and V. R. Leeworthy.

2005. Long-term trends in the recreational lobster fishery of Florida, United States: Landings, effort, and implications for management. N. Z. J. Mar. Freshw. Res. 39(3):733-747.

Silberman, J. D., S. K. Sarver, and P. J. Walsh.

1994. Mitochondrial DNA variation and population structure in the spiny lobster Panulirus argus. Mar. Biol. 120(4):601-608.

Simons, A. M.

2004. Many wrongs: the advantage of group navigation. Trends. Ecol. Evol. 19(9):453-455.

Stelzenmüller, V., Rogers, S. I., and Mills, C. M.

2008. Spatio-temporal patterns of fishing pressure on UK marine landscapes, and their implications for spatial planning and management. ICES J. Mar. Sci. 65:1081-1091. 
Stephenson, R. L.

1999. Stock complexity in fisheries management: a perspective of emerging issues related to population sub-units. Fish. Res. 43:247-249.

Tamura, K., and M. Nei.

1993. Estimation of the number of nucleotide substitutions in the control region of mitochondrial DNA in humans and chimpanzees. Mol. Biol. Evol. 10:512526.

Tessier N, Bernatchez L.

1999. Stability of population structure and genetic diversity across generations assessed by microsatellites among sympatric populations of landlocked Atlantic salmon (Salmo salar L.). Mol. Ecol. 8:169-179.

Tringali, M. D., S. Seyoum, and S. L. Schmitt.

2008. Ten di-and trinucleotide microsatellite loci in the Caribbean spiny lobster, Panulirus argus, for studies of regional population connectivity. Mol. Ecol. Resour. 8(3):650-652.

Truelove, N. K., S. Griffiths, K. Ley-Cooper, J. Azueta, I. Majil, S. J. Box, D. C. Behringer, M. J. Butler, and R. F. Preziosi.

2015. Genetic evidence from the spiny lobster fishery supports international cooperation among Central American marine protected areas. Conserv. Genet. 16(2):347-358.

Truelove, N. K., A. S. Kough, D. C. Behringer, C. B. Paris, S. J. Box, R. F. Preziosi, and M. J. Butler IV.

2017. Biophysical connectivity explains population genetic structure in a highly dispersive marine species. Coral Reefs. 36(1):233-244.

Truelove, N. K., K. Ley-Cooper, I. Segura-García, P. Briones-Fourzán, E. Lozano-

Álvarez, B. F. Phillips, S. J. Box, and R. F. Preziosi.

2015. Genetic analysis reveals temporal population structure in Caribbean spiny lobster (Panulirus argus) within marine protected areas in Mexico. Fish. Res. 172:44-49.

Van Oosterhout, C., W. F. Hutchinson, D. P. Wills, and P. Shipley.

2004. MICRO-CHECKER: software for identifying and correcting genotyping errors in microsatellite data. Mol. Ecol. Resour. 4(3):535-538.

Venables, W. N. and B. D. Ripley.

2002. Modern Applied Statistics with S, 4th ed. Springer. NY. 
Weir, B.S. and C. C. Cockerham.

1984. Estimating F-statistics for the analysis of population structure. Evolution. 38(6): 1358-1370.

Witham, R., R. M. Ingle., and H. W. Sims Jr.

1964. Notes on postlarvae of Panulirus argus. Quart Journ Florida Acad Sci. 27:289-297.

Yao, N., and Y. Zhang.

2018. Investigating Temporal Variation in Stable Carbon and Nitrogen Isotope Values of Florida Caribbean Spiny Lobster Panulirus argus Recruits. Bull. Mar. Sci. 94(3):847-861.

Young, C. M., and F. S. Chia.

1987. Abundance and distribution of pelagic larvae as influenced by predation, behavior and hydrographic factors. In: Reproduction of marine invertebrates, vol. 9 (A. C. Giese, J. S. Pearse, and V. B. Pearse, eds.), p. 385-463. Blackwell/Boxwood, Palo Alto. 


\section{Table Caption}

Table 1. Results of the Analysis of Molecular Variance (AMOVA) on ten microsatellite loci among the monthly Caribbean spiny lobster recruits that were collected from two sites in the Keys. The inbreeding coefficients $\left(F_{\mathrm{IS}}\right)$ and the fixation index $\left(F_{\mathrm{ST}}\right)$ are given in the table. Significant P-values are indicated by asterisks. 
Table 1

\begin{tabular}{|c|c|c|c|c|}
\hline Source of Variation & $\%$ var & $F$-stat & $F$-value & $P$-value \\
\hline Among Individual & 0.131 & $F_{\text {IS }}$ & 0.136 & $0.00001 *$ \\
\hline Among Population & 0.035 & $F_{\mathrm{ST}}$ & 0.035 & $0.00001 *$ \\
\hline
\end{tabular}




\section{Figure Captions}

Figure 1. Map of the two sites: Long Key (LK) and Big Munson (BM) in the Keys, Florida, United States of America, from which samples were collected.

Figure 2. Results of the pairwise genetic differentiation ( $G$ "sT) analysis of the postlarvae collected at Florida Keys monthly from August 2014 to July 2016. (A) Heatmap of pairwise $G$ "st values of the monthly postlarvae. The levels of the genetic differentiation are color-coded (blue $=$ low value, red $=$ high value). (B) Temporal autocorrelation function for $G$ "st value of the postlarvae.

Figure 3. Proportions of observed full- and half-siblings of the postlarvae collected at Florida Keys monthly from August 2014 to July 2016 that are different from the proportions expected by chance. The expected proportions of kinship were calculated using 1000 pairs of randomized populations for each month. The significant differences between observed and expected percentages of the half- and full-siblings are indicated by asterisks.

Figure 4. Subdivision of clusters according to the results of DAPC analysis. The entire postlarvae samples are clustered into three groups based on genetic similarity. Unique genetic clusters are indicated with different colors (blue $=$ Cluster 1 , yellow $=$ Cluster 2 , and green $=$ Cluster 3 )

Figure 5. The composition of the three clusters (Blue=Cluster 1, yellow=Cluster 2, and green $=$ cluster 3 ) of the postlarvae that were collected from August 2014 to July 2016 based on the results of DAPC analysis. (A) Monthly composition of the three clusters. The entire collection of postlarvae is clustered into three groups, determined by Bayesian Information Criterion based on the genetic similarity. (B) Membership probabilities of individual Caribbean spiny lobster recruit belonging to genetically unique clusters. Each vertical bar represents an individual spiny lobster and is divided into color segments that are proportional to the probability of belonging to a genetically unique cluster. The month is displayed on top of the figure and the black vertical line separates each month. 
Figure 1

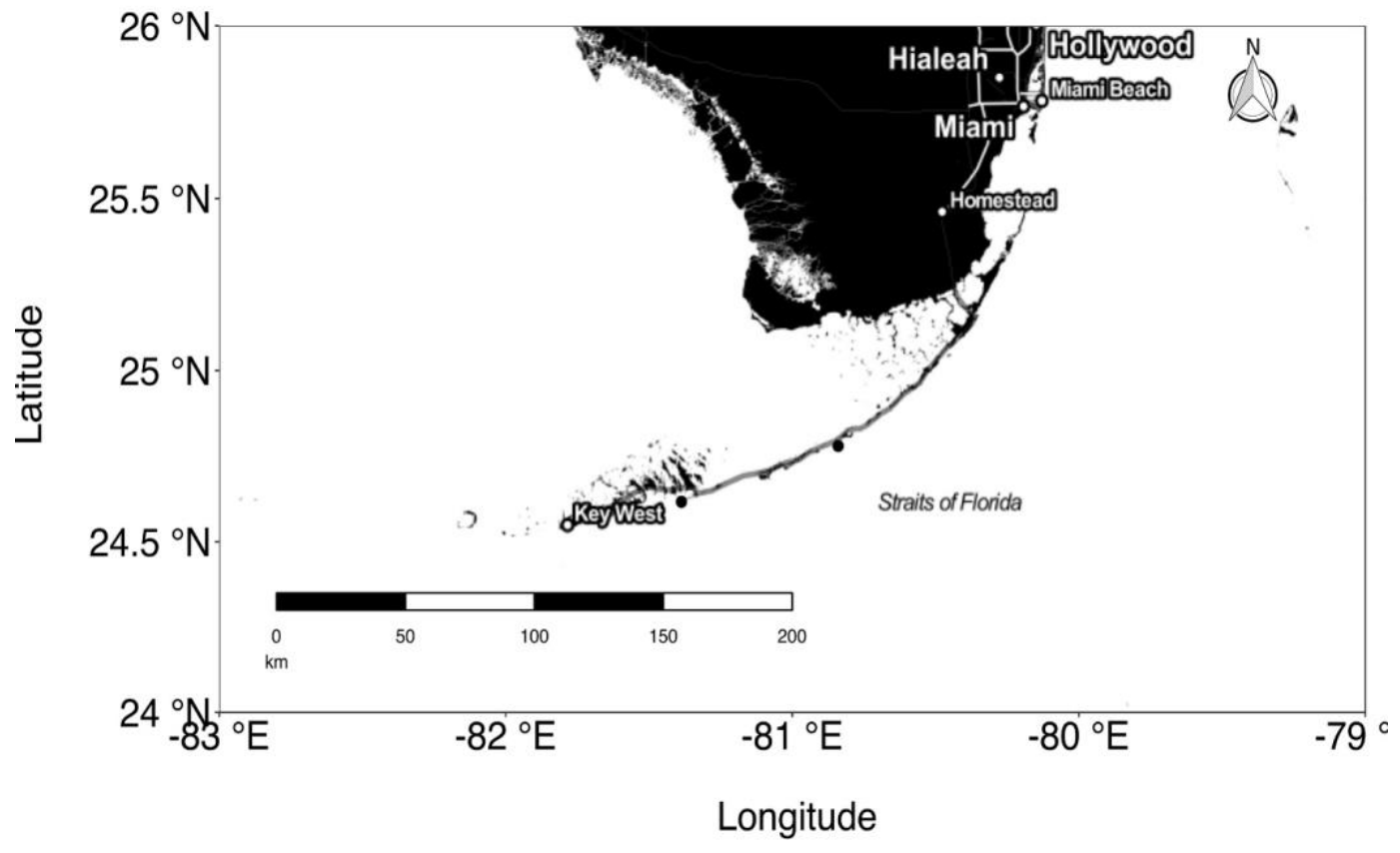


Figure 2

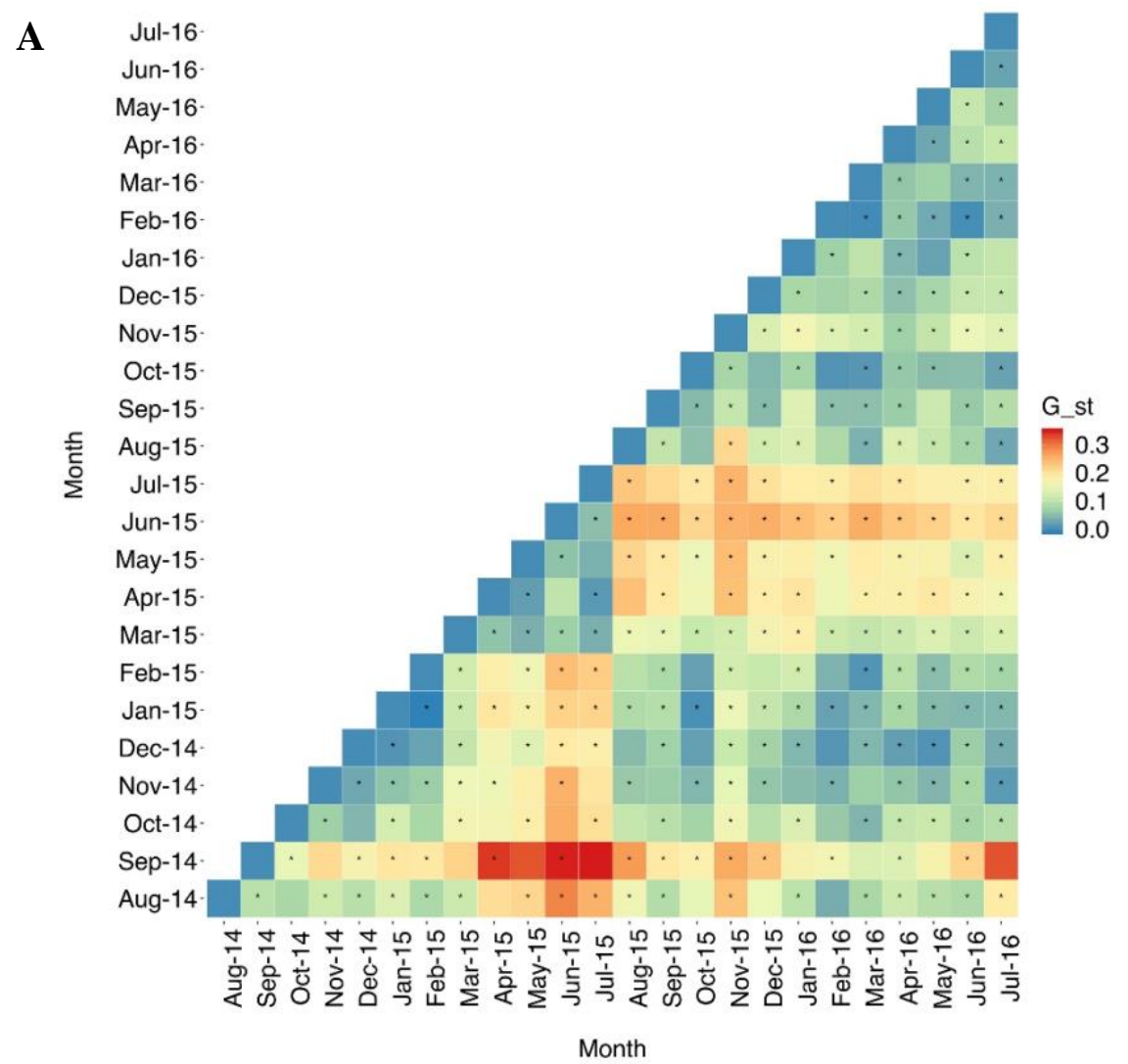

B

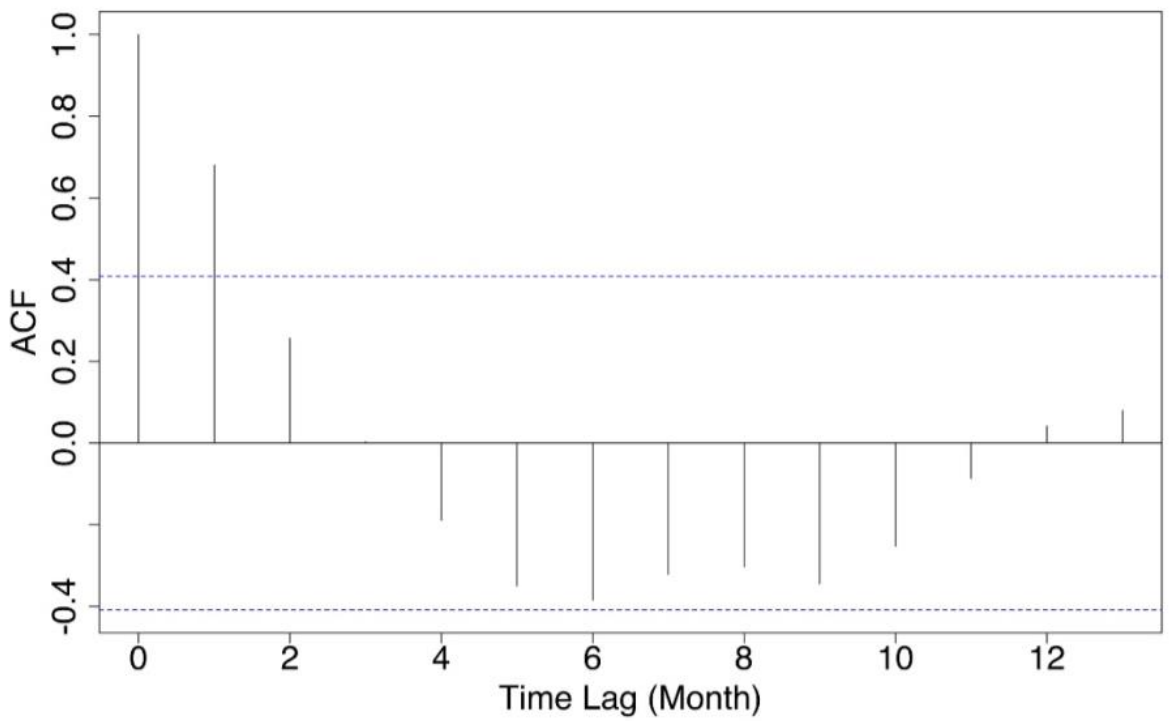


Figure 3.

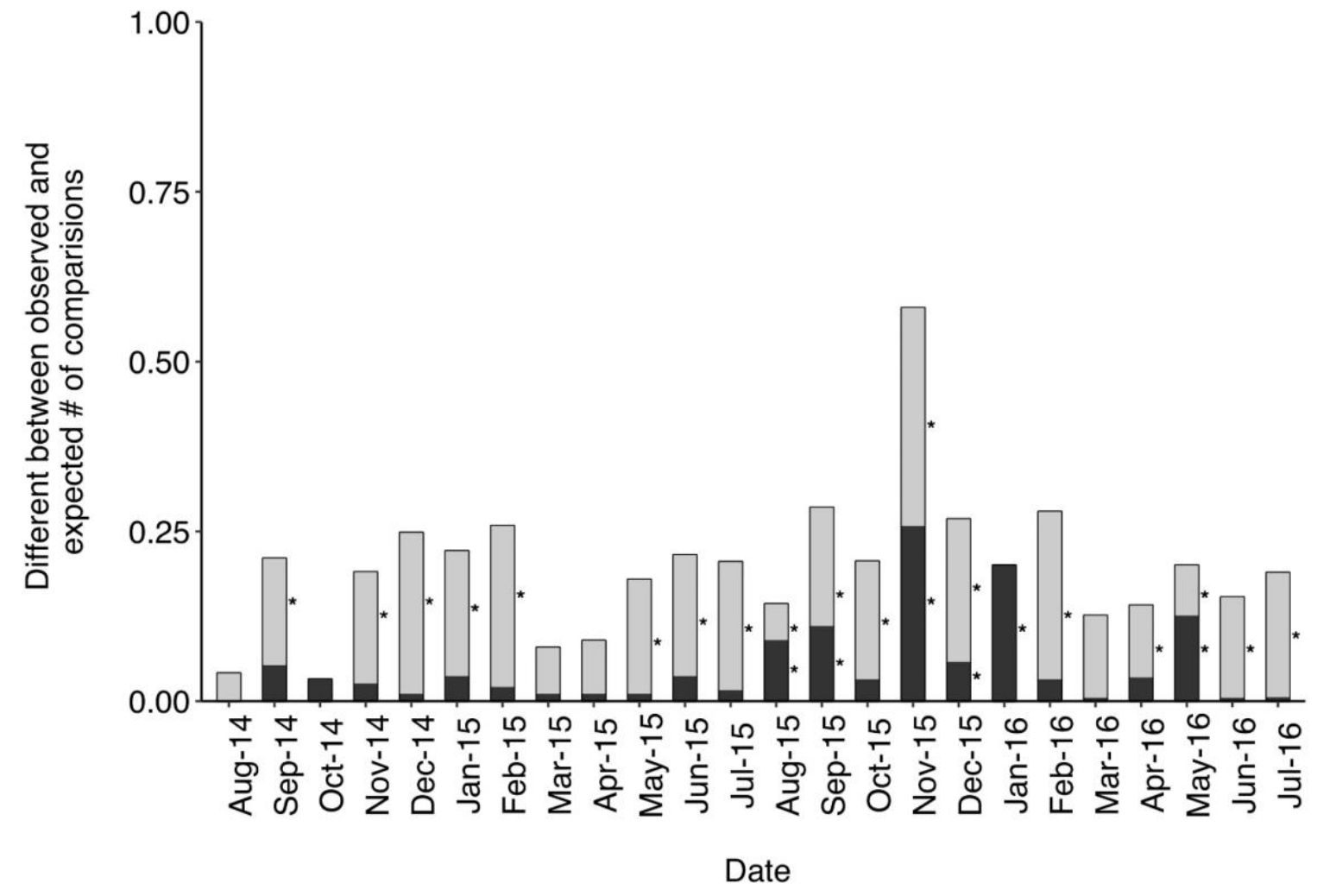

Full Siblings $\square$ Half Siblings 
Figure 4.

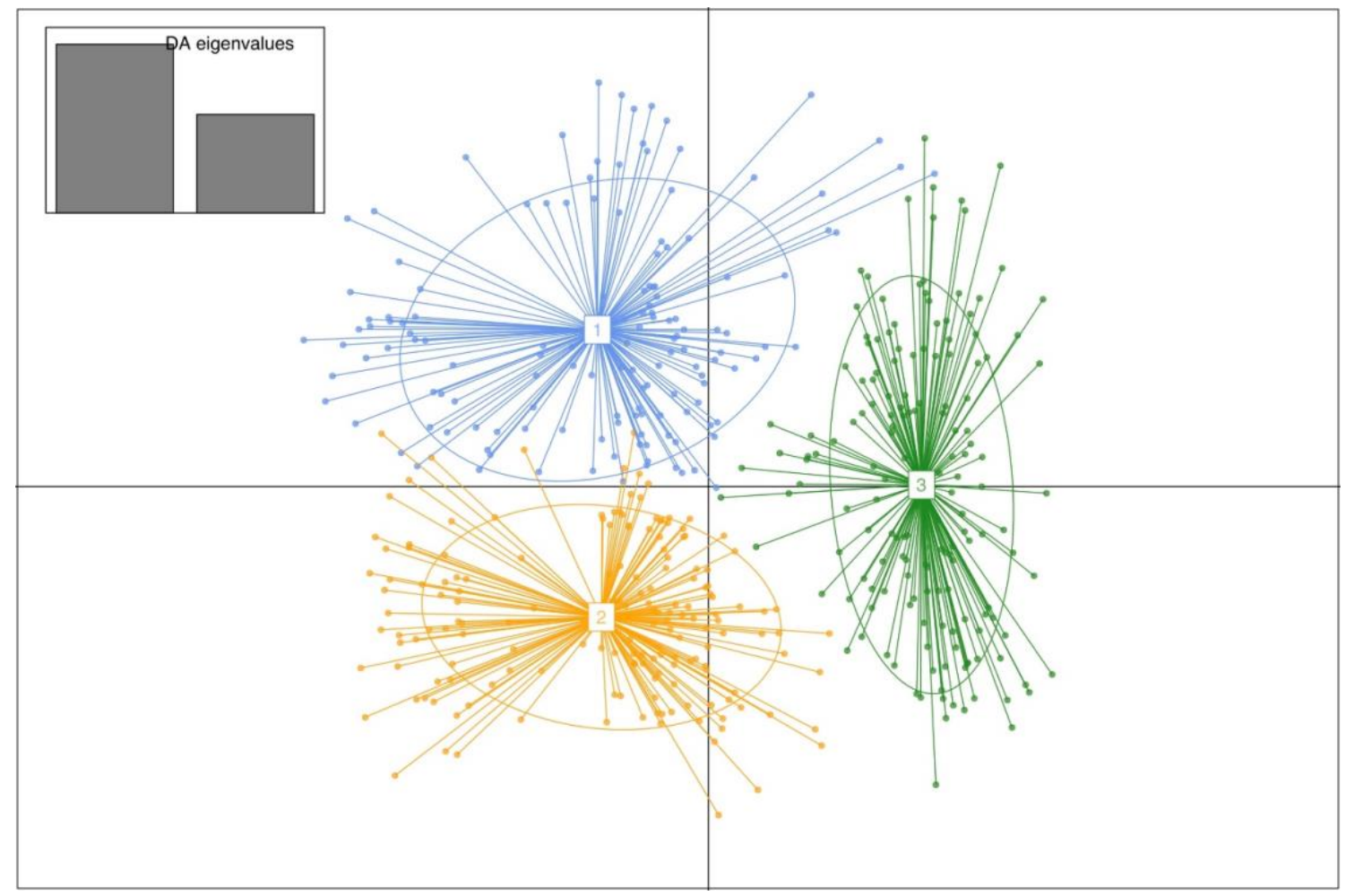


Figure 5.
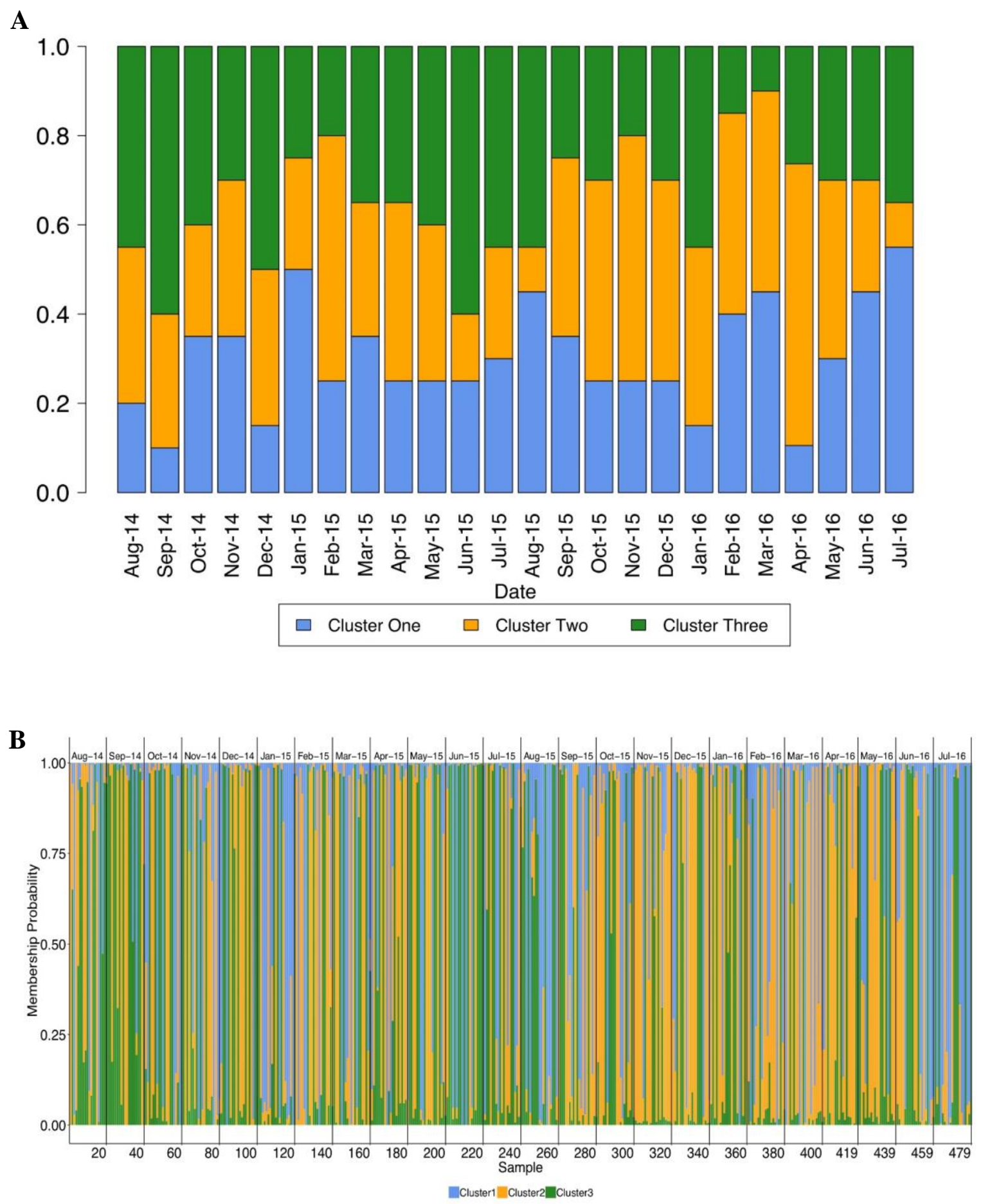
Supplemental Martials

Table Caption

Table 1. General statistic Summary of the Panulirus argus postlarvae that collected monthly from August 2014 to July 2016. It includes average number of effective sample size $(\mathrm{N})$, average observed heterozygosity $\left(\mathrm{H}_{\mathrm{o}}\right)$, allelic richness (AR), average expected heterozygosity $\left(\mathrm{H}_{\mathrm{s}}\right)$, inbreeding coefficient $\left(\mathrm{G}_{\mathrm{is}}\right)$.

Table 2. The Genetic differentiation among $\left(G\right.$ "sт) and within $\left(\mathrm{H}_{\mathrm{s}}\right)$ three clusters based on the results of DAPC analysis. 
Table S1.

\begin{tabular}{|c|c|c|c|c|c|c|}
\hline Population & Num & $\begin{array}{c}\text { Effective } \\
\text { Num }\end{array}$ & AR & Ho & $\mathrm{H}_{\mathrm{t}}$ & $\mathrm{G}_{\text {is }}$ \\
\hline 14-Aug & 10.250 & 5.675 & 10.064 & 0.608 & 0.807 & 0.246 \\
\hline 14-Sep & 8.917 & 5.416 & 8.782 & 0.625 & 0.779 & 0.197 \\
\hline 14-Oct & 8.583 & 5.267 & 8.461 & 0.604 & 0.767 & 0.213 \\
\hline 14-Nov & 8.000 & 4.565 & 7.906 & 0.658 & 0.745 & 0.116 \\
\hline 14-Dec & 9.000 & 5.350 & 8.868 & 0.629 & 0.769 & 0.182 \\
\hline 15-Jan & 8.417 & 5.223 & 8.314 & 0.608 & 0.761 & 0.201 \\
\hline 15-Feb & 8.500 & 5.410 & 8.385 & 0.546 & 0.725 & 0.247 \\
\hline 15-Mar & 9.583 & 5.510 & 9.398 & 0.642 & 0.746 & 0.140 \\
\hline 15-Apr & 10.333 & 5.763 & 10.134 & 0.675 & 0.763 & 0.115 \\
\hline 15-May & 8.250 & 5.631 & 8.169 & 0.675 & 0.758 & 0.110 \\
\hline 15-Jun & 7.750 & 4.224 & 7.632 & 0.563 & 0.720 & 0.219 \\
\hline 15-Jul & 8.417 & 5.119 & 8.306 & 0.637 & 0.760 & 0.161 \\
\hline 15-Aug & 8.083 & 5.316 & 7.994 & 0.688 & 0.788 & 0.128 \\
\hline 15-Sep & 7.417 & 4.868 & 7.345 & 0.637 & 0.743 & 0.142 \\
\hline 15 -Oct & 8.000 & 5.358 & 7.923 & 0.571 & 0.764 & 0.253 \\
\hline 15-Nov & 7.750 & 3.737 & 7.640 & 0.679 & 0.680 & 0.002 \\
\hline 15-Dec & 7.333 & 4.596 & 7.249 & 0.642 & 0.733 & 0.124 \\
\hline 16-Jan & 7.667 & 4.483 & 7.569 & 0.646 & 0.738 & 0.125 \\
\hline 16-Feb & 8.417 & 4.929 & 8.294 & 0.638 & 0.753 & 0.153 \\
\hline 16-Mar & 8.083 & 4.947 & 7.977 & 0.592 & 0.749 & 0.210 \\
\hline 16-Apr & 7.833 & 4.550 & 7.833 & 0.561 & 0.706 & 0.204 \\
\hline 16-May & 8.583 & 4.863 & 8.460 & 0.621 & 0.716 & 0.133 \\
\hline 16-Jun & 8.333 & 5.329 & 8.231 & 0.642 & 0.751 & 0.145 \\
\hline 16-Jul & 9.083 & 5.837 & 8.968 & 0.600 & 0.776 & 0.226 \\
\hline
\end{tabular}


Table S2.

\begin{tabular}{|c|c|c|c|}
\hline Cluster & Cluster 1 & Cluster 2 & Cluster 3 \\
\hline Cluster 1 & 0 & 0.199 & 0.280 \\
\hline Cluster 2 & 0.199 & 0 & 0.208 \\
\hline Cluster 3 & 0.280 & 0.208 & 0 \\
\hline $\mathrm{H}_{\mathrm{s}}$ & 0.673 & 0.622 & 0.601 \\
\hline
\end{tabular}




\section{Figure Caption}

Figure S1. Proportions of each of the three discrete genetic clusters on 10 locations thought out the greater Caribbean identified by the population genetics program STRUCTURE from Truelove et al. 2017. 
Figure S1.

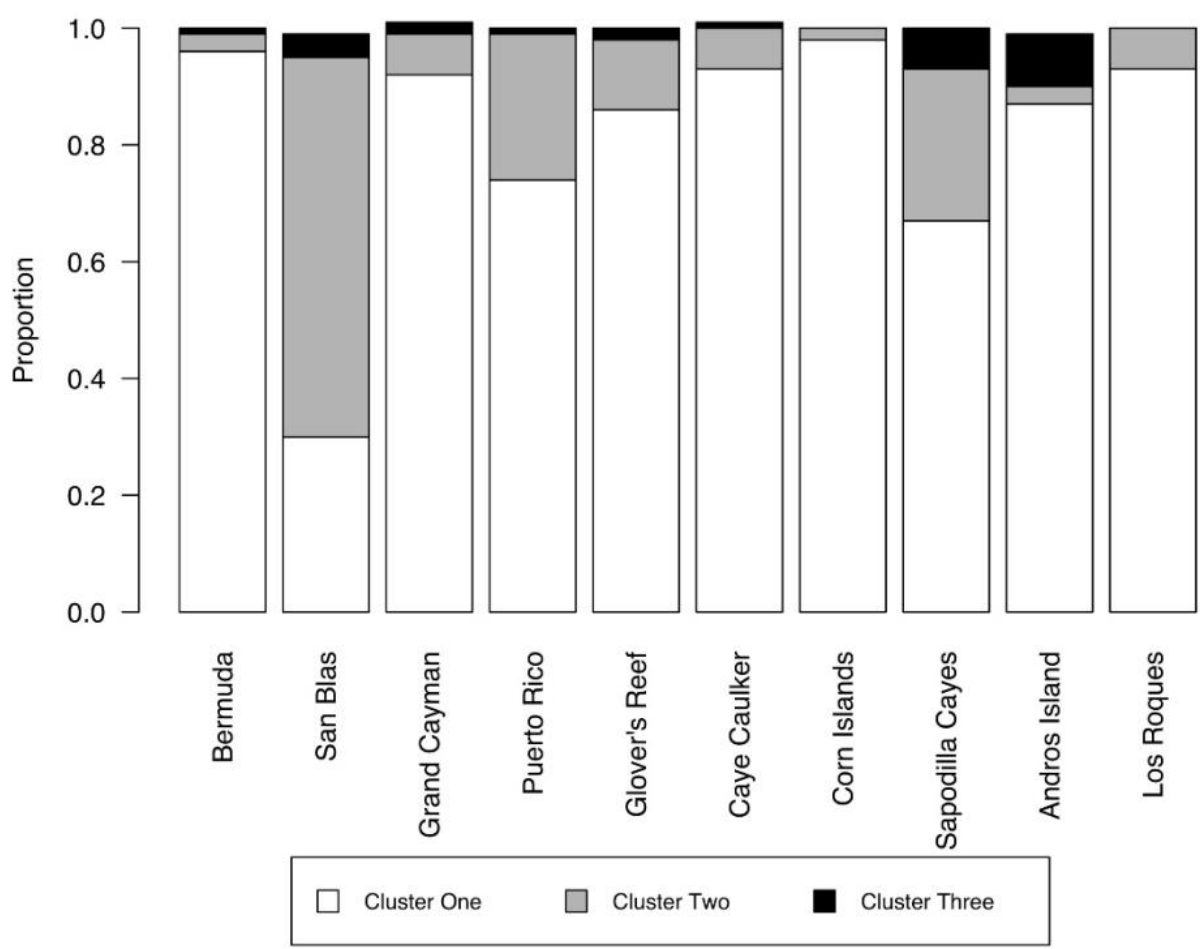


CHAPTER IV IMPACTS OF STOCK SPATIAL STRUCTURE AND CONNECTIVITY ON THE STOCK ASSESSMENT AND MANAGEMENT OF CARIBBEAN SPINY LOBSTER STOCKS 


\begin{abstract}
The Caribbean spiny lobster (Panulirus argus) is one of the most valuable fisheries species in Florida. However, the annual landing of $P$. argus has decreased for the past decade most likely a result of decline of the stock (SEDAR, 2010). In order to manage the stocks more effectively, fisheries scientists and managers around the world have proposed multiple harvest strategies. However, most of these strategies did not account for spatial connectivity caused by dispersal of larval stages. The long pelagic larval lifespan drifts with currents for six to nine months. Therefore, including the spatial structure between the Unite States and upstream stocks is necessary to identify effective management strategies for the Florida spiny lobster stock. In my project, we use a biophysical model to simulate the recruitment process and derive the connectivity matrix among the stocks. Then we evaluated the impact of management strategies of upstream stocks on the Florida stock. We also compared the results from stock assessment with spatial structure and without spatial structure. The results indicate that ignoring spatial connectivity of the stock could lead to bias in the stock assessment and reduce effectiveness of the management strategies.
\end{abstract}




\section{Introduction}

Traditional fisheries population dynamics theories are founded on the concept of a unit stock, which assumes the individuals in the population share the same gene pool, are selfperpetuating, and are isolated from other populations (Quinn and Deriso 1999; King 2007). The stock assessment and management are also created on the basis of the same assumption that there is no exchange among stocks. However, the assumption of no exchange among stocks might not always be realistic (Waples and Gaggiotti 2006). Research has suggested that ignoring the spatial structure among the stocks results in bias and errors in stock assessment (Guan et al. 2013), and consequently reduces the efficacy of fishery management strategies (Stephenson 1999; Holland 2003; Stelzenmüller et al. 2008) and increases the probability of overexploitation (Ying et al. 2010). Therefore, including spatial structure in stock modeling and assessment has become an important option.

A metapopulation consists of several sub-populations linked by immigration and emigration (Gotelli 2008). The concept of metapopulation has been adopted by ecologists, introduced in conservation ecology (Lande 1987; Hastings 1991), and has been increasingly used in stock assessments (Secor 2001; Kritzer and Sale, 2004; Fromentin and Powers 2005). Previous studies revealed that for highly migratory species, models employing the metapopulation framework were more accurate in estimating stock status than the unit-stock models (Hart and Cadrin 2004). 
Fishery management strategy evaluation (MSE) involves using simulations to compare the effectiveness among different management scenarios in terms of achieving management objectives (Punt et al. 2016). Among a set of candidate strategies, MSE could identify the management strategies that are robust to the uncertain of stocks and capable of balancing multiple objectives (Holland 2010). Management strategies

Evaluation (MSE) can also consider long term trade-offs among objectives. Over the past two decades, MSE has been used to design effective management strategies on the stocks with spatial structures (Plaganyi et al. 2013; Dichmont et al. 2013) and has been proven to be a useful tool in conserving fishery resources, especially in rebuilding fisheries (Butterworth 2010). Therefore, MSE could be a promising tool in developing a robust management for Caribbean fisheries.

The Caribbean spiny lobster (Panulirus argus) is harvested by 30 countries and supports one of the most valuable fisheries in the Caribbean region (Heileman 2007). Because of its high economic value, various fisheries management strategies have been developed for $P$. argus. Fishery regulations of $P$. argus stocks in the Caribbean commonly include a minimum harvest size, a closed fishing season, and a prohibition on the harvesting of females with eggs (Table 1). The minimum harvest size limits the size of $P$. argus that can be legally harvested by a fishery. The minimum harvest size ranges from $74 \mathrm{~mm}$ carapace length (CL; Mexico) to $120 \mathrm{~mm}$ CL length (Venezuela) in the Caribbean. Most countries employed a minimum harvest size of around 76 to $83 \mathrm{~mm} \mathrm{CL}$. In the countries with high minimum harvest size (i.e., > $90 \mathrm{~mm} \mathrm{CL}$ ), the compliance rate for this regulation is questionable. For example, in Venezuela, the fishing pressure occurred 
around $74.5 \mathrm{~mm} \mathrm{CL}$ and increased dramatically after $98.5 \mathrm{~mm} \mathrm{CL}$ (FAO 2001). The length of the closed fishing season lasts from two (Nicaragua) to five (Venezuela) months in the Caribbean, which is usually consistent with the local spawning season. The harvest prohibition protects female lobsters with eggs from being harvested by a fishery.

Current $P$. argus management regulations in the Caribbean region were created solely on the basis of the assumption that stocks are isolated from each other. However, the assumption of independent stock might not be consistent with the long pelagic larvae stage of $P$. argus. During the pelagic larvae stage, a larval stage called the phyllosoma, can drift with currents for six to nine months before settling in the inshore habitat (Goldstein et al. 2008; Matsuda et al. 2008). The long pelagic life history leads to the hypothesis that a spatial structure exists among $P$. argus stocks in the Caribbean. The results of recent studies, including biophysical modeling (Kough et al. 2013), genetic markers (Truelove et al. 2017; Yao et al. under review) and stable isotope analysis (Yao and Zhang 2018) have all provided evidence to support hypothesis of metapopulation. Therefore, understanding the spatial structure among stocks and its impacts is necessary to develop robust and effective stock assessment and management.

In the current project, I provide a case study to evaluate effects of spatial structure on the stock assessment and fishery management of $P$. argus. I first determine the connectivity among the $P$. argus stocks using biophysical modeling. Then, I investigated the bias of stock assessments following different spatial structure assumptions. Furthermore, I evaluated the effectiveness of different management strategies under the metapopulation 
framework. The results of my project are expected to provide insights to improve current spiny lobster fishery management.

\section{Method and Materials}

\section{Connectivity}

In my study, the connectivity matrix was estimated by a Lagrangian stochastic individual-based model (IBM) coupled with 1/12-degree Hybrid Coordinate Ocean Model (HYCOM) of 2014. The IBM used a back-calculation to track 100 pseudo spiny lobsters recruits from Florida back to their original stocks. The drift period last from six to nine months (Goldstein et al. 2008). The location of each pseudo spiny lobster at the end of each time step (an hour) was determined by the water speeds in their current locations. A random walk was also added to the movement estimation at the end of each time step. The IBM also integrated the best available biological knowledge on the phyllosoma larval, including the vertical distribution (Yeung and McGowan 1991), the time of hatching and mortality rates. The predicted trajectory of each individual in the end of each time step was recorded. Then, the seasonal connectivity among different substocks was summarized following these trajectories. The connectivity estimated from the IBM was represented by a $n \times n$ matrix:

$$
C_{t}=\left(c_{i j}\right)
$$

where $n$ is the number of the sub-stock, $C_{t}$ is the matrix at time step $t$, element

$c_{i j}$ corresponds to the proportion of individuals migrate from sub-stock $i$ to sub-stock $j$ during time step $t$ (Artzey-Randrup and Stone 2010). 


\section{Operating model}

The "true" population structure assumed for the simulations was that of a metapopulation. The metapopulation included $P$. argus stocks in the Caribbean that have contributed more than $1 \%$ to the total Florida recruitment in 2014 , on the based of the results of biophysical modeling. Note that stocks included in the metapopulation framework would be referred to as sub-stocks. The sub-stocks were connected via the connectivity matrix described in the connectivity section.

The population dynamics of each sub-stock were simulated via an operating model using life history and fishery parameters from the latest $P$. argus stock assessment. In the case that no stock assessment was currently available for a sub-stock, we assumed that the life history was similar to the nearby sub-stock and the fishery parameters were standardized using the landing ratio from the nearby sub-stock.

The population dynamics of the sub-stock in the metapopulation were given by the equation:

$$
N_{t+1, j}^{s}=N_{t, j}^{s} e^{-Z_{t, j}^{s}} G_{j}^{s}+R_{t, j^{-}}^{s} C_{t, j}^{s}
$$

where $N_{t, j}^{S}$ is the abundance of the sub-stock j of sex $s$ at time step $t, Z_{t, j}^{s}$ is the total mortality of the sub-stock in time step $t . G_{j}^{s}$ is the sex specific growth transition matrix of sub-stock $j$, and was developed outside the model for the Florida stock (Zhang and Yao 
2018). $R_{t, j}^{s}$ is the recruitment of sex $s$ that arrived at subs-tock $j$ at time step $t$ (after the phyllosoma larval stage). Note that we used a size-structured stock assessment model for the Florida sub-stock (Yao and Zhang 2016), in which the recruitment is defined as the number of individuals growing from less than $46 \mathrm{~mm}$ CL to the size larger than $46 \mathrm{~mm}$ CL. Therefore, when estimating the recruitment in the Florida stock assessment, the relative abundance of the settled recruitment is input for the observational sub-module, meanwhile assuming the juvenile natural mortality over time is constant. $C_{t, j}^{s}$ is the catch of sub-stock $j$ in time step $t$.

The spawning stock biomass of sub-stock $j$ was determined at the end of each time step $t$ $\left(S S B_{t, j}\right.$ expressed as number of eggs). Among all sub-stocks, the stock-recruiting (S-R)

function was only determined for the Florida stock. Therefore, I applied the S-R function (SEDAR 2005) to all sub-stocks to calculate the potential recruitment before the phyllosoma larval stage. Then, the potential recruitment after the phyllosoma larval stage arrived at sub-stock $j$ via the connectivity matrix at the beginning of every time step $t$ is calculated as

$$
R_{t, j}=\sum f\left(S S B_{i, t-1}\right) C_{i, j} M
$$

where $R_{t, j}$ is the recruitment arrived at sub-stock $j$ at time step $t . S S B_{t-1, i}$ is the spawning stock biomass of sub-stock $i$ at time step $t-1 . c_{i, j}$ correspond to the proportion of recruitment migrate from sub-stock $i$ to sub-stock $j . M$ is the natural mortality of the phyllosoma larval stage. 
The total commercial annual catch of each sub-stock was calculated using equation:

$$
C_{t}^{s}=\sum \frac{F_{t} S e l_{l}^{s}}{Z_{t, l}^{s}} N_{t, l}^{s}\left(1-e^{-Z_{t, l}^{s}}\right) e^{\epsilon}
$$

where $C_{t}^{s}$ is the predicted catch for sex $s$ at time step $t . F_{t}$ is the fishing mortality at time step $t . S e l_{l}^{s}$ is the catch selectivity for sex $s$ size $l, e^{\varepsilon}$ was the log-normally distributed observational errors.

And fishery dependent- and independent- stock abundance indices $I_{t}^{p}$ was calculated using equation:

$$
I_{t}^{p}=q^{p} \sum N_{t, l}^{s} S e l_{l}^{p, s} e^{\epsilon}
$$

where $q^{p}$ is the catchability of survey $p . S^{p e l} l_{l}^{p, s}$ is the survey selectivity for survey $p$ sex $s$ size $l . e^{\varepsilon}$ was the log-normally distributed observational errors.

The "true" population simulation ran for 60 years and 100 iterations. The "observed" data (total commercial annual catch and fishery dependent- and independent- stock abundance indices) were generated from each iteration and used as input data for the estimation models with different spatial structure assumptions.

\section{Estimation model}

Two spatially explicit models were considered in the stock assessment: (i) "independentpopulation" and (ii) "metapopulation". In the (i) spatial structure, each sub-stock was 
considered isolated from each other. The recruitment was assumed to only be contributed by the local spawning stock biomass (SSB). The population dynamics of each sub-stock can be described as:

$$
N_{t+1}^{s}=N_{t}^{s} e^{-Z_{t}^{s}} G^{s}+R_{t^{-}}^{s} C_{t}^{s}
$$

where $R_{t}^{s}$ is the self-recruitment at time $t, N_{t+1}^{s}, N_{t}^{s}, Z_{t}^{s}, G^{s}$ and $C_{t}^{s}$ are defined as above.

In the (ii) spatial structure, we "correctly" define the spatial structure between the Florida stock and other sub-stocks in the meta-population. We used equation (1) to (5) to represent the population dynamics in (ii). The predicted total commercial annual catch and fishery dependent- and independent- stock abundance indices were produced in each estimation model. The predicted data from each scenario and "observed" data from "true" population were used to formulate the Bayesian likelihood functions to optimize parameters in the stock assessment model. A total number of 125 parameters were estimated and each parameter followed either a log-normal distribution:

$$
p(X \mid \hat{X})=\int\left[\frac{1}{\sqrt{2 \pi} \delta_{X} X_{t}} \exp \left(-\frac{\left(\ln \left(X_{t}\right) \cdot \ln \left(\hat{X}_{t}\right)\right)^{2}}{2 \delta_{X}{ }^{2}}\right)\right]
$$

where $\sigma$ is the standard deviation of $\log$-transformed $X_{t}^{j}$.

Or a normal distribution:

$$
p(X \mid \hat{X})=\int\left[\frac{1}{\sqrt{2 \pi} X_{t}} \exp \left(-\frac{\left(X_{t}-\hat{X}_{t}\right)^{2}}{2 \delta_{X}{ }^{2}}\right)\right]
$$

where $\sigma$ is the standard deviation of log-transformed $X_{t}$. 


\section{Stock assessment bias estimation}

Fishing mortality (F), SSB and recruitment (R) estimated from estimation models with two spatial structures ((i) Independent-population and (ii) Metapopulation) were used for the bias comparison. For a given spatial structure, the relative bias (RB) and average relative bias (ARB) for each simulation run will be calculated:

$$
R B=\sum_{i=\text { start }}^{\text {end }} \sqrt{\left(\frac{Y_{E s t, i}-Y_{\text {True }, i}}{Y_{\text {True }, i}}\right)^{2}} / n
$$

and

$$
A R B=\sum_{i=\text { start }}^{\text {end }}\left(\frac{Y_{\text {Est },}-Y_{\text {True }, i}}{Y_{\text {True }, i}} / n\right)
$$

where $Y_{E s t, i}$ and $Y_{T r u e, i}$ are the estimated and "true" stock biomass or fishing mortality for time step $i$, respectively, and $n$ is the number of time steps from the start to the end. The $R B$ measures relative bias and errors, while $A R B$ focuses on the general biases of stock assessment models. The mean and the confidence interval (CIs) of $R B$ and $A R B$ over the 100 simulation runs were summarized to represent the bias and uncertainty of stock assessment models.

\section{Management scenarios simulation}

To improve the current management of the Florida spiny lobster fishery, the combination of three input controls (minimum harvest size, closed fishing season and harvest prohibition) on different levels of intensity were tested in my study (Table 2). The minimum catch size ranges from 72 to $120 \mathrm{~mm}$ CL with an uneven interval between $1 \mathrm{~mm}$ and $5 \mathrm{~mm}$. The range of closed season was from 2 to 5 months with an interval of 
half month. I also investigated the impacts of the prohibition on harvesting females with eggs. A total of 337 scenarios, including the current management scenario were investigated in my project. For each scenario, one-hundred Monte Carlo simulation runs were conducted for 60 years.

The objective of Florida $P$. argus fishery management is to maintain the stock status in a healthy level while continue the current fishing level. Adhering to the management objective, minimum SSB (Min-SSB-FL), SSB of the final year (Fin-SSB-FL), total commercial landing (L-FL), commercial landing variation (LV-FL) of the Florida stock and the final year SSB (Fin-SSB-Meta) and commercial landing of the meta-population (L-Meta) were selected as performance measures to evaluate the effectives of each management scenario. Min-SSB-FL, Fin-SSB-FL and Fin-SSB-Meta measure the stock condition of the Florida stock and entire metapopulation. Following the objective, higher values of SSB performance measures are preferred. Meanwhile, L-FL and L-Meta measure the commercial landing from the Florida stock and entire metapopulation. Higher landings are also preferred based on the objective but has a lower priority than maintaining a healthy stock. In addition, LV-FL measures the variation among the annual landing during the simuation. A smaller LV-FL indicates more a stable annual catch, which is preferred. The performance measures were measured at the end of the simulation, and management scenarios with the most optimal results were identified by comparing above performance measures. 


\section{Results}

\section{Connectivity}

The results of the connectivity for 2014 are presented in Figure 1. The results suggest that the Florida stock have received recruitment from nine stocks in the dry season (Fig. 1A) and eight stocks in the wet season from the Caribbean (Fig. 1B). They also indicate that self-recruitment is the biggest source of recruitment (49\% of total recruitment in the dry season and $32 \%$ in the wet season) for the Florida stock in both seasons. However, neither the proportion of self-recruitment has exceeded 50\%. Additionally, the Venezuelan stock is the second biggest source population for Florida stock with $26 \%$ recruitment contribution in the dry season and $21 \%$ recruitment contribution in the wet season. Furthermore, five other stocks including Honduras, Nicaragua, Panama, Jamaica and Mexico have contributed more than $1 \%$ but less than $10 \%$ of the total Florida recruitment in both seasons. Therefore, these eight stocks: Florida, Venezuela, Honduras, Nicaragua, Panama, Jamaica, Colombia and Mexico are included as sub-stocks in the meta-population framework for this project (Fig. 2). The connectivity matrices summarized on the seasonal basis (dry/wet) were used to link the recruitment among the sub-stocks in the meta-population framework.

\section{Bias estimation}

The results of the bias estimation suggest that the stock assessment scenario in which spatial structure is ignored (i) yielded significantly higher $R B$ and $A B A$ for $\mathrm{F}, \mathrm{SSB}$ and $\mathrm{R}$ than the scenario in which spatial structure is correct specified (ii) (Table 3). In scenario (i), the F and R are significant overestimated (Fig 3A, and 3C), while the SSB (Fig 3B) is 
significantly underestimated from the "true" values. In contrast, parameters estimated in scenario (ii) are significant closer to the "true" value. Additionally, the variation ranges of the parameters estimated in scenario (i) also shows significant difference from the ranges of "true" values. Meanwhile, the variation of the parameters estimated from scenario (ii) and the "true" parameters are mostly overlapped.

\section{Management strategies Evaluation}

The outcomes of each management scenario of six performance measures are displayed using the heatmap (Fig. 4-9). In general, the expected pattern is described as the following: Min-SSB-FL (Fig.4), Fin-SSB-FL (Fig. 5), and Fin-SSB-Meta (Fig. 8) increase as the minimum harvest size and the length of closed fishing season increase. Conversely, LV-FL (Fig.7), L-FL (Fig. 6) and L-Meta (Fig. 9) over the simulation period display a reverse trend from the previous three performance measures: a high minimum harvest size and length of closed season would lead to a low L-FL, L-Meta and LV-FL. The results of management scenarios with female protection (Fig. 4-9 A) perform better (higher SSB and higher landing) than the scenarios without female protection (Fig. 4-9 B) in almost all performance measures. The only exception is the LV-FL, where scenarios without female protection display a smaller LV-FL than the scenarios with female protection. Furthermore, the results also indicate that certain management scenarios could yield better performance measures than expected. Such exception scenarios are selected as the optimal management scenarios for each objective (Table 4). 
The comparisons of the most optimal scenarios are displayed in Figure.10, with both the mean and variation of each performance measure demonstrated. The results follow the general patterns that are observed from the heatmap. However, there is a deviation between the scenarios with $81 \mathrm{~mm}$ CL and $82 \mathrm{~mm}$ CL minimum harvest size. While achieving a similar Min-SSB-FL and Fin-SSB, scenarios with $81 \mathrm{~mm}$ CL minimum harvest size yield a significant smaller amount of Florida landing and result in the lowest L-Meta. On the basis of the results above, I select 3 management scenarios including 76 mm CL minimum harvest size five months closed season, 82mm CL minimum harvest size four months closed season, and 86mm CL minimum harvest size with 3.5 months closed season as the finalists to compare with the current management strategy on the six performance measures.

The comparison of four management scenarios listed above suggest that no proposed management scenario performed better than the current one on all six performance measures. Management scenarios with $82 \mathrm{~mm}$ CL minimum harvest size and four months closed season, $86 \mathrm{~mm}$ CL minimum harvest size with 3.5 months closed season have achieved better performance on five out of six measures. However, these two management strategies would result in Florida landing reductions; the management scenario with a minimum harvest size of $86 \mathrm{~mm} \mathrm{CL}$ would result a $75 \%$ landing reduction, while the scenario with a minimum harvest size of $82 \mathrm{~mm}$ CL would lead to a $25 \%$ landing reduction. 


\section{Discussion}

The highly migratory larvae stage of the Caribbean spiny lobster has led to high levels of connectivity among sub-stocks in the Caribbean region. The unclear spatial structure among the stocks has been an issue for the $P$. argus stock assessment and management. Therefore, the objectives of my study are 1) to investigate the spatial structure among $P$. argus sub-stocks in the Caribbean using biophysical modeling, 2) to understand how spatial structure impacts stock assessment, and 3) to evaluate the management strategies under the meta-population framework.

\section{Connectivity}

The connectivity result of my study reveals that Florida $P$. argus stock received the majority of recruitment from other Caribbean stocks in 2014. It is consistent with that of previous biophysical modeling (Kough et al. 2013), stable isotope analysis (Yao and Zhang 2018) and genetic markers (Yao et al. under review). In my studies, neither the proportion of self-recruitment has exceeded $50 \%$. This result agrees with the assertion of Kough et al. (2013) that Florida stock receives more recruits from outside their boundaries. In contrast to their study, my study suggests different combinations and proportions of source populations for the Florida stock. First, self-recruitment estimated from our results occupys a $15 \%$ larger proportion of total recruitment. In addition, among the 9 top source populations identified in their study, only 5 of them are identical to the results of our study. One possible explanation for the discrepancy between the results of these two biophysical modeling studies may be the change on the ocean circulation. Since the ability to swim is not fully developed in the phyllosoma larvae, the fluctuations of 
currents could significantly impact the larval dispersal. Therefore, the possible shift on the currents could be the responsible for the difference on the compositions of source populations.

Among the three methods that have been used to understand the connectivity in my dissertation, biophysical modeling has led to the most refined results, and is able to identify source populations. Meanwhile, due to the lack of information from source populations, stable isotope analysis and genetic markers could only identify clusters from recruits. The isotopic and genetic signals from potential source populations are necessary to link Florida stock recruits back to their source populations. Therefore, collecting these pieces of information should be recommended for future research. Furthermore, biophysical model has suggested that the number of source populations for the Florida stock is twice as much as the numbers of clusters identified by the stable isotope analysis and genetic markers. It indicates that multiple sub-stocks in the Caribbean region might carry similar genetic or stable isotopic signals. In addition, results from stable isotope analysis and genetic markers could be used to validate results of the biophysical modeling. The comparison among these three methods provides insight into the method selections, especially for the study area where the environment has led to a high homogeneous condition.

\section{Stock assessment bias estimation}

Previous simulation studies have stated that ignoring the spatial structure among substocks in the stock assessment can significantly impact the estimations of fishing 
mortality (F), stock size and recruitment (R) (Punt and Butterworth 1995; Porch et al. 2001; Hart and Cadrin 2004; Guan et al. 2013) and further hinder the accuracy of the stock assessment. Our study has further supported this statement. In addition, previous simulation studies also point out that the results of the stock assessment with spatial structure would lead to more reform results than treating each sub-stock isolated (Punt and Restrepo 1995; Porch et al. 1998). This dependence is mainly due to the misspecification of the SSB. Therefore, we would expect a higher bias from the stock assessment with independent-population spatial assumption on a sub-stock with high levels of connectivity (e.g. Florida) than low levels of connectivity (e.g. Bahamas and Cuba). Furthermore, the stock assessment under meta-population framework is considered highly dependent on levels of connectivity among the stocks (Curitis and Naujokaitis-Lewis 2008; Ying et al. 2014). Therefore, testing the sensitivity of the stock assessment on different levels of connectivity is also recommended to evaluate the uncertainty of the stock assessment under the meta-population framework.

In my study, the estimated recruitment from the stock assessment model where the spatial structure was ignored shows notable bias. It indicates that estimating the S-R relationship under the "independent population" model is inappropriate for the Florida stock. It is consistent with the conclusion from SEDAR 2010 that the S-R relationship is not well determined for the Florida stock. Meanwhile, recruitment estimated from the stock assessment with the "correct" spatial structure, is close to the "true" value. Based on these results, integrating a meta-population framework could be a promising method to further our knowledge on the S-R relationship of P. argus stocks in the Caribbean. 
Furthermore, the life stage at which density-dependent compensation occurs is crucial to the results obtained from stock assessments under the meta-population framework (Ralston and O'Farrell 2008). Therefore, testing the uncertainty of the stock assessment on where density-dependent compensation occurs should be also included in the analysis.

\section{Management strategies evaluation}

A total number of 337 management scenarios are tested in this project. Six performance measures are selected to evaluate each management scenario. Overall, the results of different management scenarios follow a general trend: values of landing-related performance measures (L-FL, L-Meta and LV-FL) decrease as the minimum harvest size and the length of closed season increase. Meanwhile, values of SSB-related performance measures (Min-SSB-FL, Fin-SSB-FL and Fin-SSB-Meta) increase as the minimum harvest size and the length of the closed season increase. The management scenarios with female protections overall perform better in both SSB- and landing-related performance measures. The comparison of the selected optimal scenarios (Fig.10) has revealed that management scenarios with a minimum harvest size below $82 \mathrm{~mm}$ CL would likely lead to the collapse of Colombia sub-stock. It demonstrates the importance of applying MSE on a fine scale when testing management scenarios. Then, three management scenarios are selected to compared with the current Florida $P$. argus management. The results of the comparison suggest that the current management tends to maximize Florida commercial landing but might lead to a reduction on the SSB of the Florida stock (Fig. 11). Since it has been suggested that the $P$. argus stocks in the Caribbean are either fullyor over-exploited (Chavez 2009), the current strategy could put the Florida stock in the 
risk of depletion. It also suggests that no scenario achieves better performance on all 6 performances measures than the current management. Therefore, the trade-off among management objectives have to be considered during the management strategy selection. Afterward, 2 management strategies perform better than the current management at 5 out of 6 performance measures. Among these two scenarios, the strategies with a minimum harvest size of $86 \mathrm{~mm}$ CL would lead to a potential $50 \%$ reduction in the total L-FL. Due to the importance of $P$. argus fisheries to the economy in the regions (Heileman 2007), it is unrealistic to reduce such a high value fishery to $50 \%$ of the current L-FL. Therefore, management strategies of a minimum harvest size of $82 \mathrm{~mm} \mathrm{CL}$ with 5 months of closed fishing season may be a better strategy, although this scenario would still result in a $25 \%$ reduction of the L-FL.

\section{Implication for management}

Currently, $P$. argus stocks in the Caribbean are managed independently by their countries. Management strategies were created based on the assumption that local recruitment receives contribution exclusively from local spawning stock. Nonetheless, this assumption might not reflect the life history of $P$. argus. My study has put the effectiveness of management strategies based on this assumption into question. The results indicate that management of other stocks in the Caribbean could potentially influence the status of the Florida stock and vice versa. Therefore, an international comanagement would be more appropriate to optimize the benefit for each country. 
All of stocks in the Caribbean protect females with eggs from harvesting. Based on our results, this protection is necessary to maintain a healthy stock, as well as to potentially maximize landings. Removing this female protection would lead to the collapse of the stocks (e.g. Colombia). Our study also suggests that increasing the minimum harvest size from $76 \mathrm{~mm}$ CL to $82 \mathrm{~mm}$ CL could significantly increase Min-SSB-FL, Fin-SSB-FL and Fin-SSB-Meta. It could also increase L-Meta, although the trade-off of this scenario is the $25 \%$ reduction in L-FL. Moreover, our study only focused on the Florida stock, and assumes a unified management among Caribbean stocks. Future MSE studies could be done on different target stock or stocks and allowing flexibility in the management of each stock to achieve different objectives.

Several previous studies have also shown the risks of ignoring spatial structure of the meta-population in fishery management (Frank and Brickman 2000); this includes the Atlantic cod, Atlantic herring and Alaska red king crab (Hutchings 1996; 2000; Stephenson 1999; Wooster 1992). The Caribbean Sea has one of the most complex current systems in the world. It has led to high levels of connectivity among the stocks for highly migratory species. Based on the life history, developing international comanagement will not only benefit the $P$. argus fishery, but any fishery of migratory species (e.g. red snappers). Furthermore, each country in the Caribbean has its own objectives of fishery. This has added difficulties in the management all the stocks as a whole. Therefore, MSE should be used to select the managements that balance the benefit of each country. 


\section{Conclusion}

My study integrates the simulations with connectivity to understand the impacts of spatial structure on the stock assessment and management. Our results indicate that the Caribbean $P$. argus stocks were demographically open. In addition to the selfrecruitment, approximately 9 source populations in the Caribbean have contributed to the Florida stock in 2014. My results also suggest that the particular combination of source populations might change based on currents. Furthermore, because spatial structure exists among Caribbean P. argus stocks in the Caribbean, stock assessment without accounting connectivity could result in significant bias and impact the effectiveness of the management. The results of MSE of my study also suggest that the current management of Florida $P$. argus fishery is more focused on the landing than maintaining SSB. Based on the fact that most $P$. argus stocks in the Caribbean were either fully- or overexploited, I recommend to improve the current management by increasing the size limit to $82 \mathrm{~mm} \mathrm{CL}$ and keeping the same length for the closed season. Furthermore, an international fisheries co-management could be highly beneficial for this species.

\section{Acknowledgements}

We acknowledge B Hunting for the proofreading. We also acknowledge $\mathrm{J}$ Trelxer for his input. This study was mainly funded by FIU and Florida Sea Grant College Program (R/LR-B-69 and R/LR-B-74). This is contribution \#X of the Marine Education and Research Center of the Institute for Water and the Environment at FIU. 


\section{Literature Cited}

Artzy-Randrup, Y., and Stone, L. 2010. Connectivity, Cycles, and Persistence Thresholds in Metapopulation Networks. PLoS Comput. Biol. 6: e1000876.

Butterworth, D.S. 2007. Why a management procedure approach? Some positives and negatives. ICES J. Mar. Sci. 64: 613-617.

Chavez, E.A. 2009. Socio-economic assessment for the management of the Caribbean spiny lobster. Proc Gulf Carib Fish Inst. 60: 193-196.

Dichmont, C.M., Ellis, N., Bustamante, R.H., Deng, R., Tickell, S., Pascual, R., Lozano-Montes, H., and Griffiths, S. 2013. EDITOR'S CHOICE: evaluating marine spatial closures with conflicting fisheries and conservation objectives. J. Appl. Ecol. 50(4): 1060-1070.

FAO. 2001. Report on the FAO/DANIDA/CFRAMP/WECAFC Regional Workshops on the Assessment of the Caribbean Spiny Lobster (Panulirus argus). Roma.

Frank, K.T., and Brickman, D. 2000. Allee effects and compensatory population dynamics within a stock complex. Can. J. Fish. Aquat. Sci. 57(3): 513-517.

Fromentin, J.M., and Powers, J.E. 2005. Atlantic bluefin tuna: population dynamics, ecology, fisheries and management. Fish and Fish. 6: 281-298.

Goldstein, J.S., Matsuda, H., Takenouchi, T., and Butler, M.J. 2008. The complete development of larval Caribbean spiny lobster Panulirus argus (Latreille, 1804) in culture. J. Crust. Biol. 28(2): 306-327.

Gotelli, N.J. 2008. A primer of ecology. 4th ed. Sunderland: Sinauer Associates.

Guan, W., Cao, J., Chen, Y., and Cieri, M. 2013. Impacts of population and fishery spatial structures on fishery stock assessment. Can. J. Fish. Aquat. Sci. 70(8): 1178-1189.

Hart, D.R., and Cadrin, S.X. 2004. Yellowtail flounder (Limanda ferruginea) off the Northeastern United States: implications of movement among stocks. Applications in RSMAS. Pp 230-243. Oxford University Press, N.Y.

Hastings, A. 1991. Structured models of metapopulation dynamics. Metapopulation Dynamics pp. 57-71. Academic Press, London.

Heileman, S., 2007, February. Thematic report for the insular Caribbean sub-region. In: The CLME Synthesis Workshop. pp53. 
Holland, D.S. 2010. Management Strategy Evaluation and Management Procedures: Tools for Rebuilding and Sustaining Fisheries, OECD Food, Agriculture and Fisheries Working Papers, No. 25, OECD Publishing. doi: $10.1787 / 5 \mathrm{kmd} 77$ jhvkjf-en.

Holland, D.S. 2003. Integrating spatial management measures into traditional fishery management systems: The case of the Georges Bank multispecies groundfish fishery. ICES J. Mar. Sci. 60: 915-929.

Hollowed, A.B., and Wooster, W.S. 1992. Variability of winter ocean conditions and strong year classes of Northeast Pacific groundfish. In ICES Mar. Sci. Symp. 195: $433-444$.

Hutchings, J.A. 2000. Collapse and recovery of marine fishes. Nature. 406(6798): 882.

King, M. 2007. Fisheries Management, in Fisheries Biology, Assessment and Management, Second Edition, Blackwell Publishing Ltd., Oxford, UK.

Kough, A.S., Paris, C.B., and Butler, M.J. 2013. Larval Connectivity and the International Management of Fisheries. PloS one, 8, e64970.

Kritzer, J.P., and Sale, P.F. 2004. Metapopulation ecology in the sea: from Levins' model to marine ecology and fisheries science. Fish and Fish. 5(2): 131-140.

Lande, R. 1987. Extinction thresholds in demographic models of territorial populations. Amer. Nat. 130: 624-635.

Naujokaitis-Lewis, I.R., Curtis, J.M., Arcese, P., and Rosenfeld, J. 2009. Sensitivity analyses of spatial population viability analysis models for species at risk and habitat conservation planning. Conserv. Biol. 23(1): 225-229.

Plagányi, É.E., Skewes, T.D., Dowling, N.A., and Haddon, M. 2013. Risk management tools for sustainable fisheries management under changing climate: a sea cucumber example. Clim. Change. 119(1): 181-197.

Pope, J. 2002. Input and output controls: the practice of fishing effort and catch management in responsible fisheries. A Fishery Manager's Guidebook: Management Measures and Their Application. p.75.

Porch, C.E, Kleiber, P., Turner, S., Sibert, J., Bailey, R., and Cort, J. L. 1998. The efficacy of VPA models in the presence of complicated movement patterns. Col. Vol. Sci. Pap. ICCAT. 50: 591-622.

Porch, C.E., Turner, S.C., and Powers, J.E. 2001. Virtual population analyses of Atlantic bluefin tuna with alternative models of transatlantic migration: 1970-1997. Col. Vol. Sci. Pap. ICCAT. 52(3): 1022-1045. 
Punt, A.E., and Hobday, A. 2009. Management strategy evaluation for rock lobster, Jasis edwardsii, off Victoria, Australia: accounting for uncertainty in stock structure. New Zeal j Mar Fresh. 43: 485-509.

Punt, A.E., and Butterworth, D.S. 1995. The effects of future consumption by the Cape fur seal on catches and catch rates of the Cape hakes. 4. Modelling the biological interaction between Cape fur seals Arctocephalus pusillus pusillus and the Cape hakes Merluccius capensis and M. paradoxus. Afr. J. Mar. Sci. 16(1): 255-285.

Punt, A.E., and Restrepo, V.R. 1995. Some effects of ignoring mixing when managing fish populations subject to limited mixing. ICES Long-term Management Measures Working Group WP1.

Punt, A.E., Butterworth, D.S., de Moor, C.L., De Oliveira, J.A., and Haddon, M. 2016. Management strategy evaluation: best practices. Fish and Fish. 17(2): 303-334.

Quinn, T.J., and Deriso, R.B. 1999. Quantitative Fish Dynamics. Oxford University Press, N. Y. pp. 542.

Ralston, S., and O'Farrell, M.R. 2008. Spatial variation in fishing intensity and its effect on yield. Can. J. Fish. Aquat. Sci. 65(4): 588-599.

Secor, D.H., Rooker, J.R., Zlokovitz, E., and Zdanowicz, V. 2001. Identification of riverine, estuarine, and coastal contingents of Hudson River striped bass based upon otolith elemental fingerprints. Mar. Ecol. Prog. Ser. 211: 245-253.

SouthEast Data, Assessment, and Review (SEDAR). 2010. Updated spiny lobster stock assessment 2010. Key West, FL.

Stelzenmüller, V., Rogers, S.I., and Mills, C.M. 2008. Spatio-temporal patterns of fishing pressure on UK marine landscapes, and their implications for spatial planning and management. ICES J. Mar. Sci. 65: 1081-1091.

Stephenson, R. L. 1999. Stock complexity in fisheries management: a perspective of emerging issues related to population sub-units. Fish. Res. 43: 247-249.

Truelove, N.K., Kough, A.S., Behringer, D.C., Paris, C.B., Box, S.J., Preziosi, R.F., and Butler IV, M.J. 2017. Biophysical connectivity explains population genetic structure in a highly dispersive marine species. Coral Reefs. 36(1): 233-244.

Waples, R.S., and Gaggiotti, O. 2006. What is a population? Mol. Ecol. 15: 1419-1439.

Yao, N., Zhang Y. 2016 Developing a size-structured stock assessment model for spiny lobster (Panulirus argus) in the Southeast United States. 68th Gulf and Caribbean Fisheries Institute Conference Proceeding. Panama City, Panama. 
Yao, N., Bracken-Grissom, H., and Y. Zhang. Recruitment dynamics of the Florida Caribbean spiny lobster (Panulirus argus) revealed by microsatellites and its implication for fishery management. Fish. Bull. (under review)

Yao, N., and Y. Zhang. 2018. Investigating temporal variation in stable carbon and nitrogen isotope values of Florida Caribbean spiny lobster Panulirus argus recruits. Bull. Mar. Sci. 94(3): 847-861.

Yeung, C., and McGowan, M.F. 1991. Differences in inshore-offshore and vertical distribution of phyllosoma larvae of Panulirus, Scyllarus and Scyllarides in the Florida Keys in May-June, 1989. Bull. Mar. Sci. 49(3): 699-714.

Ying, Y., Chen, Y., Lin, L., and Gao, T. 2011. Risks of ignoring fish population spatial structure in fisheries management. Can. J. Fish. Aquat. Sci. 68(12): 2101-2120.

Zhang, Y., and Yao, N. 2018. Developing growth transition matrices for Caribbean spiny lobster (Panulirus argus) using mark-recapture data. Mar. Coast. Fish. 10(5): 481-492. 


\section{Table Caption.}

Table 1. The input regulation of Caribbean spiny lobster fishery of stocks in the Caribbean.

Table 2. Descriptions and levels of the management regulations used for the management strategies evaluation (MSE).

Table 3. The results of RA and ABA bias between the "true" parameters and parameters estimated from stock assessment without spatial structure scenario (i) and stock assessment with the "correct" spatial structure scenario (ii).

Table 4. The results of the optimal management scenarios selected based on the 6 performance measures. 
Table 1.

\begin{tabular}{|c|c|c|c|}
\hline Stocks & $\begin{array}{l}\text { Closed Fishing } \\
\text { season }\end{array}$ & $\begin{array}{l}\text { Minimum harvest size } \\
\text { Carapace Length (CL) }\end{array}$ & $\begin{array}{c}\text { Harvest } \\
\text { Prohibition }\end{array}$ \\
\hline Florida & $\begin{array}{l}4 \text { months (1 April } \\
-31 \text { July) }\end{array}$ & 76mm CL & $\begin{array}{c}\text { Female with } \\
\text { eggs }\end{array}$ \\
\hline NE Cuba & $\begin{array}{c}3.5 \text { months (15 } \\
\text { February - } 30 \\
\text { June) }\end{array}$ & 76mm CL & $\begin{array}{c}\text { Female with } \\
\text { eggs }\end{array}$ \\
\hline Honduras & $\begin{array}{l}4 \text { months (1 March } \\
-30 \text { June) }\end{array}$ & 80mm CL & $\begin{array}{c}\text { Female with } \\
\text { eggs }\end{array}$ \\
\hline Nicaragua & $\begin{array}{l}2 \text { months (1 April } \\
-2 \text { June) }\end{array}$ & 75mm CL & $\begin{array}{c}\text { Female with } \\
\text { eggs }\end{array}$ \\
\hline Colombia & $\begin{array}{c}3 \text { months (1 April } \\
\text { to } 30 \text { June) }\end{array}$ & $82 \mathrm{~mm} \mathrm{CL}$ & $\begin{array}{c}\text { Female with } \\
\text { eggs }\end{array}$ \\
\hline Panama & $\begin{array}{l}4 \text { months (1 March } \\
\text { - } 30 \text { June) }\end{array}$ & $83 \mathrm{~mm} \mathrm{CL}$ & $\begin{array}{c}\text { Female with } \\
\text { eggs }\end{array}$ \\
\hline Jamaica & $\begin{array}{c}3 \text { months (1 April } \\
\text { to } 30 \text { June) }\end{array}$ & 76mm CL & $\begin{array}{c}\text { Female with } \\
\text { eggs }\end{array}$ \\
\hline Venezuela & $\begin{array}{l}5 \text { months (1 May } \\
\text { to } 31 \text { October) }\end{array}$ & $120 \mathrm{~mm} \mathrm{CL}$ & $\begin{array}{c}\text { Female with } \\
\text { eggs }\end{array}$ \\
\hline Mexico & $\begin{array}{c}4 \text { months (1 March } \\
\text { - } 30 \text { June) }\end{array}$ & 74mm CL & $\begin{array}{c}\text { Female with } \\
\text { eggs }\end{array}$ \\
\hline
\end{tabular}


Table 2.

\begin{tabular}{|c|c|c|}
\hline Management regulations & Ranges & No. of scenarios \\
\hline Minimum harvest size & From 72mm to $110 \mathrm{~mm}$ & 24 \\
\hline Close fishing season & From 2 to 5 months & 7 \\
\hline Harvest Prohibition & Yes/No & 2 \\
\hline
\end{tabular}


Table 3.

\begin{tabular}{|c|c|c|c|}
\hline Parameters & Bias Type & Scenario (i) & Scenario (ii) \\
\hline \multirow{2}{*}{ Fishing Mortality } & RA & 2.201 & 0.124 \\
\cline { 2 - 4 } & ABA & 2.201 & -0.121 \\
\hline Spawning Stock & RA & 0.673 & 0.123 \\
\cline { 2 - 4 } Biomass & ABA & -0.673 & 0.122 \\
\hline \multirow{2}{*}{ Recruitment } & RA & 0.211 & 0.007 \\
\cline { 2 - 4 } & ABA & 0.211 & 0.007 \\
\hline
\end{tabular}


Table 4.

\begin{tabular}{|c|c|c|c|}
\hline Objectives & $\begin{array}{l}\text { Minimum harvest size } \\
\text { Carapace Length (CL) }\end{array}$ & $\begin{array}{l}\text { Closed } \\
\text { Fishing } \\
\text { Season }\end{array}$ & $\begin{array}{c}\text { Harvest } \\
\text { Prohibition }\end{array}$ \\
\hline $\begin{array}{l}\text { Minimum SSB of the } \\
\text { Florida stock (Min-SSB- } \\
\text { FL) }\end{array}$ & $\begin{array}{c}76 \mathrm{~mm}, 81 \mathrm{~mm}, 82 \mathrm{~mm}, \\
86 \mathrm{~mm}\end{array}$ & & Yes \\
\hline $\begin{array}{c}\text { Final year SSB of the } \\
\text { Florida stock (Fin-SSB- } \\
\text { FL) }\end{array}$ & $76 \mathrm{~mm}, 86 \mathrm{~mm}, 96 \mathrm{~mm}$ & & Yes \\
\hline $\begin{array}{l}\text { Commercial landing of } \\
\text { the Florida stock (L-FL) }\end{array}$ & $\begin{array}{c}76 \mathrm{~mm}, 81 \mathrm{~mm}, \\
82 \mathrm{~mm}, 86 \mathrm{~mm}, 96 \mathrm{~mm}\end{array}$ & & Yes \\
\hline $\begin{array}{l}\text { Landing variation of the } \\
\text { Florida stock (FL-FL) }\end{array}$ & $\begin{array}{l}\text { 76mm CL, } 81 \mathrm{~mm} \mathrm{CL}, \\
82 \mathrm{~mm} \mathrm{CL} \text { and } 96 \mathrm{~mm}\end{array}$ & & Yes \\
\hline $\begin{array}{l}\text { Final year SSB of the } \\
\text { metapopulation (Fin- } \\
\text { SSB-Meta) }\end{array}$ & $76 \mathrm{~mm}, 81 \mathrm{~mm}, 94 \mathrm{~mm}$ & $4,4.5$ & Yes \\
\hline $\begin{array}{l}\text { Commercial landing of } \\
\text { the metapopulation (L- } \\
\text { Meta) }\end{array}$ & $82 \mathrm{~mm}-94 \mathrm{~mm}$ & & Yes \\
\hline
\end{tabular}




\section{Figure Caption.}

Figure 1. Results of Florida recruitment composition of 2014 derived from the results of biophysical modeling. A. Dry Season. B. Wet Season.

Figure 2. The map of sub-stocks in the Caribbean that are included in the metapopulation framework.

Figure 3. The value of "true" parameters and results of parameters estimated from the stock assessment ignores the spatial structure (i) and the stock assessment model specifics the "correct" spatial structure (ii). (A. Fishing mortality. B. Spawning stock biomass)

Figure 4. The results of minimum spawning stock biomass (SSB) of the Florida stock (Min-SSB-FL) from management scenarios with different minimum-size limit (X-axis) and lengths of closedd season (Y-axis) under metapopulation framework under metapopulation framework. A. heatmap of the management scenarios with female conservation. B. heatmap of the management scenarios without female conservation. The result values are color-coded (blue $=$ low value, red $=$ high value).

Figure 5. The results of final year spawning stock biomass (SSB) of the Florida stock (Fin-SSB-FL) from management scenarios with different minimum-size limit (X-axis) and lengths of closed season (Y-axis) under metapopulation framework. A. heatmap of the management scenarios with conservation. B. heatmap of the management scenarios without conservation. The result values are color-coded (blue $=$ low value, red $=$ high value).

Figure 6. The results of commercial landing of the Florida stock (L-FL) from management scenarios with different minimum-size limit (X-axis) and lengths of closed season (Y-axis) under metapopulation framework. A. heatmap of the management scenarios with conservation. B. heatmap of the management scenarios without conservation. The result values are color-coded (blue $=$ low value, red $=$ high value).

Figure 7. The results of commercial landing variation of the Florida stock (LV-FL) from management scenarios with different minimum-size limit (X-axis) and lengths of closed season (Y-axis) under metapopulation framework. A. heatmap of the management scenarios with conservation. B. heatmap of the management scenarios without conservation. The result values are color-coded (blue $=$ low value, red $=$ high value).

Figure 8. The results of final year spawning stock biomass (SSB) of the metapopulation (Fin-SSB-Meta) from management scenarios with different minimum-size limit (X-axis) and lengths of closed season (Y-axis) under metapopulation framework. A. heatmap of the management scenarios with conservation. B. heatmap of the management scenarios without conservation. The result values are color-coded (blue $=$ low value, red $=$ high value). 
Figure 9. The results of commercial landing of the metapopulation (L-Meta) from management scenarios with different minimum-size limit (X-axis) and lengths of closed season (Y-axis) under metapopulation framework. A. heatmap of the management scenarios with conservation. B. heatmap of the management scenarios without conservation. The result values are color-coded (blue $=$ low value, red $=$ high value).

Figure 10. The comparisons of the selected optimal management scenarios (minimumsize limit $76 \mathrm{~mm}$ CL, $81 \mathrm{~mm}$ CL, 82mm CL and 96mm CL) mean $\pm \mathrm{sd}$. A. Minimum spawning stock biomass (SSB) of the Florida stock (Min-SSB-FL). B. Final spawning stock biomass (SSB) of the Florida stock (Fin-SSB-FL). C. Total Florida commercial landing (L-FL). D. Landing variation of the Florida stock (LV-FL). E. Final year spawning stock biomass (SSB) of the metapopulation (Fin-SSB-Meta). F. Total commercial landing of the metapopulation (L-Meta).

Figure 11. The comparisons of the selected optimal management scenarios (minimumharvest size 76mm CL and 4.5 months closed fishing season, 82mm CL with 4 month closed fishing season and 96mm CL with 3.5 months closed fishing season) and the current management. The gradient is based on the minimum and the maximum values in each performance measures. 
Figure 1.

A 2014 Dry Season Recruitment

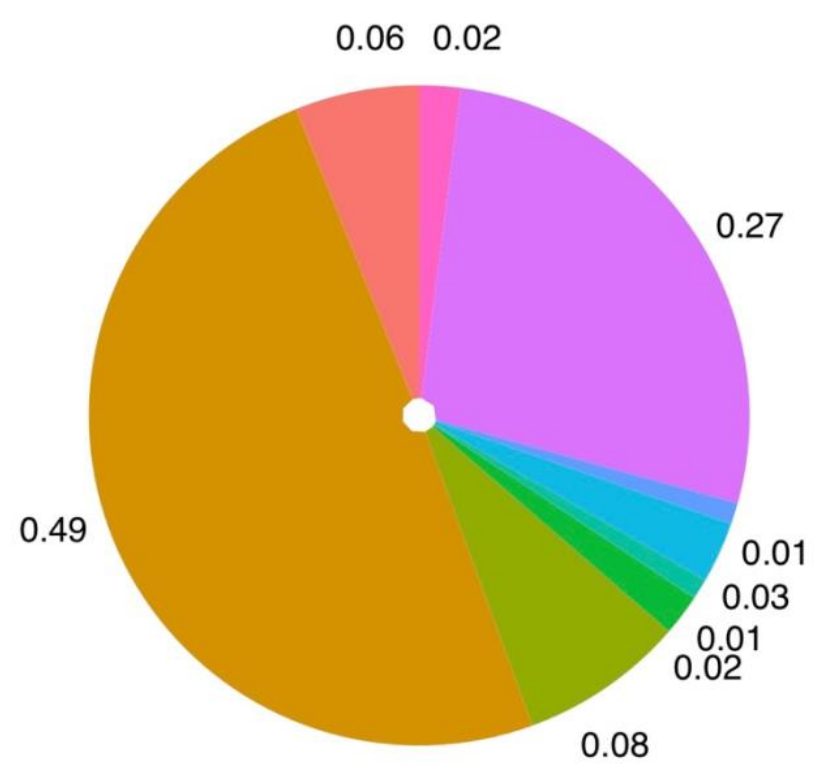

Columbia

Florida

Honduras

Jamaica

Mexico

Nicaragua

Panama

Venezuela

West.Islands

2014 Wet Season Recruitment

B

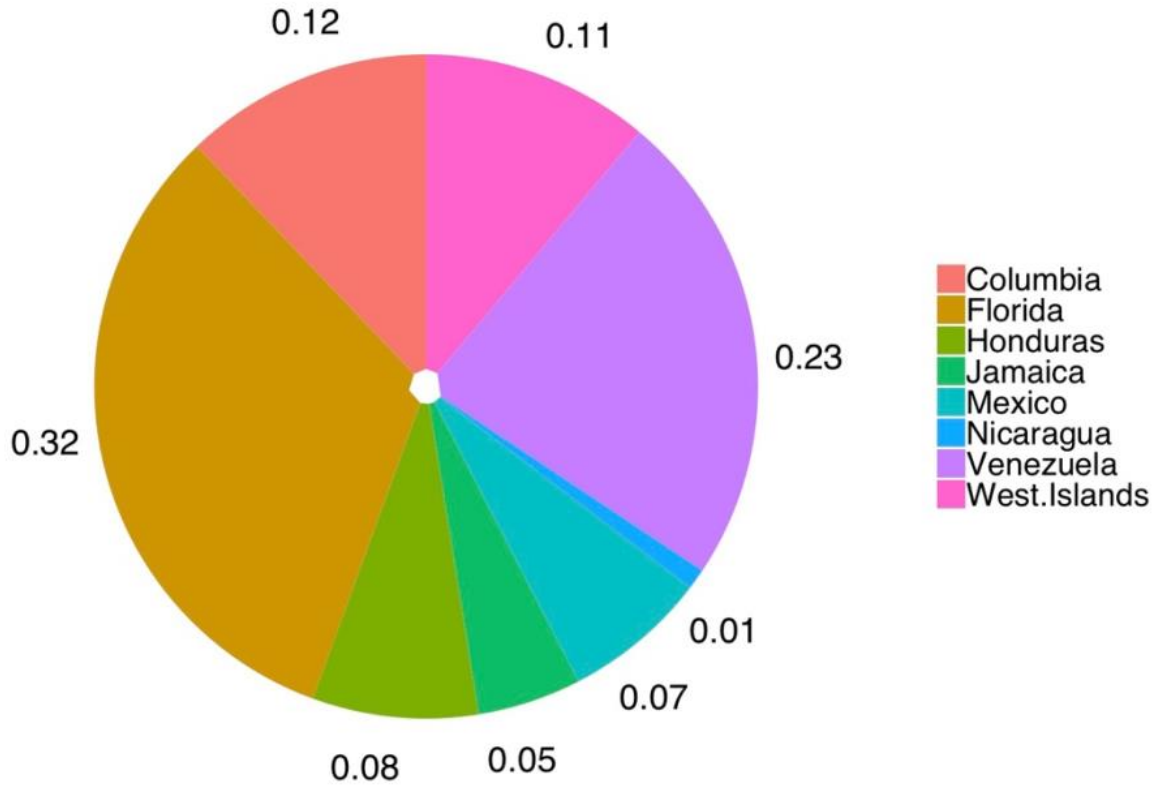


Figure 2.

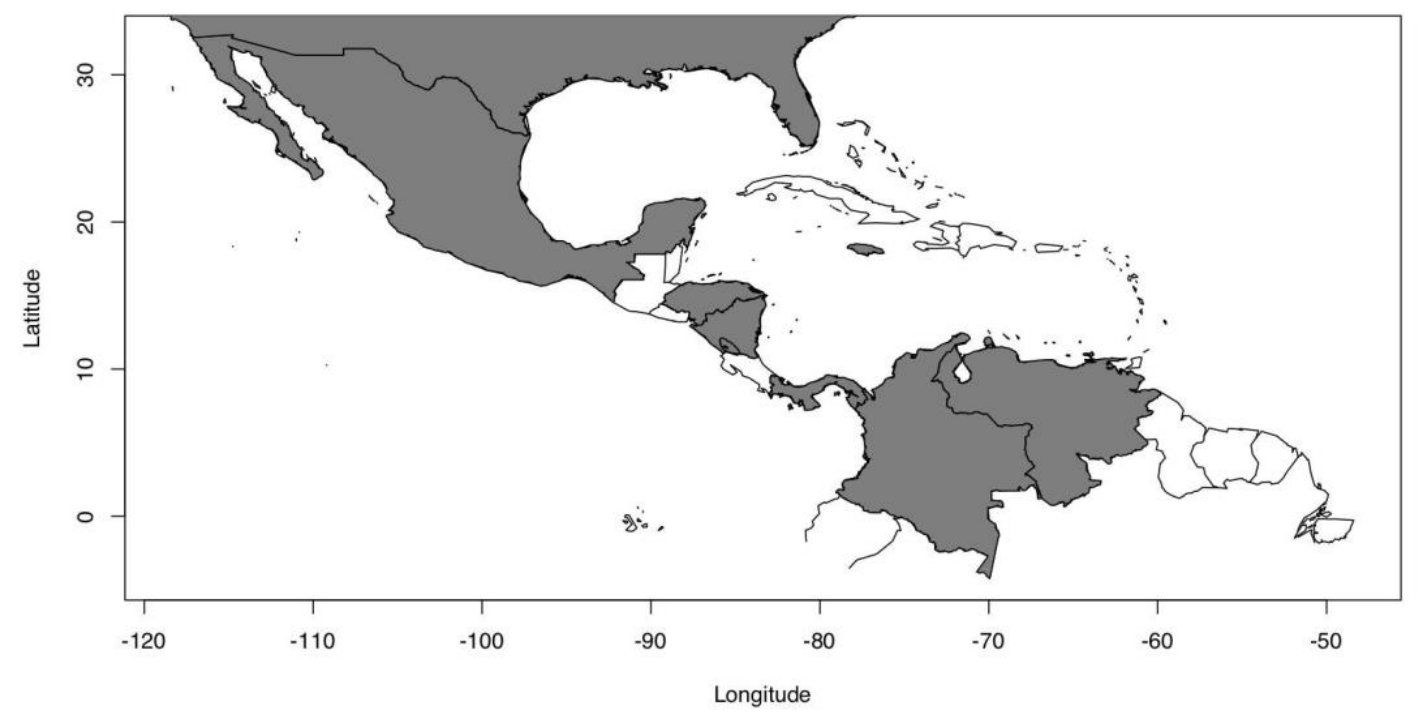


Figure 3.
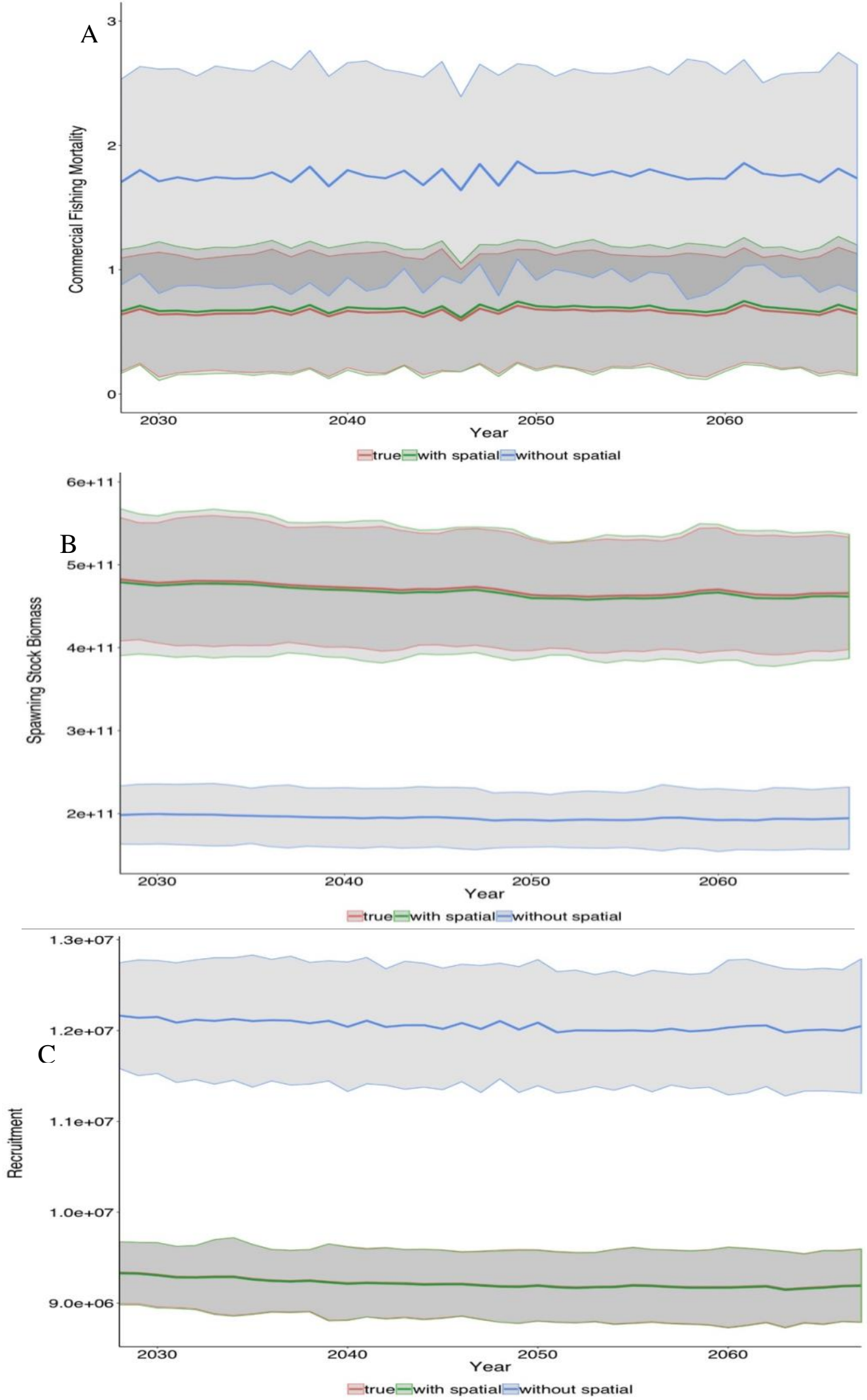
Figure 4.
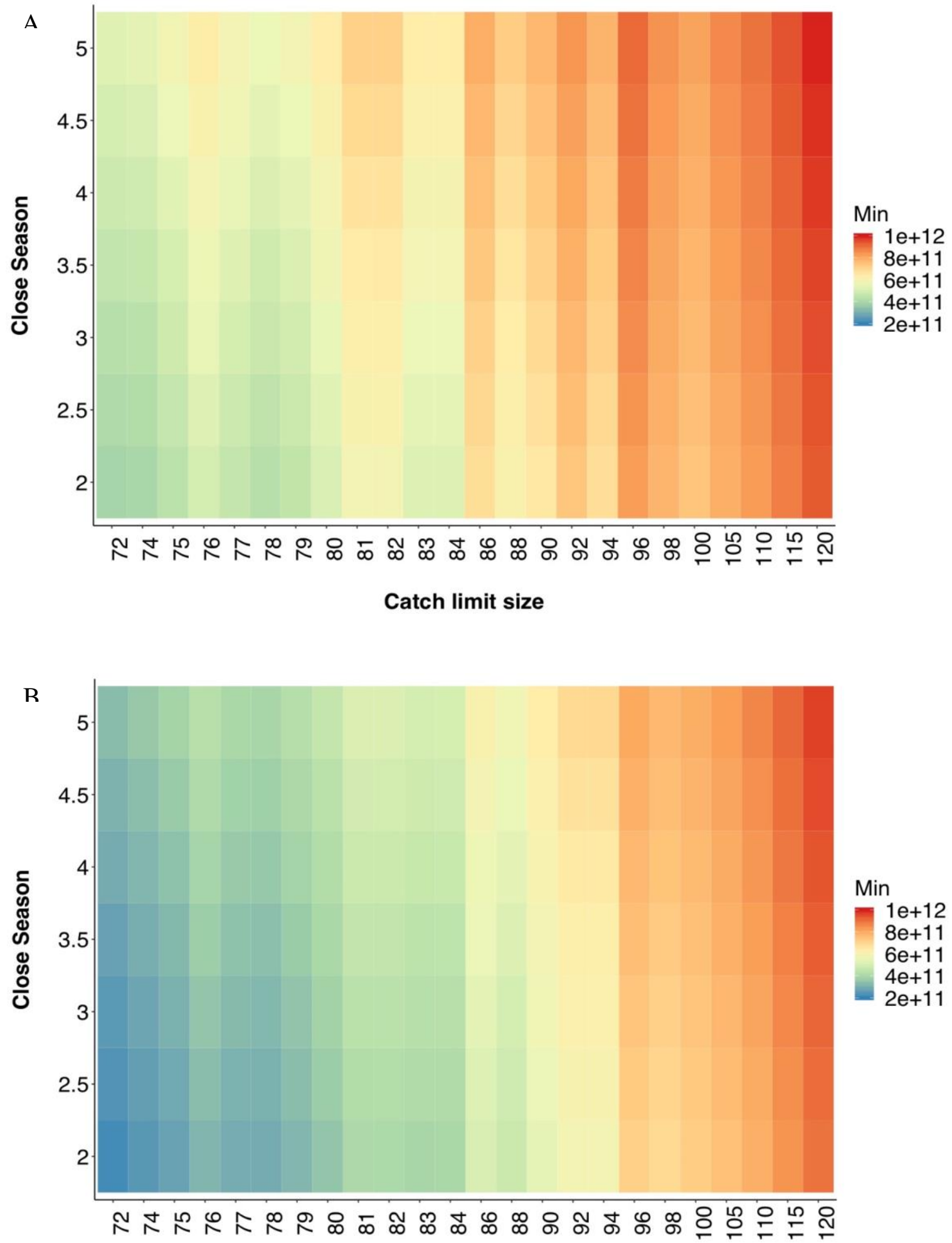

Catch limit size 
Figure 5.

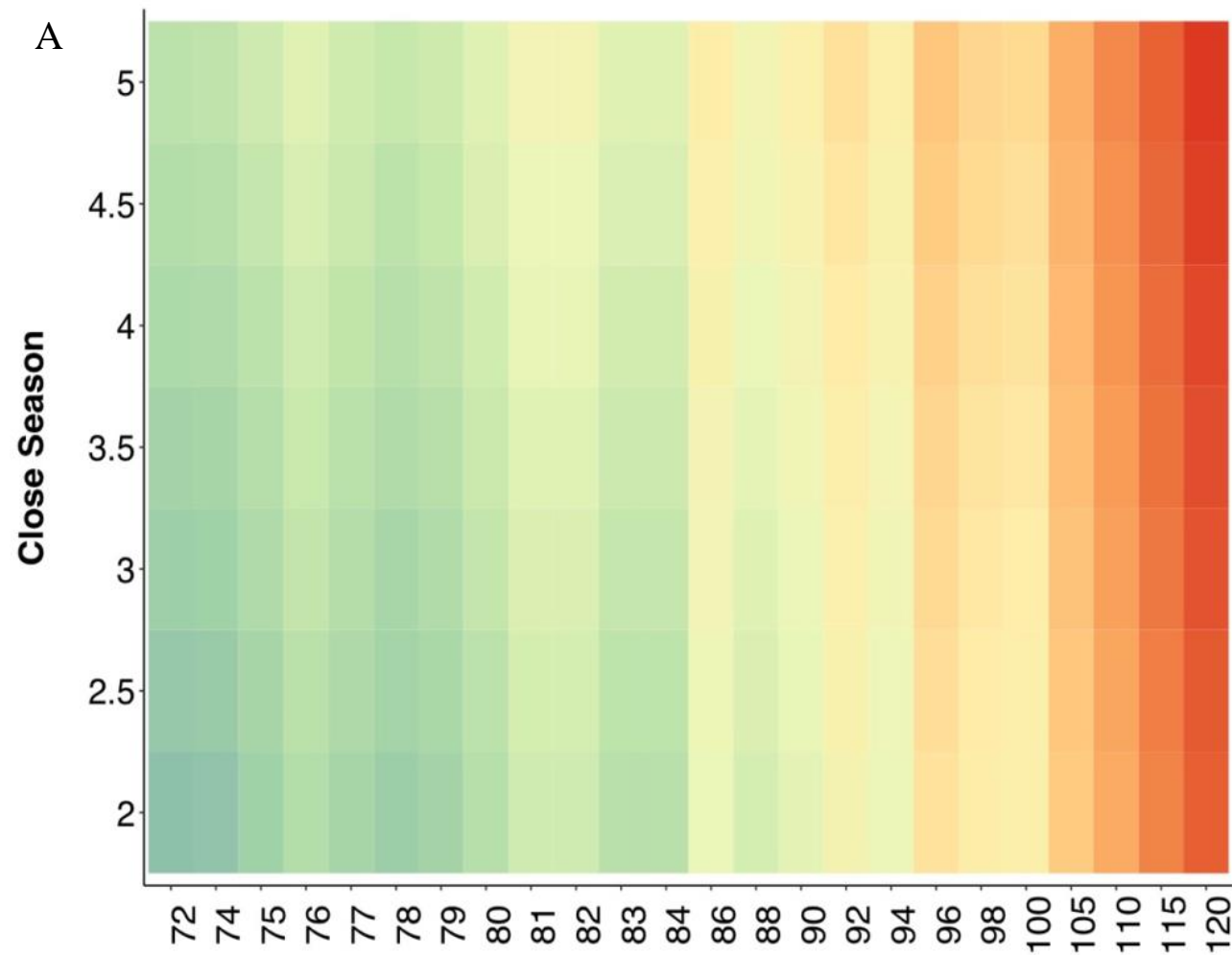

Final

$1.25 \mathrm{e}+12$

$1.00 \mathrm{e}+12$

$7.50 \mathrm{e}+11$

$5.00 \mathrm{e}+11$

$2.50 \mathrm{e}+11$

\section{Catch limit size}

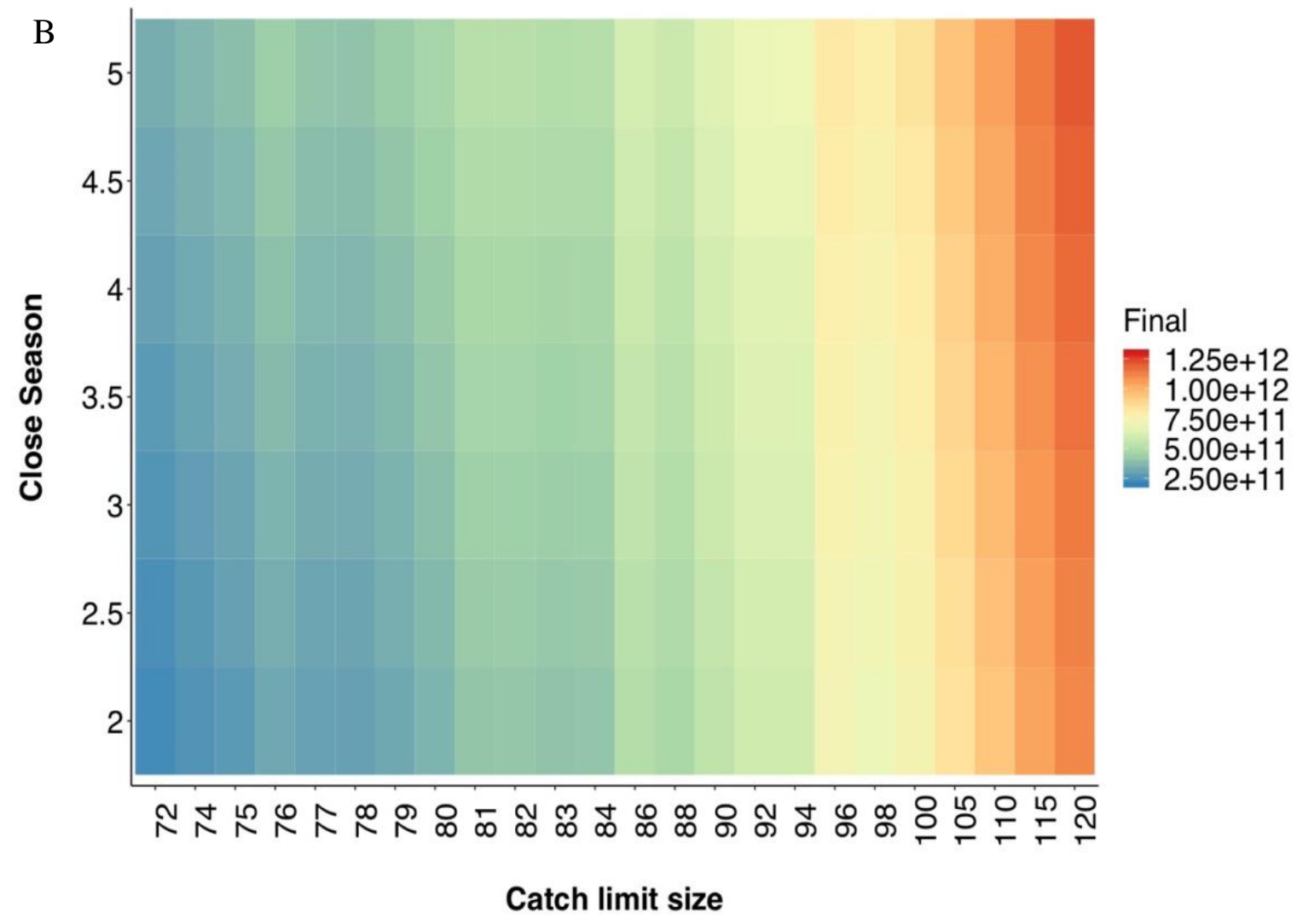


Figure 6.
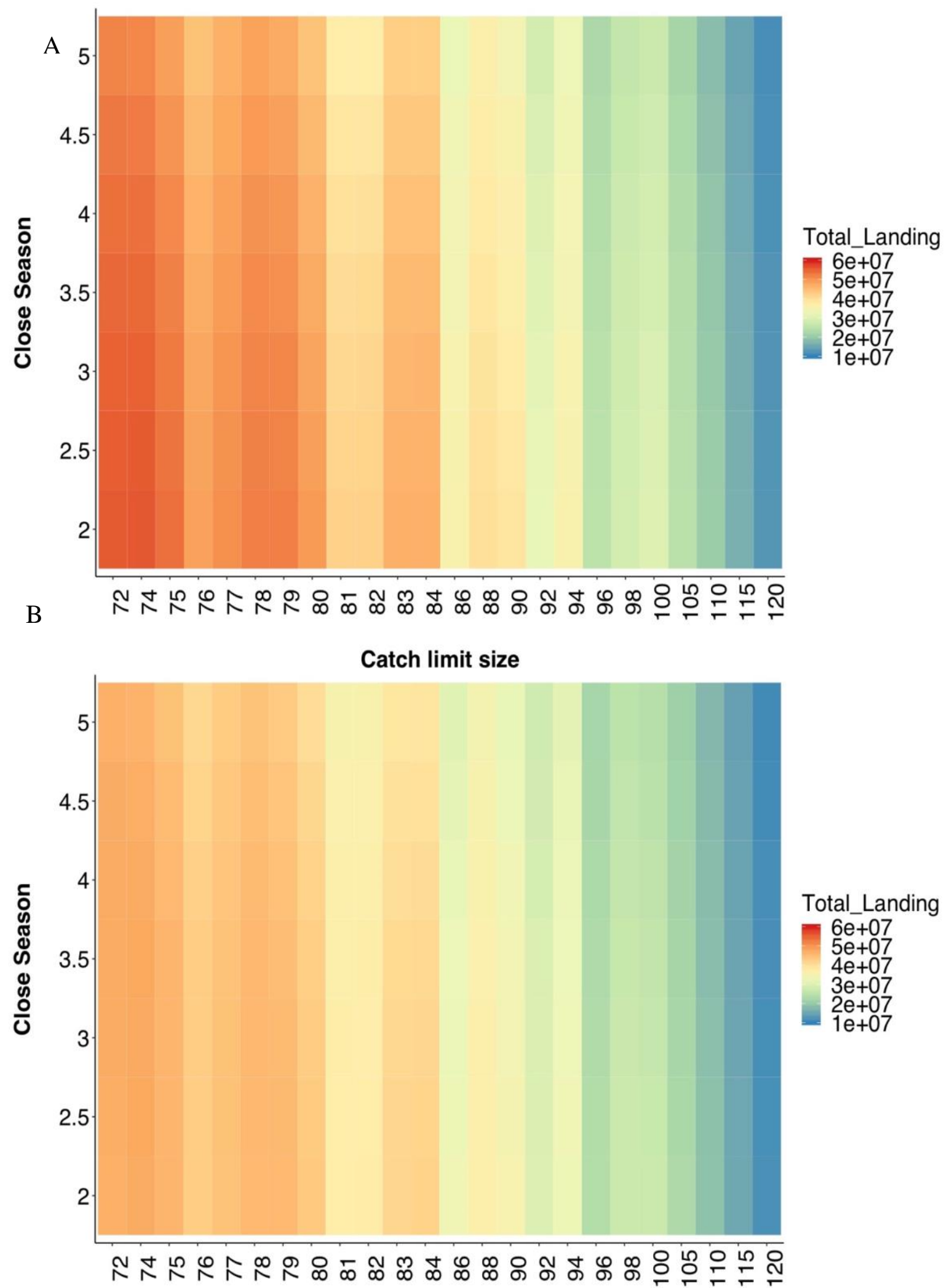

Catch limit size 
Figure. 7.

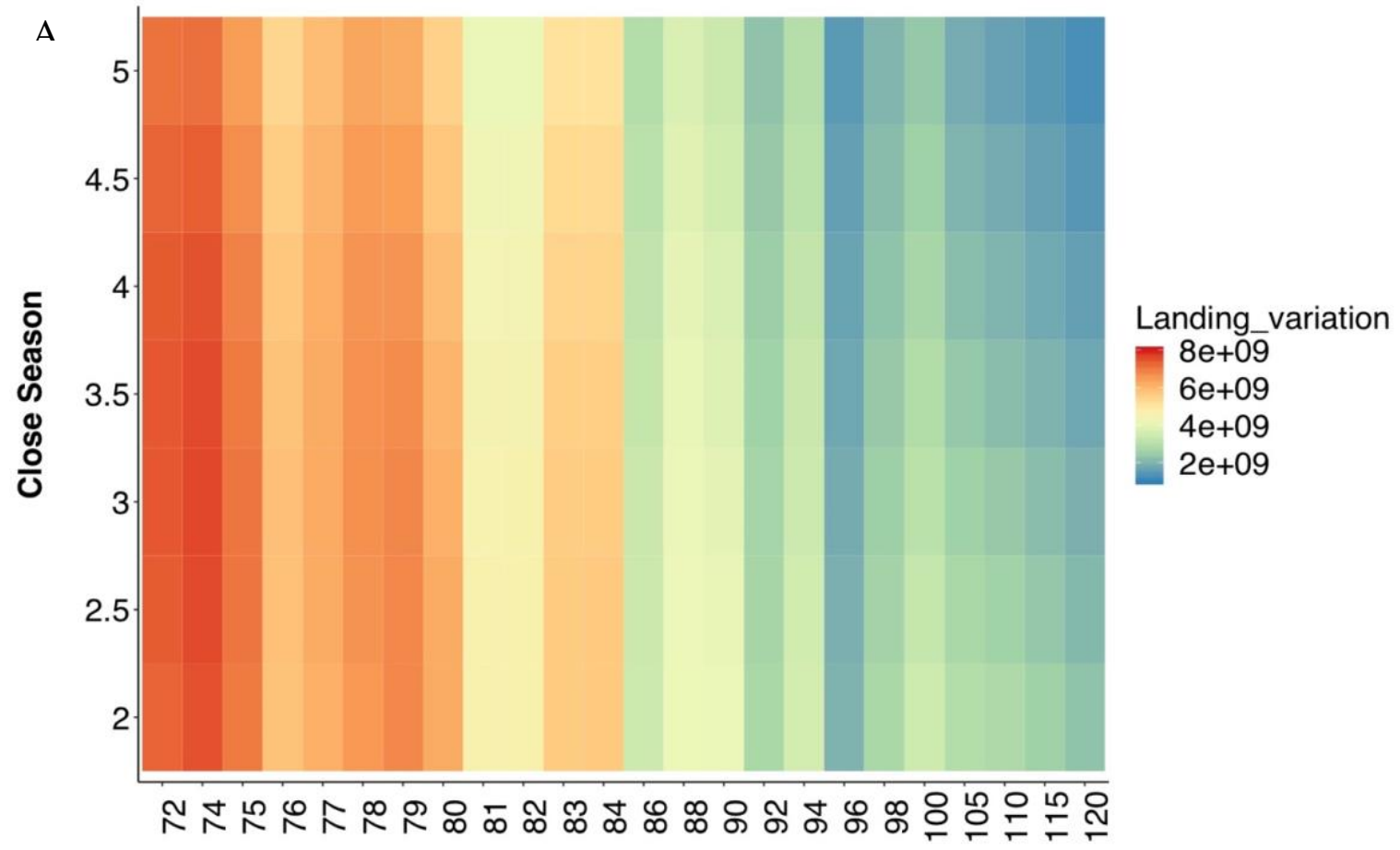

Catch limit size

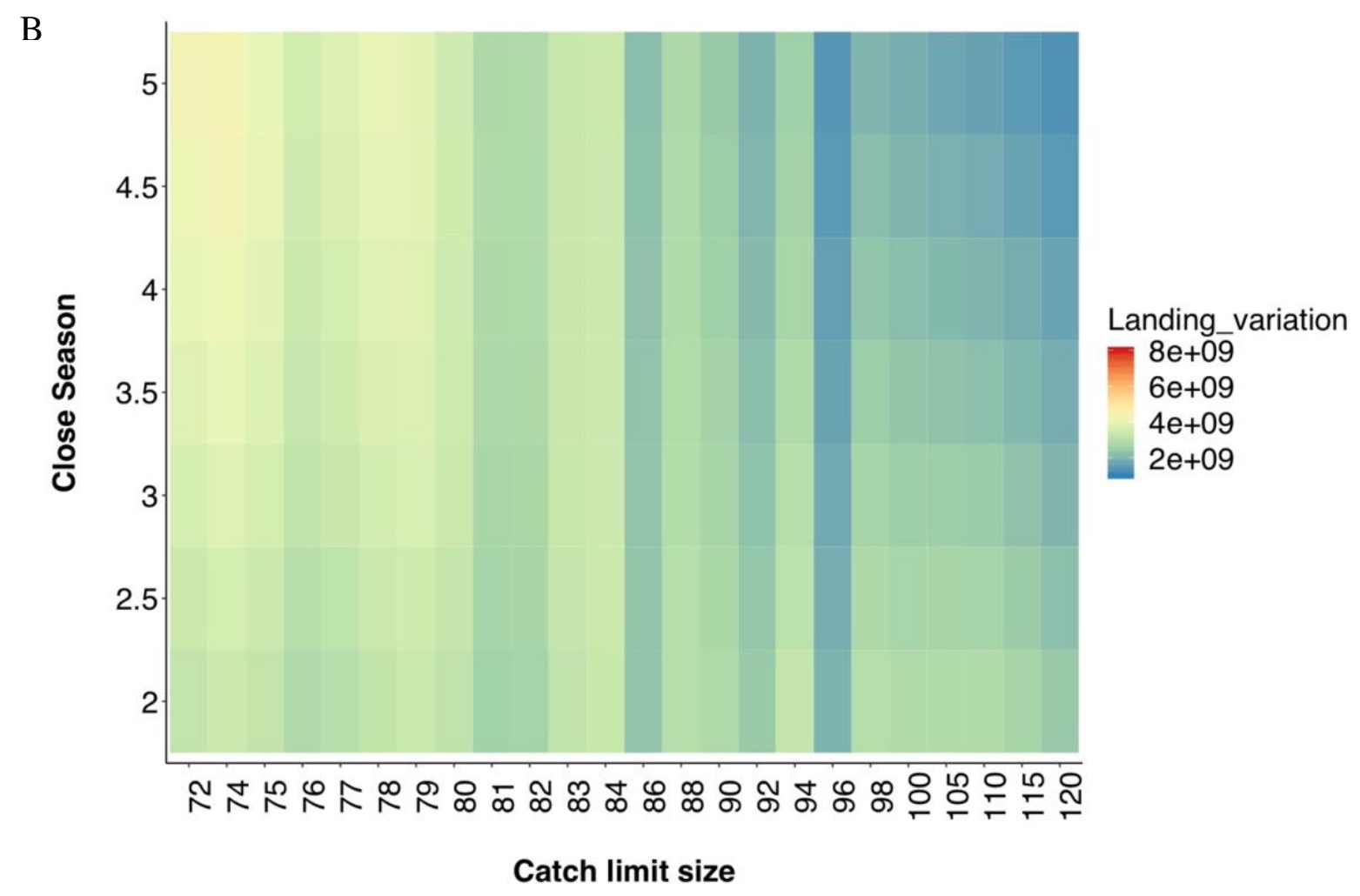


Figure 8.
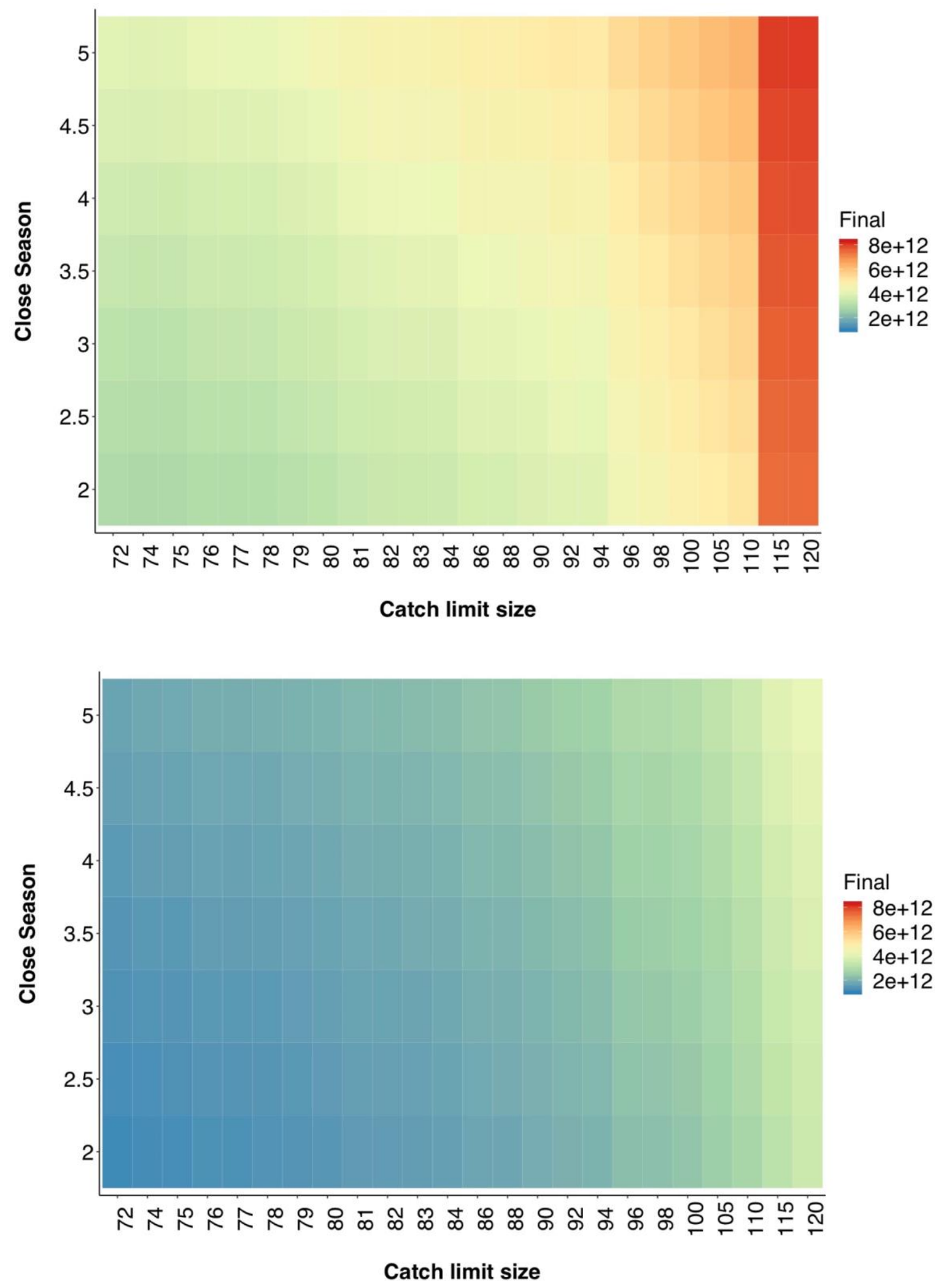
Figure 9.

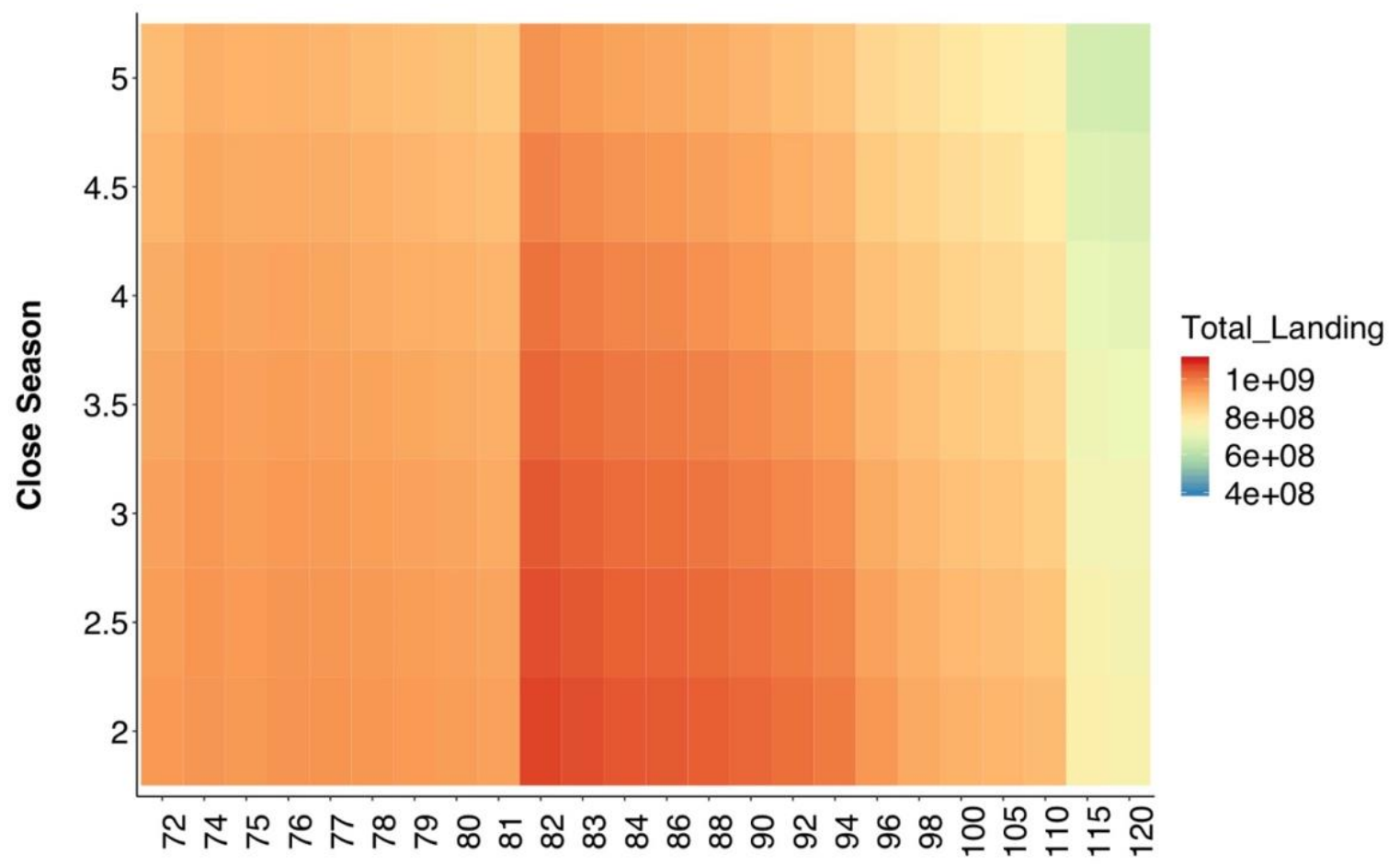

Catch limit size

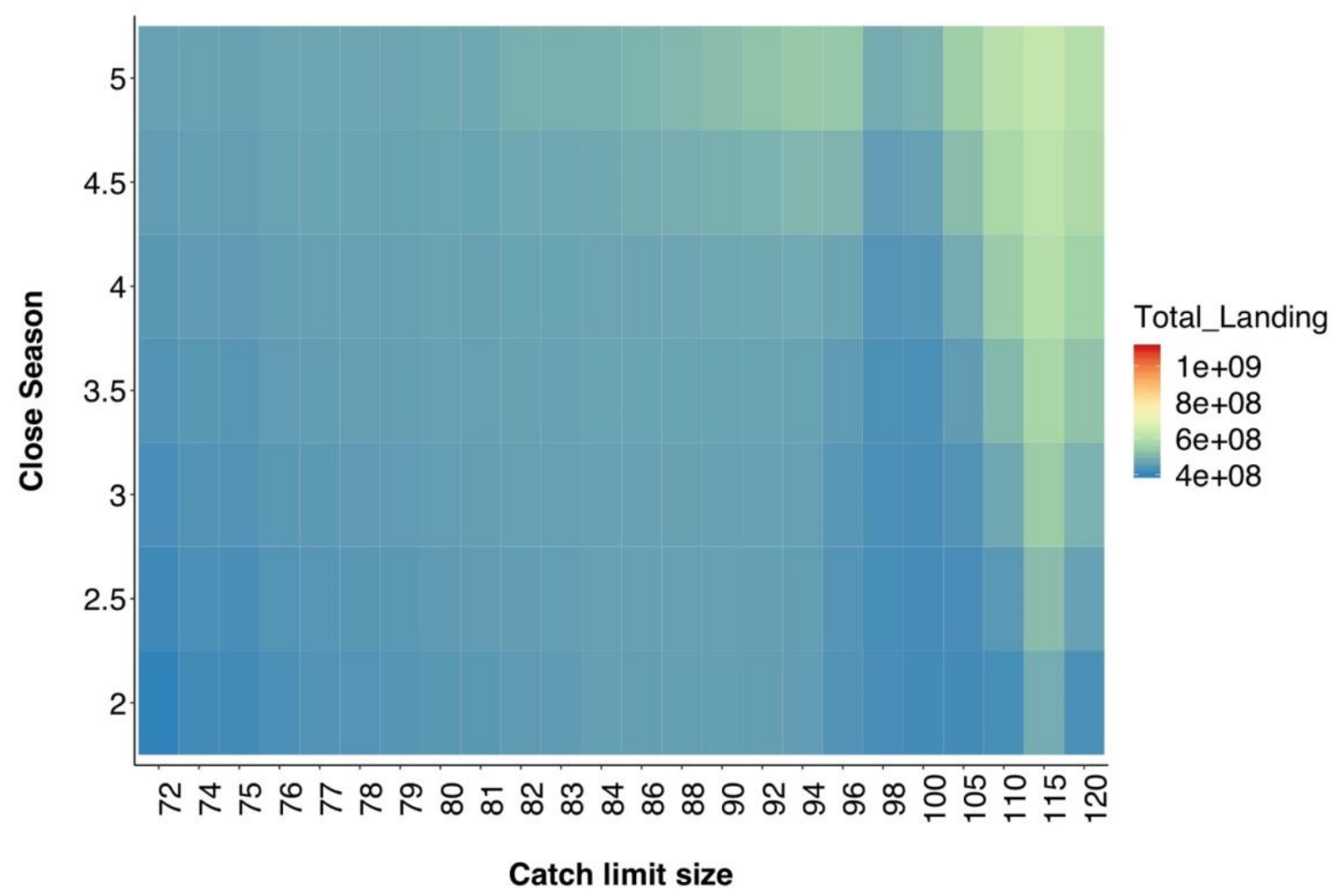


Figure 10.
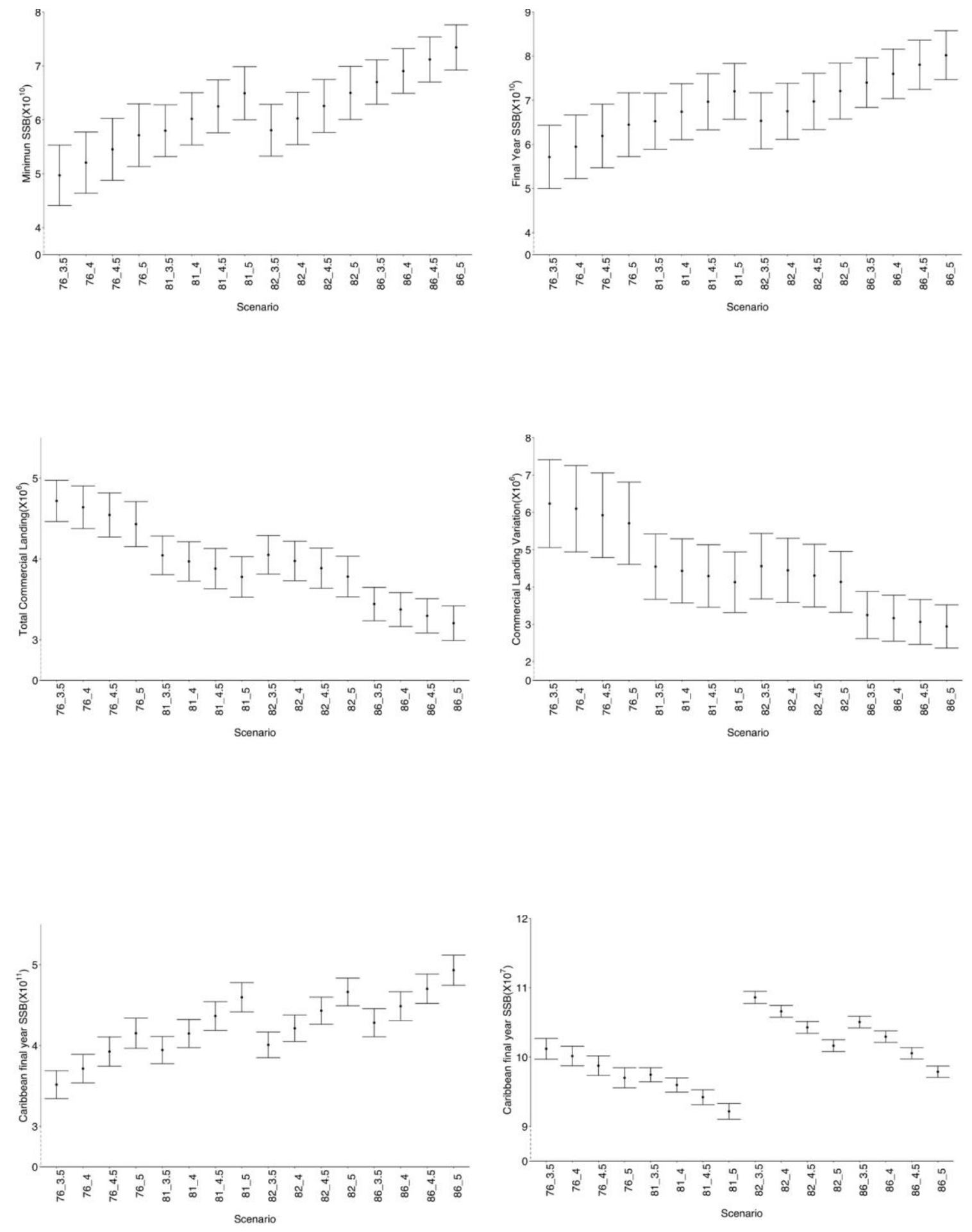
Figure 11.

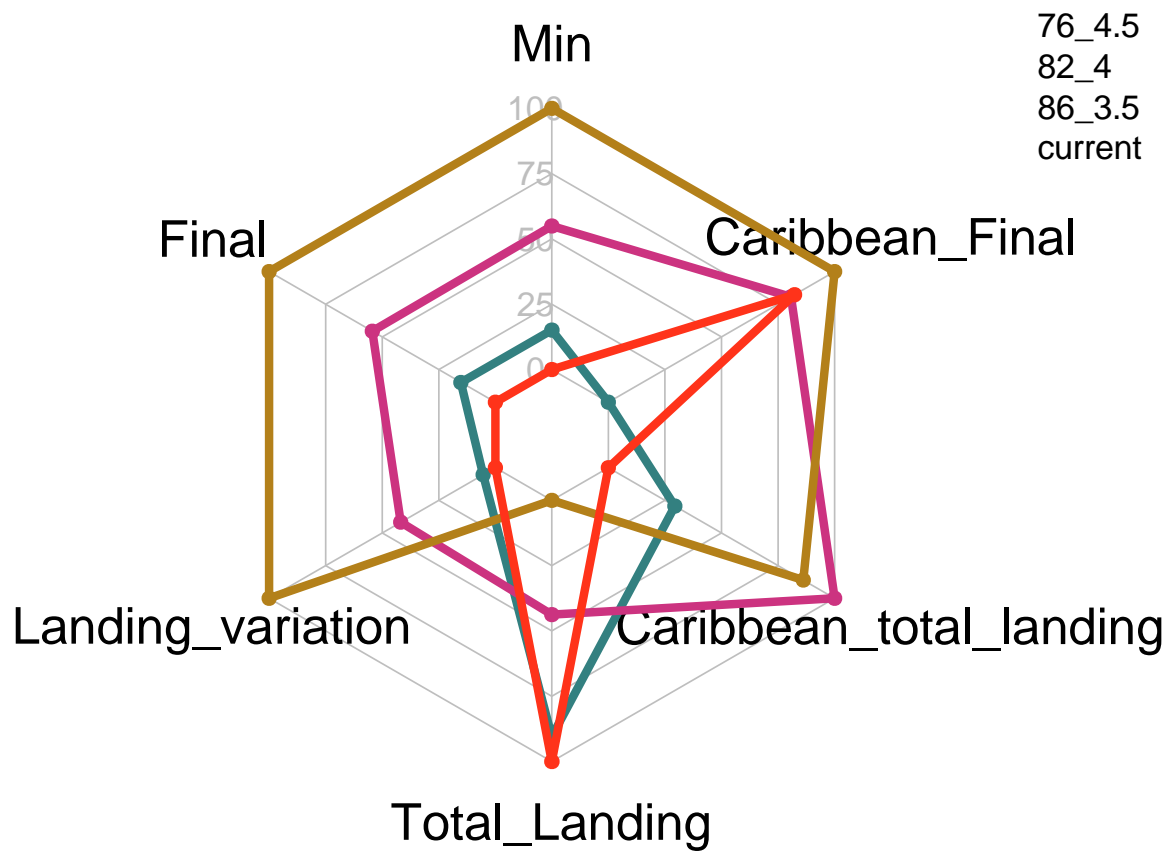


CHAPTER V GENERAL CONCLUSION 
The Caribbean spiny lobster (Panulirus argus) supports one of the most valuable fisheries in the Caribbean. It has been harvested by 30 countries and yields nearly $\$ 1$ billion USD profit annually (Ehrhardt et al. 2010). However, it has suggested that the stock of this valuable species is either over or fully exploited. Therefore, devising effective managements has become a pressing issue for this species.

The long pelagic larval stage of $P$. argus implies connectivity exists among stocks in the Caribbean region. Evidences from biophysical modeling and genetic analysis have supported this theory (Kough et al. 2013; Truelove et al. 2017). Furthermore, previous simulation studies have suggested that ignoring the connectivity among substocks can hinder the robustness of the stock assessment and management (Punt and Butterworth 1995; Porch et al. 2001; Hart and Cadrin 2004). Therefore, investigating the connectivity as well as impacts of spatial structure on management strategies are necessary to develop effective management for the $P$. argus fishery. In my dissertation, stable isotope analysis (Chapter II), genetic analysis (Chapter III) and biophysical modeling (Chapter IV) have been applied on the Florida recruitment from August 2014 to July 2016 to understand the recruitment variations of the Florida stock, and the connectivity that exists between the Florida stock and other Caribbean stocks. Then, simulation studies and management strategies evaluation (MSE) have also been used to investigate the impacts of spatial structure on stock assessment and develop a robust management procedure. 
In Chapter II, I applied the carbon and nitrogen stable isotope analyses on three sub-stages of the non-feeding pueruli (clear, semi-pigmented, and pigmented) as well as on the feeding, first juvenile stage that settled in the Florida Keys from August 2014 to July 2016. The result of this chapter indicates notable dry/wet temporal variation, as well as significant oscillations, which are observed among $\delta^{13} \mathrm{C}$ and $\delta^{15} \mathrm{~N}$ values from the lunar monthly samples. This result also suggests that the migration of recruits to the Florida coast is a dynamic process, with various contributions from different source populations to recruits. The results of cluster analyses of the stable isotope values also reveal that four clusters could have contributed to the observed Florida recruits. The results of this chapter support the hypothesis that the Florida spiny lobster stock receives recruits from multiple source populations outside Florida, in addition to self-recruitment. Therefore, the impacts of spatial connectivity on $P$. argus recruitment should not be ignored.

In Chapter III, twelve microsatellites were used on the postlarvae to test the same hypothesis: the Florida stock is demographic open. The results of this chapter further support this hypothesis. They also indicate that there are multiple potential source populations contributing to the Florida stock. The monthly clusters display a well-mixed pattern, indicating that the source population may change from month to month. Furthermore, the high percentage of kinship that occurred in certain months during the two-year sampling period provides potential evidence supporting the hypothesis that pelagic marine larvae benefit from traveling in groups. 
However, the results of these two studies are not able to assign each recruitment cluster to its source population due to the lack of stable isotopic or genetic information from all potential source population areas in the Caribbean. Therefore, future research should design to fill in this knowledge gap to present a complete map of source populations to the Florida stock.

Chapter IV focuses on investigating the impacts of spatial structure on the stock assessment and management procedure. In this project, biophysical modeling was used to simulate fine scale connectivity among Caribbean stocks. Then, a metapopulation framework was built based on this connectivity. Then, simulation and MSE was developed under this framework. The results of biophysical modeling indicate that 9 stocks in the Caribbean have contributed to the Florida stock, including self-recruitment in 2014. Therefore, those 9 stocks are included as "sub-stocks" in the metapopulation framework. In addition, among the three different approaches (stable isotope analysis, genetic markers and biophysical modeling) that I used to investigate connectivity in my dissertation, the biophysical modeling results in the highest resolution; meanwhile, stable isotope analysis and genetic markers could be used to validate results from the biophysical modeling. The results of my simulation study suggest that ignoring spatial structure would lead to significant bias on stock assessment. They also illustrate that incorporating spatial structure into the management procedure is vital for the development of effective management strategies. In addition, MSE could consider long term trade-offs among objectives, and incorporate a full range of uncertainty (Punt et al. 2016). It is able identify the most robust management scenario based on objectives for 
my project. It has been proven to be useful for actualizing international cooperation in the $P$. argus fishery management. The most optimal MSE scenario proposed by my dissertation could be used as a reference case to improve current management and build a sustainable spiny lobster fishery in the Caribbean.

\section{LITERATURE CITED:}

Ehrhardt, N.M., Puga, R., and Bulter IV, M.J., 2010. The Caribbean spiny lobster, Panulirus argus, fisheries. In: Towards Marine Ecosystem-Based Management in the Wider Caribbean. (L. Fanning, R. Mahon, and P. McConney, eds.), p. 157175. Amsterdam Univ. Press, Amsterdam.

Hart, D.R., and Cadrin, S.X., 2004. Yellowtail flounder (Limanda ferruginea) off the Northeastern United States: implications of movement among stocks. Applications in RSMAS. Pp 230-243. Oxford University Press, New York.

Porch, C.E., Turner, S.C., and Powers, J.E., 2001. Virtual population analyses of Atlantic bluefin tuna with alternative models of transatlantic migration: 1970-1997. Col. Vol. Sci. Pap. ICCAT, 52(3), pp.1022-1045.

Punt, A.E. and Butterworth, D.S., 1995. The effects of future consumption by the Cape fur seal on catches and catch rates of the Cape hakes. 4. Modelling the biological interaction between Cape fur seals Arctocephalus pusillus pusillus and the Cape hakes Merluccius capensis and M. paradoxus. South African Journal of Marine Science, 16(1), pp.255-285.

Punt, A.E. Butterworth, D.S. de Moor, C.L. De Oliveira, J.A. and Haddon, M., 2016. Management strategy evaluation: best practices. Fish and Fishery. 17(2): 303334. 
VITA

\section{NAN YAO}

Born, Jianyang, China

2006-2010

B.Sc., Biology

Ocean University of China

Qingdao, China

2010-2013

M.Sc., Biology

Auburn University

Auburn, Alabama

\section{PUBLICATIONS}

Yao N, Zhang Y. (2018). Investigating temporal variation in stable carbon and nitrogen isotope values of Florida Caribbean spiny lobster Panulirus argus (Latreille, 1804) recruits. Bulletin of Marine Science. 94(3):847-861.

Zhang Y, Yao N. (2018). Developing growth transition matrices for Caribbean spiny lobster (Panulirus argus) using mark-recapture data. Marine and Coastal Fisheries. 10(5): 481-492.

Yao N, Zhang Y. (2016). Developing a size-structured stock assessment model for spiny lobster (Panulirus argus) in the Southeast United States. Proceedings of the 68th Gulf and Caribbean Fisheries Institute. Panama City, Panama. 